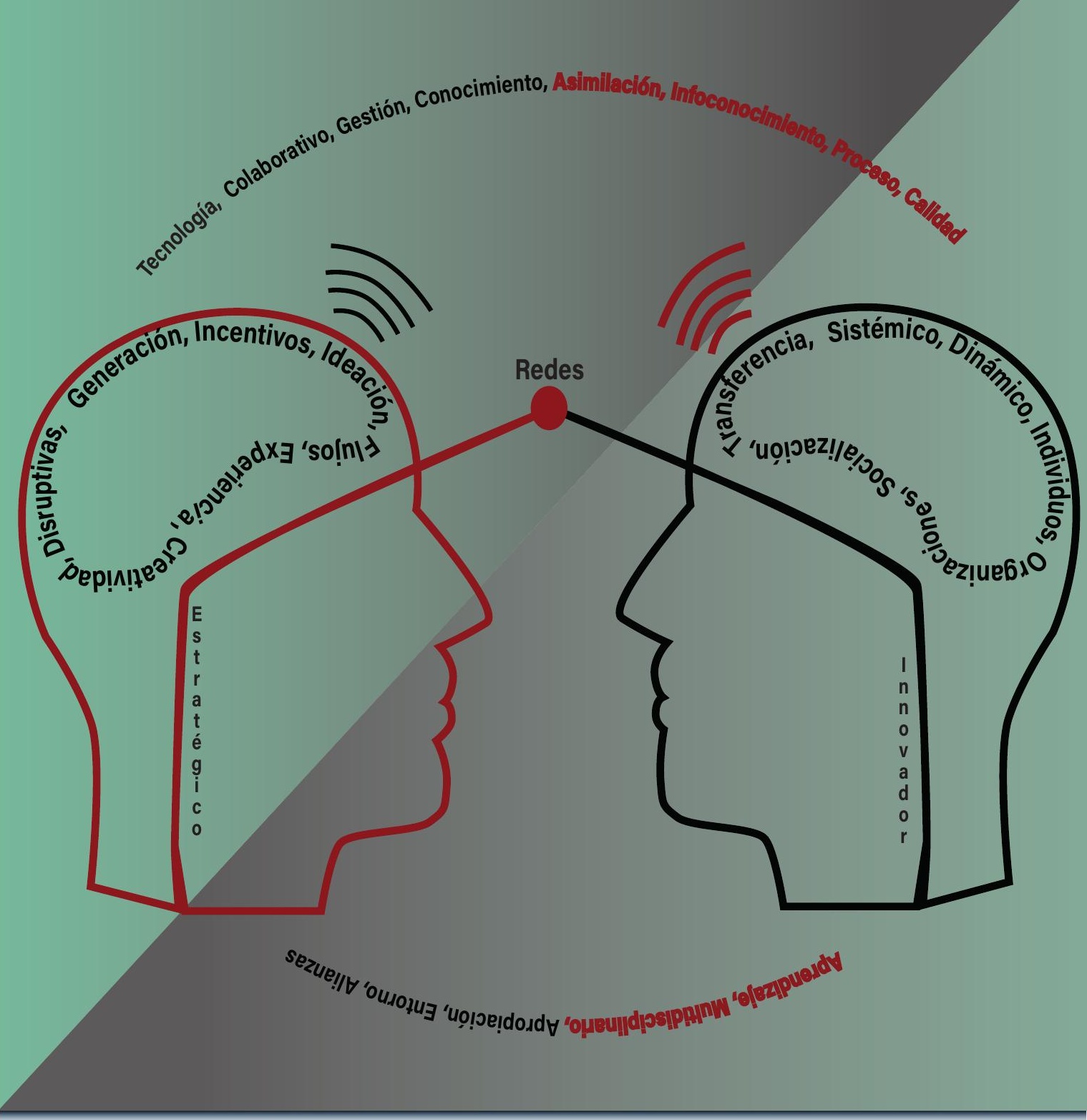

\title{
Gestión Integrada del Conocimiento y la Innovación
}

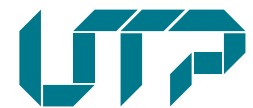

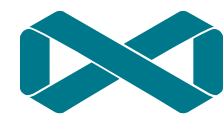

Editorial UTP
María Beatriz Valencia Bonilla 


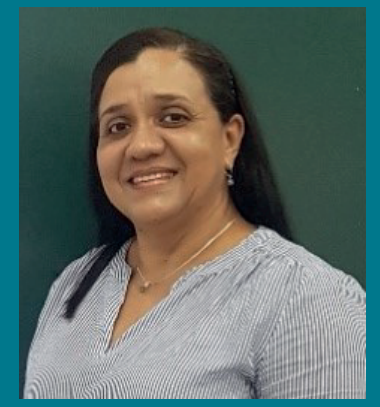

María Beatriz Valencia Bonilla( Pereira, Risaralda, Colombia, 1969).

Doctora en Ciencias Económicas de la Universidad de La Habana, Licenciada en Áreas Técnica de la Universidad Tecnológica de Pereira

Profesora Titular de la Facultad de Tecnología de la Universidad Tecnológica de Pereira.

$\mathrm{Ha}$ publicado artículos en revistas especializadas nacionales e internacionales

Pertenece al Grupo de Investigación: Logística Estrategía en la Cadena de Suministro

mabeva@utp.edu.co

La Editorial de la Universidad Tecnológica de Pereira tiene como política la divulgación del saber científico, técnico y humanístico para fomentar la cultura escrita a través de libros y revistas científicas especializadas.

Las colecciones de este proyecto son: Trabajos de Investigación, Ensayos, Textos Académicos y Tesis Laureadas.

Este libro pertenece a la Colección Trabajos de Investigación. 


\section{Gestión Integrada del Conocimiento y la Innovación}

María Beatriz Valencia Bonilla

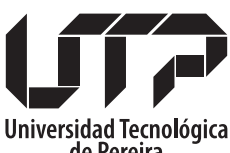

de Pereira

Colección Trabajos de Investigación

Facultad de Tecnología 
Valencia Bonilla, Maria Beatriz

Gestión integrada del conocimiento y la innovación / María

Beatriz Valencia Bonilla. - Pereira : Universidad Tecnológica

Pereira, 2020.

112 páginas. - (Colección Trabajos de investigación).

ISBN: 978-958-722-462-7

elSBN: 978-958-722-469-6

1. Gestión del conocimiento 2. Planificación estratégica 3.

Toma de decisiones 4. Gestión industrial 5. Información -

Administración 6. Cultura organizacional

CDD. 658.4038

\section{Autora}

(C) María Beatriz Valencia Bonilla

\section{Universidad Tecnológica de Pereira \\ Pereira, Colombia}

\section{Proyecto de investigación}

Modelo de Gestión Integrada del Infoconocimiento y la innovación para el Centro de Innovación y Desarrollo Tecnológico de Pereira, Colombia (Tesis Doctoral), con código: 9-16-6

\section{Universidad Tecnológica de Pereira}

Vicerrectoría de Investigaciones, Innovación y Extensión

Editorial Universidad Tecnológica de Pereira

Pereira, Colombia

\section{Coordinador editorial:}

Luis Miguel Vargas Valencia

luismvargas@utp.edu.co

Teléfono 3137381

Edificio 9, Biblioteca Central "Jorge Roa Martínez"

Cra. 27 No. 10-02 Los Álamos, Pereira, Colombia

www.utp.edu.co

Montaje y producción:

David Restrepo Suarez.

Universidad Tecnológica de Pereira

Impresión y acabados: Gráficas Olímpica S.A 


\section{Dedicatoria}

A Dios, por guiarme y acompañarme en este caminar A la memoria de mis padres, los cuales amo y extraño enormemente A Yilo, mi hermano quien ya no está conmigo y recuerdo muchísimo A Pequeño, mi hermano por su humildad y a quien llevaré en mi corazón A Tona, mi gemela con quien he compartido todo desde el vientre de nuestra querida madre

A Valentina, mi hija quien es mi razón de ser y mi propulsor

A Rafa, mi esposo por entenderme y creer en mí A mis hermanos y sobrinos por su admiración y apoyo constante A Hernando, mi cuñado por su persistencia y su lucha hasta el final A Simón por su ternura y compañía

\section{Agradecimientos}

Mis más sinceros agradecimientos y eterna gratitud a todas las Instituciones y personas que hicieron posible la culminación de este gran desafío el cual me permitió demostrarme a mí misma que a pesar de tantas dificultades y vicisitudes es posible alcanzar los sueños con fe y esperanza como: Universidad de La Habana,CETED, Universidad Tecnológica de Pereira, CIDT, Universidad Cooperativa de Colombia. Especialmente a mi tutora Dra. Katy Caridad Herrera L., Dr. Guillermo Bernaza R., a mis amigas:

Inesita R., Mayelín G., Sara Q., Melba R., Patty V., Obeida R., Marta G., Valentina K., Vivian U., Amanda G., Marleny R., Lily P., Eliana T., Adriana G., Katia F., Mónica A. $y$ mis amigos:

Victhor C., Alexander D., Jhon Jairo A., Alfredo M., Gonzalo A., Jhon Arlex C., Oscar D., Pedro Pablo B., Edison M., Víctor H., Héctor P., Luciano R., Jhon Jairo M., Gustavo C.

Quienes valoran mi amistad y cariño. 


\section{CONTENIDO}

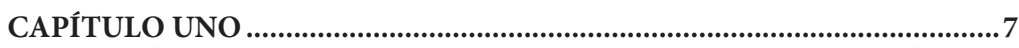

EVOLUCIÓN DEL CONCEPTO DE CONOCIMIENTO Y SU GESTIÓN .......8

1.1 Fundamentación del concepto de conocimiento...........................................

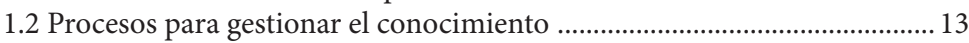

1.3 Modelos para gestionar el conocimiento ....................................................... 26

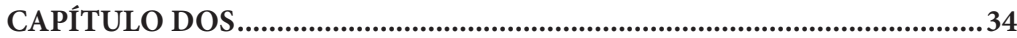

LA INNOVACIÓN Y SU GESTIÓN.............................................................35

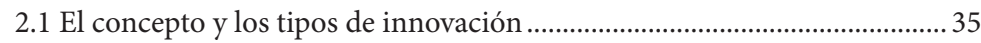

2.2 Los modelos de innovación y su gestión............................................................ 45

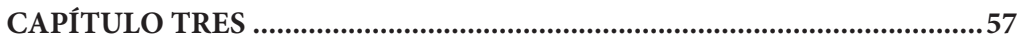

GESTIÓN INTEGRADA DEL INFOCONOCIMIENTO Y LA

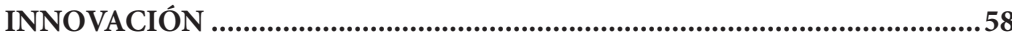

3.1 Fundamentación del modelo........................................................................... 58

3.2 Procedimiento para la aplicación del modelo de gestión integrada

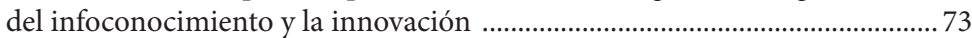

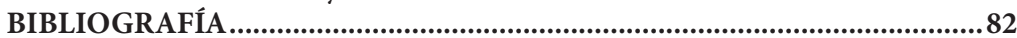




\section{FIGURAS}

Figura 1. Transformación datos-información-conocimiento.................................. 13

Figura 2. Enfoques de los autores sobre qué es la gestión del conocimiento..............17

Figura 3. Enfoques de los autores sobre cómo es el proceso de gestión del

conocimiento.

Figura 4. Enfoques de los autores sobre para qué se realiza la gestión del

conocimiento.

Figura 5. Etapas de la transferencia del conocimiento externo y su relación

con la capacidad de absorción de la organización .................................................2. 25

Figura 6. Modelo gestión del conocimiento de Nonaka y Takeuchi.........................27

Figura 7. Contexto de los activos intangibles.........................................................2

Figura 8. Modelo de gestión del conocimiento organizacional de Andersen (1999)30

Figura 9. Herramienta de Evaluación de la Gestión del Conocimiento - KMAT .. 30

Figura 10. Modelo de KPMG Consulting ................................................................. 31

Figura 11. Tipos de innovación, según su objeto y el uso de la tecnología................39

Figura 12. Radar de la innovación .......................................................................... 43

Figura 13. Modelo lineal de innovación Empuje de la Tecnología

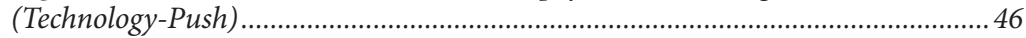

Figura 14. Modelo lineal de innovación Tirón de la Demanda (Market-Pull).......46

Figura 15. Modelo lineal de innovación en tres etapas .............................................46

Figura 17. Modelo del proceso de innovación integrado........................................... 48

Figura 18. Modelo en red para la innovación ............................................................49

Figura 19. Modelo de innovación abierta ............................................................50

Figura 20. Modelo de gestión integrada del infoconocimiento y la innovación.......60

Figura 21.Procedimiento para la aplicación del modelo propuesto ......................... 74 


\section{TABLAS}

Tabla 1. Definiciones de conocimiento.................................................................... 9

Tabla 2a. Definiciones de gestión del conocimiento (2001-2006)............................ 14

Tabla 2b. Definiciones de gestión del conocimiento (2007-2012)............................. 15

Tabla 3. Procesos identificados en la gestión del conocimiento...................................20

Tabla 4a. Definiciones de innovación del periodo 2001-2010 ................................. 36

Tabla 4b. Definiciones de innovación del periodo 2011-2017 ..................................36

Tabla 5a. Modelos de innovación abierta 2008 y 2010 ..........................................51

Tabla 5b. Modelos de innovación abierta 2011 y 2012 ……..................................52

Tabla 5c. Modelos de innovación abierta 2014 y 2015 .............................................53 


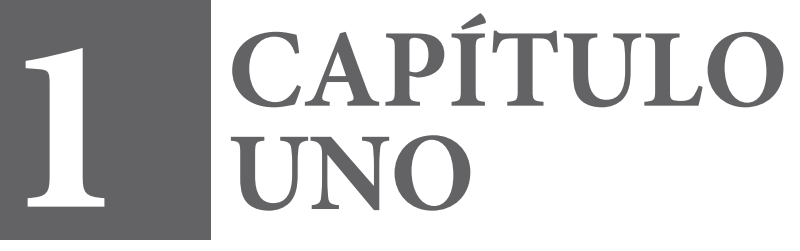




\section{EVOLUCIÓN DEL CONCEPTO DE CONOCIMIENTO Y SU GESTIÓN}

En estos tiempos de cambios acelerados, tanto los nuevos desafíos como la incertidumbre que estos generan obligan a las organizaciones a desarrollar capacidades que permitan asimilar y dar respuestas a las demandas que aparecen desde el contexto interno y externo y que se particularizan en el sistema de relaciones que la organización establece. El surgimiento de nuevos competidores, la movilización de capitales, la dificultad para retener al talento humano, las tecnologías cambiantes y las necesidades y expectativas cada vez más específicas de los clientes son elementos que requieren orientar al personal hacia paradigmas de trabajo que potencien el conocimiento y permitan una expresión creativa e innovadora en su aplicación.

La incorporación de nuevos y efectivos estilos de gestión permite a los decisores de las empresas, y organizaciones en general, conseguir el éxito y mantenerlo de forma sostenida. Para ello, la información y el conocimiento son activos intangibles indispensables para el desarrollo de cualquier organización y su adecuado aprovechamiento hace posible la mejora continua de sus procesos, el logro de resultados innovadores y, por ende, obtener mayores ventajas competitivas que conduzcan al éxito sostenido (Franch y Herrera, 2011). Los elementos mencionados constituyen los fundamentos para lo que hoy se reconoce como la economía basada en el conocimiento (Druker, 1993; Lage, 2013; Triana et al, 2005).

La asimilación e incorporación del conocimiento en el funcionamiento delas organizaciones adquiere su mayor relevancia a partir de la última década del siglo pasado, con los estudios de Peter Senge (1990), para luego desarrollarse exponencialmente 
cuando comienza a reconocerse el valor del capital intelectual y la importancia del conocimiento organizacional como activo competitivo (Edvinsson y Malone, 1997; Kaplan y Norton, 1996; Leonard, 1995; Nonaka y Takeuchi, 1995; Sveiby, 1997). Con ello, surgen las teorías de las empresas basadas en conocimiento (Grant, 1996; Hoskisson et al, 1999; Winch y Schneider, 1993) y orientadas al aprendizaje organizacional, siendo reconocidas estas organizaciones bajo el término de organizaciones basadas en el conocimiento (KBO - Knowledge Based Organizations) (Cohen y Levinthal, 1990; Garvin et al, 2008).

La comprensión del conocimiento como un recurso ha generado diferentes puntos de vista para su conceptualización y un cambio de visión de los procesos para su gestión por parte de las organizaciones, cuestiones que son abordadas en este capítulo.

\subsection{Fundamentación del concepto de conocimiento}

Para sistematizar las definiciones del término conocimiento fueron consultados 11 autores del período 1996-2017 (Tabla 1). Un análisis semántico de los conceptos formulados por los diversos autores muestra que el conocimiento es una categoría que se conforma tomando como punto de partida el reconocimiento y manejo de los datos y la información. Si bien algunos estudiosos del tema conceptualizan el conocimiento como un flujo de datos (Archibold y Escobar, 2014) o como un conjunto de información (Alfaro y Alfaro, 2012), la realidad es que existen diferencias entre estos tres conceptos.

Tabla 1. Definiciones de conocimiento

\begin{tabular}{|c|l|}
\hline Autor & \multicolumn{1}{|c|}{ Definición } \\
\hline $\begin{array}{c}\text { Andersen } \\
(1996)\end{array}$ & $\begin{array}{l}\text { El conocimiento organizacional (K) es la capacidad de las personas }(\mathrm{P}) \text { para interpretar, entender } \\
\text { y utilizar la información (I). Una capacidad (K+I) se multiplica exponencialmente en función de } \\
\text { la capacidad de compartir el conocimiento (s) que existe en la organización. } \mathrm{K}=[\mathrm{P}+\mathrm{I}]^{\mathrm{s}} .\end{array}$ \\
\hline $\begin{array}{c}\text { Muñoz y } \\
\text { Riverola } \\
(1997)\end{array}$ & Capacidad de resolver un determinado conjunto de problemas con una efectividad determinada. \\
\hline
\end{tabular}




\begin{tabular}{|c|c|}
\hline $\begin{array}{l}\text { Selva et al. } \\
\text { (1998) }\end{array}$ & $\begin{array}{l}\text { Parte conocida de un fenómeno, se representa mediante símbolos (convencionales o no). Se trata } \\
\text { de la definición, fundamentación y formalización de la parte convocada de algún universo, que } \\
\text { posibilita su almacenamiento, transferencia, aplicación y, en algunos casos, su enriquecimiento o } \\
\text { mejora. Puede identificarse con el término experiencia, específicamente cuando ésta se relaciona } \\
\text { con procesos de aprendizaje, sean formables o informales. }\end{array}$ \\
\hline $\begin{array}{c}\text { Davenport y } \\
\text { Prusak (2001) }\end{array}$ & $\begin{array}{l}\text { Mezcla fluida de experiencia, valores, información contextual y perspicacia del experto, } \\
\text { conectados entre sí que proveen un marco para la evaluación e incorporación de nuevas } \\
\text { experiencias e información. Se origina y aplica en las mentes de los conocedores. En las } \\
\text { organizaciones, el conocimiento comienza a incorporarse frecuentemente no solo en documentos } \\
\text { y en depósitos, sino también en las rutinas organizacionales, procesos, prácticas y normas. }\end{array}$ \\
\hline Ponjuán (2006) & $\begin{array}{l}\text { Conjunto de cogniciones y habilidades con las cuáles los individuos suelen solucionar } \\
\text { problemas. Comprende tanto la teoría como la práctica, las reglas cotidianas al igual que las } \\
\text { instrucciones para la acción. Se basa en datos e información, pero a diferencia de éstos, siempre } \\
\text { está ligado a las personas. Forma parte de los individuos y representa las creencias de estos } \\
\text { acerca de las relaciones causales. }\end{array}$ \\
\hline $\begin{array}{l}\text { Rodríguez et } \\
\text { al. (2009) }\end{array}$ & $\begin{array}{l}\text { Es lo que llegamos a crear y a valorar a partir de la información significativa, mediante el } \\
\text { agregado de experiencia, comunicación e inferencia. El conocimiento ocurre dentro de y entre } \\
\text { individuos. Por estar tan ligado a los seres humanos resulta complejo administrarlo, transferirlo o } \\
\text { compartirlo. }\end{array}$ \\
\hline $\begin{array}{l}\text { Alfaro y Alfaro } \\
\qquad(2012)\end{array}$ & $\begin{array}{l}\text { El conocimiento es un conjunto de información adquirida en los individuos en base a su } \\
\text { experiencia, juicios, valores, actitudes, aptitudes, el cual debe ser considerado como un recurso a } \\
\text { fin de poner en práctica capacidades para dar solución a los problemas del entorno en el que se } \\
\text { desenvuelven. }\end{array}$ \\
\hline Larrea (2012) & $\begin{array}{l}\text { El conocimiento es un conjunto de representaciones entretejidas basadas en información, con } \\
\text { análisis, interpretación y argumentación, de un determinado contexto con significación y } \\
\text { consciencia de sus interrelaciones. }\end{array}$ \\
\hline $\begin{array}{c}\text { Franch y } \\
\text { Herrera (2011) }\end{array}$ & $\begin{array}{l}\text { Aquella información que ha sufrido determinados procesos mentales: interiorización, análisis, } \\
\text { fijación, aplicación, etc., que permite al sujeto tener un dominio de los sucesos o hechos que } \\
\text { ocurren en la sociedad y solucionar determinados problemas. Requiere aplicar la intuición y la } \\
\text { sabiduría propias de la persona, a la información, que a su vez esta proviene de datos, para } \\
\text { obtener un resultado. }\end{array}$ \\
\hline $\begin{array}{c}\text { Archibold y } \\
\text { Escobar (2014) }\end{array}$ & $\begin{array}{l}\text { Flujo de datos que se mueven en el interior de la organización a través de Tecnologías de la } \\
\text { información y Comunicación (TIC) y Sistemas de Información, que aportan estabilidad a las } \\
\text { organizaciones y generan en ellas capacidades y habilidades para enfrentarse a las dinámicas de } \\
\text { la era post industrial. }\end{array}$ \\
\hline $\begin{array}{l}\text { La Fe Jiménez } \\
\text { (2017) }\end{array}$ & $\begin{array}{l}\text { Es un recurso económico de naturaleza intangible, consistente en habilidades, experiencias, } \\
\text { documentos y relaciones que influyen en el logro de los resultados de las empresas. }\end{array}$ \\
\hline
\end{tabular}

Davenport y Prusak (2001) definen los datos como un conjunto de hechos distintos y objetivos, relativos a eventos, los cuales en un contexto organizacional pueden manifestarse como registros estructurados de las diferentes transacciones. En la norma internacional ISO 9000:2015 (Organización Internacional de Normalización, 2015a), se plantea que los datos son los hechos 
que pueden ser observados sobre un objeto sin proveer ningún juicio de valor o interpretación, constituyendo la materia prima de la información.

La información, por su parte, son datos que tienen un significado en un contexto determinado al ser integrados, organizados e interpretados, pero sin constituir aun conocimiento. A diferencia de los datos, la información está íntimamente relacionada formal o informalmente con las dinámicas de las organizaciones, por lo que es susceptible de variadas interpretaciones. El significado de la información depende de la percepción de quien la recibe respecto a su utilidad.

El conocimiento es creado por las personas mediante la interpretación de la información, pasando por un proceso de análisis y razonamiento que permite identificar, vincular, relacionar y comparar información para crear resultados y tomar decisiones efectivas. Es una capacidad muy particular de cada individuo, que se adquiere con el aprendizaje y la experiencia. Nace de la interpretación y del análisis de informaciones, como un proceso particular que ocurre en la mente de las personas y se manifiesta en los comportamientos. Sin embargo, el conocimiento no se queda en el ámbito personal, sino que pasa a ser un activo intangible como conocimiento organizacional.

Para Nonaka y Takeuchi (1995), la creación del conocimiento organizacional debe entenderse como un proceso que amplía el conocimiento creado individualmente y lo cristaliza como parte de la red de conocimientos de la organización. Este conocimiento se encuentra alojado en las mentes de las personas que componen la organización, así como en los diversos formatos o bases de datos y en las propias prácticas de la organización (Davenport y Prusak, 2001). Si bien la generación del conocimiento individual es eminentemente un proceso de reflexión, el conocimiento organizacional se genera mediante los procesos de interacción e integración social, en los cuales se realiza la conversión de los datos en información y, a su vez, la transformación de la información en conocimiento, mediada por el aprendizaje organizacional. 
Resulta interesante el posicionamiento realizado por Alba (2015) al considerar que el vínculo con la información transciende su condición de ser el insumo fundamental para el conocimiento, ya que esta autora resalta el papel de la información como vía por la cual el conocimiento se transporta y se comunica. Bajo este enfoque, se genera un constructo que supera a la mera información, denominado por la autora "infoconocimiento", y que se define como

la integración de los flujos de información y conocimiento entre los actores de una organización o conjunto de ellas (cadena), sus experiencias, aprendizajes y competencias, a partir del desarrollo de un pensamiento en espiral con enfoque de proceso, creciente y sinérgico, que agrega valor y crea las bases para la innovación. (Alba y Herrera, 2016, p. 85)

Las organizaciones deben adquirir, generar y desarrollar aquellos conocimientos que son pertinentes para el logro de sus metas, objetivos y estrategias, por lo que deben considerar sus conocimientos actuales y determinar cómo adquirir o acceder a los conocimientos necesarios con los cuales aún no se cuenta (Organización Internacional de Normalización, 2015b). El conocimiento es un recurso vital para las organizaciones, que se necesita gestionar en función de tomar las decisiones adecuadas, minimizar los riesgos y aprovechar las oportunidades. Es uno de los principales factores en los que las organizaciones basan la consecución y el sustento deventajas competitivas. El conocimiento en las organizaciones se manifiesta como conocimiento tácito y como conocimiento explícito (León, 2008; Nonaka et al., 2006; Núñez, 2004).

El conocimiento tácito está incorporado en los individuos; es difícil de formalizar y de comunicar, pues es altamente personal. El medio de transmisión es a través del contacto directo con el sujeto. Tiene que ver con la experiencia, la sabiduría y la creatividad; 
es intuición y capacidad de hacer algo, no necesariamente está acompañado de la capacidad de explicar cómo se hace, siendo difícil de transmitir de forma oral o escrita.

El conocimiento explícito se encuentra estructurado, y muchas veces documentado, para facilitar su difusión. Es aquel que se conoce que se posee y se emplea de manera consciente (Belly, 2004). Es transmisible en la comunicación mediante los lenguajes convencionales externos, ya que está soportado en cualquier tipo de fuente, es codificable y fácil de transferir; por ejemplo: políticas, especificaciones técnicas, planes y procedimientos.

Para Henczel (2000), el proceso de conversión de los datos en información es un proceso de creación de conocimiento, tanto tácito como explícito, que constituyen los activos del conocimiento que necesita la organización para una buena gestión (Figura 1).

Figura 1. Transformación datos-información-conocimiento

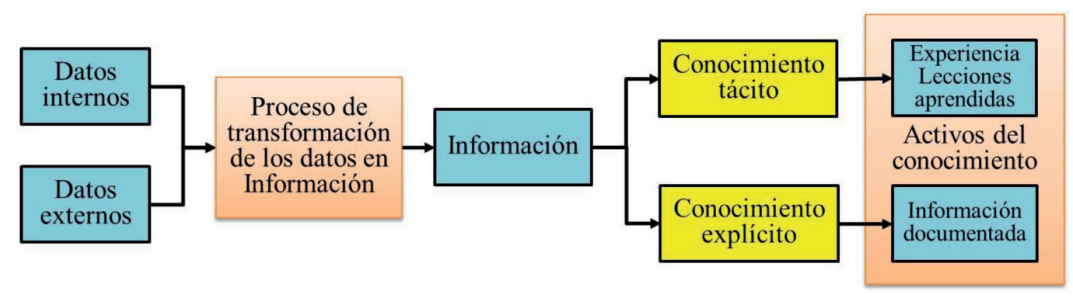

\subsection{Procesos para gestionar el conocimiento}

La incorporación del conocimiento en las organizaciones devino en herramienta de gestión, llamada gestión del conocimiento, vinculada en su desarrollo a diversos beneficios para el desempeño individual, grupal y organizacional. Para abordar el tema la autora se plantea varias interrogantes: ¿qué es?; ¿cómo se concibe?; ¿para qué se realiza?; ¿qué se requiere para su aplicación? Para dar respuesta a estas cuestiones se estudiaron las propuestas realizadas por diferentes autores del presente siglo: Davenport y Prusak (2001), Artiles (2001), Barreiro (2001), 
Medellín (2001); Bustelo y Amarilla (2001), Simeón (2001), (CIDEC, 2004)ํㅜ , Gómez et al. (2005), Ponjuán (2006), Dánjer (2006), León, Ponjuán y Rodríguez M. (2006), Rodríguez D. (2006), Simón (2008), Hermida (2009), Galvis (2009), González (2010), López (2010), Bejerano (2011), Franch y Herrera (2011), Anand y Singh (2011), Acosta (2012), Monagas (2012), Alfaro y Alfaro (2012), Alba (2013; 2015), Texidor (2013), Rodríguez y González (2013), Archibold y Escobar (2014), La Fé Jiménez (2017) y Pérez Morfi (2018). Las definiciones analizadas fueron agrupadas en tres períodos: 2001-2006 (Tabla 2a), 2007- (Tabla 2b) y (Tabla 2c).

En respuesta a ¿qué es la gestión del conocimiento? los autores consultados plantean diferentes enfoques que van desde considerarla un proceso, pasando por sistema o conjunto de procesos, hasta considerarla una capacidad, un nuevo enfoque gerencial, una filosofía o el arte de crear valor. Al agrupar las categorías relacionadas, se observa que el criterio con mayor presencia resulta el de considerarla un proceso (Figura 2). Este es el enfoque que subscribe la autora porque permite considerar la gestión del conocimiento como un proceso con identidad propia, abierto, flexible con varias entradas y con capacidad de articularse de manera coherente con otros procesos dentro y fuera de la organización.

Tabla 2a. Definiciones de gestión del conocimiento (2001-2006)

\begin{tabular}{|c|l|}
\hline Autores & \multicolumn{1}{c|}{ Definición } \\
\hline $\begin{array}{c}\text { Davenport y } \\
\text { Prusak (2001) }\end{array}$ & $\begin{array}{l}\text { Proceso sistémico de buscar, organizar, filtrar y presentar la información con el objetivo de mejorar } \\
\text { la comprensión de las personas en un área específica de interés. }\end{array}$ \\
\hline & $\begin{array}{l}\text { Proceso sistémico de planificar, organizar, optimizar y controlar los recursos renovables } \\
\text { (información y conocimiento) en una organización, con el objetivo de desarrollar las capacidades } \\
\text { reales y potenciales del capital intelectual que facilite el crecimiento científico, tecnológico e } \\
\text { innovador en una organización, dando respuesta a la solución de problemas, manejo de conflictos, } \\
\text { y desarrollo de la inteligencia. Todo ella unido y orientado a crear valor agregado de forma } \\
\text { continua, siendo el producto informativo una de las formas tangibles para promover, distribuir, } \\
\text { acceder y proteger los nuevos conocimientos. }\end{array}$ \\
\hline Barreiro \\
(2001) & $\begin{array}{l}\text { Proceso organizativo integrado de creación o generación de conocimiento, estructuración, } \\
\text { aportación de valor, esta cadena transita obligadamente desde la generación del saber hacer hasta } \\
\text { alcanzar su expresión más positiva y difícil de alcanzar, el saber estar. Este último estrechamente } \\
\text { ligado a las motivaciones y recompensas del individuo en la organización. }\end{array}$ \\
\hline
\end{tabular}

1 Centro de Investigación y Documentación sobre problemas de la Economía, el Empleo y las Cualificaciones Profesionales 


\begin{tabular}{|c|c|}
\hline $\begin{array}{l}\text { Medellín } \\
\text { (2001) }\end{array}$ & $\begin{array}{l}\text { Capacidad de una organización para administrar la creación, la difusión, la adaptación y utilización } \\
\text { de conocimientos valiosos y su integración en negocios, sistemas, procesos, productos y servicios. } \\
\text { Además, como las capacidades y conocimientos de una organización son parte sustancial de su } \\
\text { capital intelectual, la gestión del conocimiento es una actividad clave de la gestión del capital } \\
\text { intelectual de cualquier organización. }\end{array}$ \\
\hline $\begin{array}{l}\text { Bustelo y } \\
\text { Amarilla } \\
(2001)\end{array}$ & $\begin{array}{l}\text { Conjunto de actividades realizadas con el fin de utilizar, compartir y desarrollar los conocimientos } \\
\text { de una organización y de los individuos que en ella trabajan, encaminándolos a la mejor } \\
\text { consecución de sus objetivos }\end{array}$ \\
\hline $\begin{array}{l}\text { Simeón } \\
(2001)\end{array}$ & $\begin{array}{l}\text { Adquirir, utilizar y mejorar los conocimientos necesarios para la organización, creando un } \\
\text { ambiente que permita compartirlo y transferirlo, para que los trabajadores los utilicen en vez de } \\
\text { volver a descubrirlo. }\end{array}$ \\
\hline $\begin{array}{l}\text { CIDEC } \\
(2004)\end{array}$ & $\begin{array}{l}\text { Es el arte de crear valor ejerciendo influencias (apalancando) sobre los activos intangibles. Para ser } \\
\text { capaz de hacer esto, hay que ser capaz de visualizar la organización como algo que sólo consiste en } \\
\text { conocimiento y en flujos de conocimiento. }\end{array}$ \\
\hline Núñez (2004) & $\begin{array}{l}\text { Proceso capaz de identificar, adquirir, desarrollar, administrar el conocimiento tácito individual y } \\
\text { explicitarlo con el propósito de generar nuevos conocimientos y hacerlos disponibles para todos los } \\
\text { miembros de la organización. }\end{array}$ \\
\hline $\begin{array}{c}\text { Gómez et al. } \\
\text { (2005) }\end{array}$ & $\begin{array}{l}\text { Proceso sistemático que utiliza el conocimiento individual y colectivo de la organización orientado } \\
\text { a potenciar las competencias organizacionales y la generación de valor en pro de obtener ventajas } \\
\text { competitivas sostenibles }\end{array}$ \\
\hline $\begin{array}{l}\text { Ponjuán } \\
\text { (2006) }\end{array}$ & $\begin{array}{l}\text { Proceso sistemático e integrador de coordinación de las actividades de adquisición, creación, } \\
\text { almacenaje, y comunicación del conocimiento tácito y explícito por individuos y grupos con objeto } \\
\text { de ser más efectivos y productivos en su trabajo y cumplir los objetivos y metas de la organización. }\end{array}$ \\
\hline $\begin{array}{l}\text { Dánjer } \\
(2006)\end{array}$ & $\begin{array}{l}\text { El sistema que contempla los principales procesos y actividades relacionados con la planificación, } \\
\text { el desarrollo, la transferencia, la utilización, y la evaluación del conocimiento. Estos procesos de } \\
\text { gestión del conocimiento se aplican a cada uno de los procesos de trabajo de la organización, } \\
\text { integrándose en la gestión por procesos. Se trata de un proceso que considera en primer término, a } \\
\text { las personas, como portadores y creadores del conocimiento y que establece el entorno favorable } \\
\text { con relación a la estructura, cultura y estrategia de la organización. La organización, las personas, } \\
\text { los procesos y la tecnología, son considerados, según esta definición, como los cuatro factores } \\
\text { clave de la gestión del conocimiento. }\end{array}$ \\
\hline $\begin{array}{l}\text { León et al. } \\
\text { (2006) }\end{array}$ & $\begin{array}{l}\text { Nuevo enfoque gerencial que se basa en el reconocimiento y la utilización del valor más } \\
\text { importante de las organizaciones: los recursos humanos, su conocimiento y su disposición a } \\
\text { colocarlos a su servicio. Se soporta en un sistema que permite administrar la recopilación, } \\
\text { organización, refinamiento, análisis y diseminación del conocimiento en una organización. }\end{array}$ \\
\hline $\begin{array}{c}\text { Rodríguez } \\
\text { (2006) }\end{array}$ & $\begin{array}{l}\text { Conjunto de procesos sistemáticos (identificación y captación del capital intelectual; tratamiento, } \\
\text { desarrollo y compartimiento del conocimiento; y su utilización) orientados al desarrollo } \\
\text { organizacional y/o personal y a la generación de una ventaja competitiva para la organización y/o } \\
\text { el individuo. }\end{array}$ \\
\hline
\end{tabular}

\section{Tabla 2b. Definiciones de gestión del conocimiento (2007-2012)}

\begin{tabular}{|c|l|}
\hline Autor & \multicolumn{1}{c|}{ Definición } \\
\hline Simón (2008) & $\begin{array}{l}\text { Conjunto de procesos para crear, representar, organizar, almacenar, socializar, recuperar, generar y } \\
\text { procesar computacionalmente, conocimiento tácito y explícito, cuya integración facilite un mayor } \\
\text { aprovechamiento del conocimiento en el mejoramiento del rendimiento individual y } \\
\text { organizacional. }\end{array}$ \\
\hline Galvis (2009) & $\begin{array}{l}\text { Consiste en propiciar, compartir, conservar, actualizar y hacer crecer el conocimiento de una } \\
\text { organización, mediante el uso de políticas, estrategias, actividades, herramientas y mecanismos } \\
\text { asociados, con miras a que se convierta en un activo que genere valor y que refuerce las ventajas } \\
\text { competitivas }\end{array}$ \\
\hline Hermida & $\begin{array}{l}\text { Enfoque gerencial, basado en la identificación, captura, organización y utilización del } \\
\text { conocimiento organizacional, con la finalidad de añadir valor a los productos y servicios de una } \\
\text { organización; situando al capital humano como el principal activo con el que puede contar una } \\
\text { institución para aumentar su productividad, eficacia y eficiencia. Es una filosofía que integra } \\
\text { diferentes elementos como la información, tecnologías, y el conocimiento. Requiere de nuevas } \\
\text { formas de cultura organizacional que faciliten la generación de nuevos conocimientos entre todos } \\
\text { los integrantes de la organización. }\end{array}$ \\
\hline
\end{tabular}




\begin{tabular}{|c|c|}
\hline $\begin{array}{c}\text { González } \\
\text { (2010) }\end{array}$ & $\begin{array}{l}\text { Comprende el conjunto de procesos sistemáticos, técnicas y herramientas que hacen posible el } \\
\text { aprovechamiento eficaz del conocimiento valioso existente en la organización. Su propósito es } \\
\text { incrementar la capacidad de una organización para solucionar problemas, adaptarse a su entorno y } \\
\text { garantizar ventajas competitivas sostenibles. }\end{array}$ \\
\hline López (2010) & $\begin{array}{l}\text { Proceso que se lleva a cabo en una organización para dirigir, y controlar sus flujos de } \\
\text { conocimientos, añadiéndole valor a sus productos o servicios, permitiendo que se obtenga una } \\
\text { mayor calidad en el desempeño de sus funciones. }\end{array}$ \\
\hline $\begin{array}{l}\text { Franch y } \\
\text { Herrera } \\
(2011)\end{array}$ & $\begin{array}{l}\text { Sistema integrado que involucra lo histórico-cultural, ya que el conocimiento histórico es } \\
\text { importante para nutrirse de información y saltar brechas, evitando reinventar lo que se inventó en } \\
\text { el pasado; elementos organizativos en cuanto a procesos, mecanismos estructuras que permitan el } \\
\text { acceso, almacenamiento y transferencia de conocimientos conscientemente gestionados, que } \\
\text { tributen de forma efectiva a un proceso decisorio; el elemento tecnológico como una herramienta } \\
\text { para que las personas agilicen sus tareas. }\end{array}$ \\
\hline $\begin{array}{c}\text { Bejerano } \\
(2011)\end{array}$ & $\begin{array}{l}\text { Propicia el desarrollo de una cultura organizacional y un entorno colaborativo que permite la } \\
\text { optimización de las mismas por medio de la existencia de un liderazgo sólido, la contribución } \\
\text { mutua, así como la puesta en práctica de políticas que favorezcan la capacitación, el aprendizaje y } \\
\text { la motivación de cada miembro de la organización, teniendo en cuenta sus necesidades...sitúa al } \\
\text { capital humano como el principal activo para mejorar la calidad de la productividad, eficacia y } \\
\text { eficiencia de una institución... con el apoyo de las tecnologías adecuadas se facilitan y agilizan los } \\
\text { procesos. Es una filosofía que impone nuevas formas de cultura empresarial que permite la } \\
\text { generación de nuevos conocimientos entre las personas de la organización. }\end{array}$ \\
\hline $\begin{array}{c}\text { Anand y } \\
\text { Singh }(2011)\end{array}$ & $\begin{array}{l}\text { Gestión explícita y sistemática del conocimiento vital y está asociado a los procesos de creación, } \\
\text { adquisición, organización, uso y explotación. Requiere convertir el conocimiento personal en } \\
\text { conocimiento corporativo que pueda ser ampliamente compartido y apropiadamente aplicado en } \\
\text { toda una organización. }\end{array}$ \\
\hline Acosta (2012) & $\begin{array}{l}\text { Proceso sistemático para identificar, crear, adquirir, compartir y utilizar el conocimiento interno de } \\
\text { la organización, o el que está fuera de ésta, y que resulta necesario para que la misma logre el } \\
\text { cumplimiento de su misión de manera eficiente. Como consecuencia, se potencia la toma de } \\
\text { decisiones a todos los niveles, la creatividad, y la generación de valor; esto es, se obtienen } \\
\text { resultados superiores en la organización. }\end{array}$ \\
\hline $\begin{array}{c}\text { Alfaro y } \\
\text { Alfaro }(2012)\end{array}$ & $\begin{array}{l}\text { Proceso dinámico e interactivo a fin de detectar, generar, codificar, transferir, capturar y usar el } \\
\text { conocimiento para lograr los objetivos y resolver los problemas que enfrente la organización, y la } \\
\text { generación de ventajas competitivas. }\end{array}$ \\
\hline
\end{tabular}

\section{Tabla 2c. Definiciones de gestión del conocimiento (2013-2018)}

\begin{tabular}{|c|l|}
\hline Autor & \multicolumn{1}{c|}{ Definición } \\
\hline Alba (2013) & $\begin{array}{l}\text { La capacidad de explicitar conocimiento, es decir, codificarlo según su tipo y almacenarlo en } \\
\text { herramientas tecnológicas. Compartir conocimiento o información, esto es, diseminar } \\
\text { conocimiento y hacerlo accesible a las personas de la organización. }\end{array}$ \\
\hline $\begin{array}{c}\text { Proceso integrador de conocimientos tácitos y explícitos, que, puestos en práctica, permiten el } \\
\text { posicionamiento empresarial en las organizaciones. Debido al valor agregado que el conocimiento } \\
\text { genera, la organización se hace más productiva, con mayores niveles de calidad, mayor } \\
\text { satisfacción en los clientes; la GC permite reforzar las capacidades de los empleados y el proceso } \\
\text { de toma de decisiones tanto a nivel gerencial como organizacional y con ello el incremento de } \\
\text { ventajas en la competencia con otras empresas del mismo sector y esto se logra con una adecuada } \\
\text { gestión de información que permita operar, aprender y adaptarse a los cambios del ambiente. }\end{array}$ \\
\hline $\begin{array}{c}\text { Rodríguez y } \\
\text { González } \\
\text { (2013) }\end{array}$ & $\begin{array}{l}\text { Proceso a través del cual se crea, captura, distribuye, comparte, asimila, explota, usa y renueva el } \\
\text { conocimiento organizacional, a fin de cimentar estrategias tendientes a la generación de valor para } \\
\text { la institución y de esta manera lograr que ésta sea competitiva en un mercado cada vez más } \\
\text { exigente. }\end{array}$ \\
\hline $\begin{array}{c}\text { Archibold y } \\
\text { Escobar } \\
\text { (2014) }\end{array}$ & $\begin{array}{l}\text { Proceso práctico y teórico que conlleva a la generación de capacidades técnicas y cientificas para } \\
\text { tomar las decisiones correctas en el momento adecuado; permitiendo de esta manera, ejecutar } \\
\text { acciones acertadas dentro del giro operacional de las instituciones empresariales. }\end{array}$ \\
\hline
\end{tabular}




\begin{tabular}{|c|l|}
\hline Alba (2015) & $\begin{array}{l}\text { Proceso que abarca el tratamiento intencionado de la información y el conocimiento interno y } \\
\text { externo de la organización, de manera tal, que lo incorpora a la filosofia y mecanismos de gestión a } \\
\text { partir de un reposicionamiento del talento humano como principal activo para articular y aportar } \\
\text { valor a sus resultados, utilizando como medios los soportes tecnológicos. }\end{array}$ \\
\hline Jiménez & $\begin{array}{l}\text { conjunto de actividades integradas que se desarrollan a nivel de toda la empresa, influyendo en las } \\
\text { personas para la utilización eficiente de los recursos contenidos en el conocimiento organizacional } \\
\text { y su incremento, en la realización de los procesos internos a fin de contribuir al logro de los } \\
\text { resultados estratégicos de la organización. }\end{array}$ \\
\hline $\begin{array}{c}\text { Pérez Morfi } \\
\text { (2018) }\end{array}$ & $\begin{array}{l}\text { Proceso en el cual se enriquece el capital intelectual a partir del aprendizaje organizacional, } \\
\text { mediante la interacción entre actores que permite la transformación de la información en } \\
\text { conocimiento y viceversa (captura, transformación, creación, circulación y uso). Como resultado se } \\
\text { crean competencias para la solución de problemas, y la innovación. }\end{array}$ \\
\hline
\end{tabular}

Figura 2. Enfoques de los autores sobre qué es la gestión del conocimiento

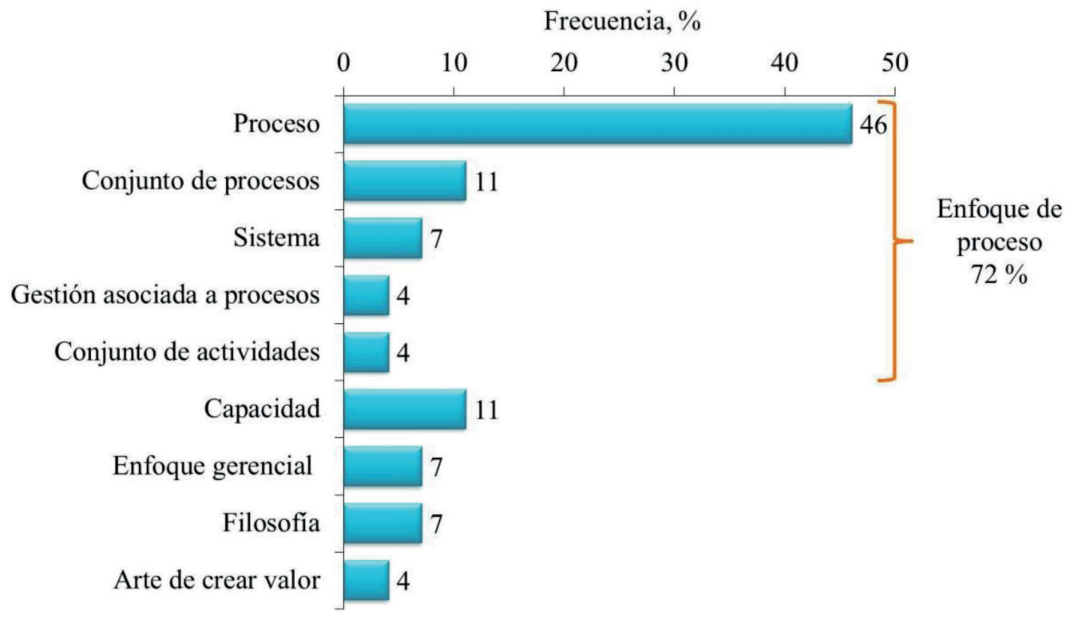

Además, los autores consultados consideran que la gestión del conocimiento es un proceso sistemático, integrador, sistémico, dinámico, interactivo, propio de la organización y que demanda de una gestión explícita en la que considera al capital humano como el principal activo de la organización. Todo esto permite considerar la gestión del conocimiento bajo un enfoque sistémico, que se integra a todos los procesos de la organización de manera explícita (Figura 3). 
Figura 3. Enfoques de los autores sobre cómo es el proceso de gestión del conocimiento

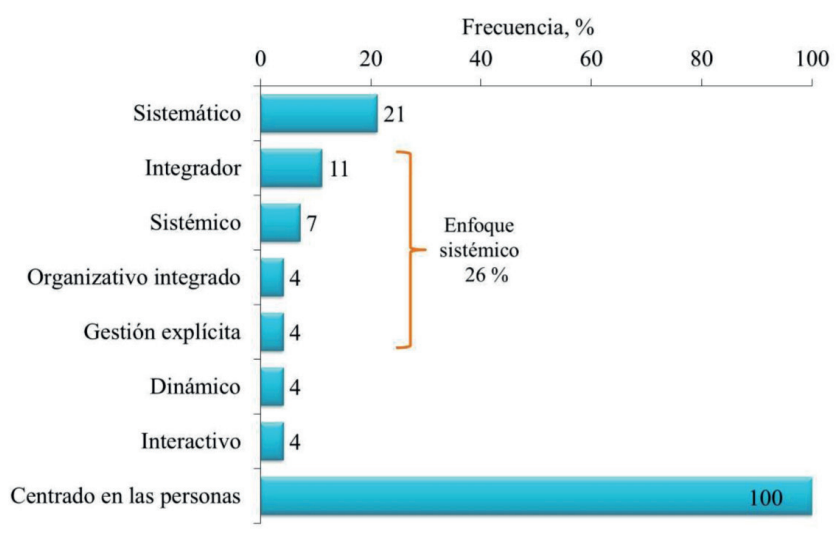

Al indagar sobre la finalidad de la gestión del conocimiento, los autores consultados declaran que se realiza para desarrollar capacidades y competencias (considerado por la autora como un objetivo intermedio), con el objetivo final de crear valor, mejorar el desempeño, obtener ventajas competitivas, cumplir la misión y los objetivos de la organización, mejorar la toma de decisiones y solucionar problemas (Figura 4). El hecho de que casi el $29 \%$ de los autores consultados consideren que el conocimiento crea valor en las organizaciones es relevante para el análisis del conocimiento y su influencia en la innovación, que realiza la autora en esta investigación.

Figura 4. Enfoques de los autores sobre para qué se realiza la gestión del conocimiento

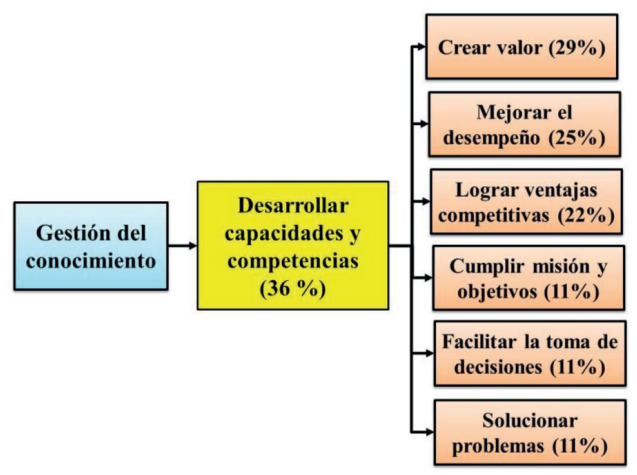


Del análisis hasta aquí realizado, puede concluirse que la gestión del conocimiento permite articular acciones mediante un proceso continuo, en crecimiento, generando un impacto en todos los componentes de la organización, que logra movilizar las capacidades individuales y colectivas dentro del contexto en que existe la organización y con ello crear valor hacia la sociedad.

Varios son los factores que determinan el éxito de la gestión del conocimiento en las organizaciones (Schmidl et al., 2011). En tal sentido, se establece la necesidad de crear un ambiente propicio para compartir y utilizar el conocimiento (Anand y Singh, 2011; Simeón, 2001), lo cual requiere incorporar la estructura, la cultura y la estrategia de la organización (Dánjer, 2006; Hermida, 2009), que promuevan un entorno colaborativo, por medio de la existencia de un liderazgo sólido, así como por la puesta en práctica de políticas que favorezcan la capacitación, el aprendizaje y la motivación de cada miembro de la organización (Bejerano, 2011).

En el proceso de la gestión del conocimiento se realiza la combinación sinérgica de la información, el individuo, los procesos de la organización, la comunicación y la tecnología con el fin de aumentar la capacidad para tomar decisiones, adaptarse al entorno y obtener ventajas competitivas. Para ello, deben realizarse una serie de actividades que permitan utilizar el conocimiento de manera adecuada y en el momento preciso (Davenport y Prusak, 2001; North y Rivas, 2008).

Para establecer los subprocesos de la gestión del conocimiento fueron estudiados diferentes autores, entre ellos: Plaz (2003), León et al. (2006), Salazar y Zarandona (2007), Rodríguez et al. (2009), González (2010), Anand y Singh (2011), Pereira (2011), Alfaro y Alfaro (2012), Lopera y Quiroz (2013), Burbano (2013), Franch y Herrera (2014), Morgan et al. (2014), Salazar (2014), Alba (2015), Franch y Guerra (2016), La Fé Jiménez (2017) y Pérez Morfi (2018). 
Las actividades de la gestión del conocimiento identificadas por los autores analizados fueron agrupadas en siete subprocesos generales (Tabla 3), ellos son:

I. Identificación: asociado al reconocimiento del conocimiento, ya sea en su planeación, en la posibilidad de reutilización de lo conocido o en su renovación. En esta etapa las organizaciones deben identificar el conocimiento que necesitan para lograr los objetivos propuestos. Las necesidades de conocimiento se identifican a todos los niveles (estratégico, funcional, de procesos, personal).

II. Adquisición: asociado al hecho de disponer del conocimiento y de las acciones que así lo permiten: localización, selección, captura. Las organizaciones determinan la forma más factible en que se debe adquirir el activo. Este proceso permite obtener aquellos activos intangibles con que no cuenta la organización o que no están suficientemente desarrollados en ella.

Tabla 3. Procesos identificados en la gestión del conocimiento

\begin{tabular}{|c|c|c|c|c|c|c|c|}
\hline \multirow{2}{*}{ Autor (año) } & \multicolumn{7}{|c|}{ Procesos } \\
\cline { 2 - 8 } & I & II & III & IV & V & VI & VII \\
\hline Probst et al. (2001) & $\mathrm{X}$ & $\mathrm{X}$ & & $\mathrm{X}$ & $\mathrm{X}$ & $\mathrm{X}$ & $\mathrm{X}$ \\
\hline Plaz (2003) & $\mathrm{X}$ & $\mathrm{X}$ & & $\mathrm{X}$ & $\mathrm{X}$ & $\mathrm{X}$ & \\
\hline León et al. (2006) & $\mathrm{X}$ & $\mathrm{X}$ & & $\mathrm{X}$ & $\mathrm{X}$ & $\mathrm{X}$ & $\mathrm{X}$ \\
\hline Rodríguez et al. (2009) & & $\mathrm{X}$ & $\mathrm{X}$ & $\mathrm{X}$ & $\mathrm{X}$ & $\mathrm{X}$ & \\
\hline González (2010) & $\mathrm{X}$ & $\mathrm{X}$ & & $\mathrm{X}$ & $\mathrm{X}$ & $\mathrm{X}$ & $\mathrm{X}$ \\
\hline Anand y Singh (2011) & & $\mathrm{X}$ & & $\mathrm{X}$ & $\mathrm{X}$ & $\mathrm{X}$ & $\mathrm{X}$ \\
\hline Pereira (2011) & $\mathrm{X}$ & $\mathrm{X}$ & & $\mathrm{X}$ & $\mathrm{X}$ & $\mathrm{X}$ & $\mathrm{X}$ \\
\hline Alfaro y Alfaro (2012) & & $\mathrm{X}$ & $\mathrm{X}$ & $\mathrm{X}$ & $\mathrm{X}$ & $\mathrm{X}$ & \\
\hline Lopera y Quiroz (2013) & $\mathrm{X}$ & & $\mathrm{X}$ & $\mathrm{X}$ & $\mathrm{X}$ & $\mathrm{X}$ & \\
\hline Burbano (2013) & & $\mathrm{X}$ & $\mathrm{X}$ & & $\mathrm{X}$ & $\mathrm{X}$ & $\mathrm{X}$ \\
\hline Franch y Herrera (2014) & $\mathrm{X}$ & $\mathrm{X}$ & & $\mathrm{X}$ & $\mathrm{X}$ & $\mathrm{X}$ & $\mathrm{X}$ \\
\hline Morgan et al. (2014) & $\mathrm{X}$ & & $\mathrm{X}$ & $\mathrm{X}$ & $\mathrm{X}$ & $\mathrm{X}$ & \\
\hline Salazar (2014) & & $\mathrm{X}$ & & $\mathrm{X}$ & $\mathrm{X}$ & $\mathrm{X}$ & $\mathrm{X}$ \\
\hline Alba (2015) & $\mathrm{X}$ & $\mathrm{X}$ & $\mathrm{X}$ & $\mathrm{X}$ & $\mathrm{X}$ & $\mathrm{X}$ & $\mathrm{X}$ \\
\hline Franch y Guerra (2016) & $\mathrm{X}$ & $\mathrm{X}$ & $\mathrm{X}$ & $\mathrm{X}$ & $\mathrm{X}$ & $\mathrm{X}$ & $\mathrm{X}$ \\
\hline
\end{tabular}




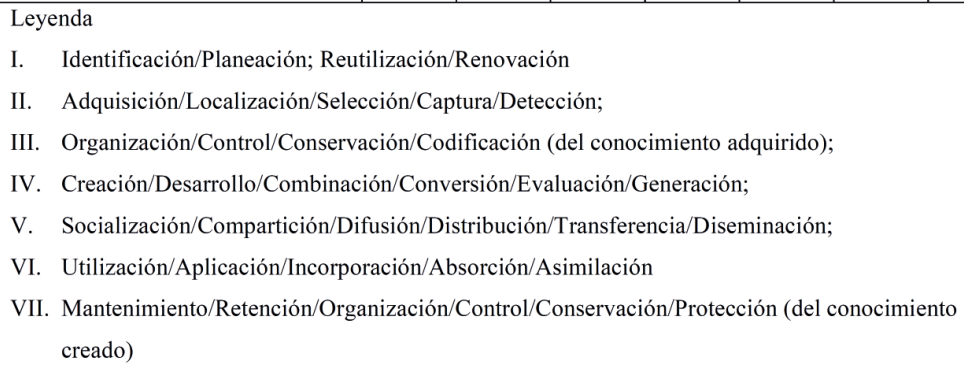

III. Organización: asociada a la conservación y codificación del conocimiento adquirido. Se requiere emplear mecanismos adecuados para convertir el conocimiento nuevamente en información y que esta pueda utilizarse por los miembros de la organización. La codificación transforma el conocimiento a un formato que permite su conservación y transferencia como información. Cuando este proceso no es posible, la organización del conocimiento se limita a la identificación de los expertos que poseen el conocimiento específico requerido. En este proceso, se emplean diversas herramientas que permiten indizar, filtrar, catalogar y clasificar al activo intangible en cuestión y otras acciones para procesar dicho conocimiento haciéndolo realmente accesible para aquellos que lo requieren.

IV. Creación: asociada al desarrollo y generación del conocimiento, su transformación como consecuencia de la combinación, conversión, evaluación. Este proceso se dirige tanto al perfeccionamiento del conocimiento organizacional como al desarrollo de los recursos humanos para la adquisición de las competencias necesarias, la obtención de mejores ideas y procesos más eficaces. Se orienta al desarrollo de los conocimientos necesarios que la organización no posee o, al menos, no en los niveles deseados y crear aquellos que no existen todavía dentro o fuera de ella.

V. Socialización: asociado a la posibilidad de compartir, difundir, distribuir y transferir y diseminar el conocimiento. El objetivo de esta etapa es transferir el conocimiento al lugar donde se 
necesita, en el momento adecuado y con la calidad requerida. El conocimiento se distribuye para que otras personas puedan encontrarlo y lo utilicen en procesos que añadan valor. Las herramientas que facilitan este proceso son: Internet, Intranet, bases de datos, comunidades de práctica, rotación de puestos de trabajo, seminarios, cursos, colaboración, talleres, aprendizaje en el trabajo diario, entre otras.

VI. Utilización: vinculada a la aplicación, incorporación, absorción y asimilación del conocimiento. Garantiza la utilización del activo intangible. Es la etapa donde el conocimiento se transforma en resultados concretos; además, se identifican y eliminan las barreras que frenan su flujo.

VII.Mantenimiento: asociadoala retención,control,conservación y protección del conocimiento creado. Este paso es significativo en la protección de los activos de conocimiento. Adquiere mayor importancia en organizaciones donde el conocimiento se localiza en pocas personas expertas en diferentes temas de importancia, cuya pérdida podría ser negativa para la organización. La pérdida de los activos de conocimiento se puede prevenir trasformando el conocimiento tácito en explícito facilitándose su transferencia.

En consecuencia, se considera que el flujo a través del cual se realiza la gestión del conocimiento como proceso mayor, abarca un conjunto de subprocesos que incluyen: la identificación, adquisición, organización, creación, socialización, utilización y mantenimiento del conocimiento, que se integran con las actividades de la organización. Estos elementos han de ser considerados cuando se aspira a modelar e implementar la gestión del conocimiento.

La identificación de siete subprocesos en la gestión del conocimiento no quiere decir que ellos se den de la misma forma en las organizaciones, ni que se trate de un flujo lineal, ya que la gestión del conocimiento es un proceso complejo, cíclico eiterativo. El carácter cíclico de la gestión del conocimiento se demuestra 
al incluir la reutilización/renovación, actividades propuestas por Plaz (2003), en el primer subproceso, conjuntamente con la identificación/planeación.

Algunos autores unen los procesos de adquisición y de creación y en él combinan varios subprocesos, tales como: la captura, la búsqueda, la recolección y la síntesis, para adquirir nuevas formas de conocimiento de fuentes externas o internas (Supyuenyong y Islam, 2006; Burbano, 2013; Lopera y Quiroz, 2013). Tanto la adquisición como la creación de conocimiento organizacional requieren la colaboración entre los individuos de la organización y las redes de socios de negocios y otras partes interesadas. La consultoría, las investigaciones colaborativas y la formación son canales a través de los cuales los conocimientos pueden ser transferidos a la organización desde fuentes externas (Guerra et al., 2017; Sosa et al., 2017).

En el enfoque aportado por Alba (2015) se integran los elementos del sistema de información al flujo del conocimiento, lo que resulta en el proceso de infoconocimiento (identificación, disponibilidad, valoración, decisiones, aplicación, socialización, transformación, registro y retroalimentación). Esta autora desarrolla el vínculo del conocimiento con las tecnologías de la información y las comunicaciones elementos que se comparten en este trabajo.

La gestión del conocimiento está íntimamente ligada al aprendizaje organizacional (Welo y Ringen, 2018). Las personas de la organización son fundamentales para el aprendizaje organizacional, mediante la creación de conocimiento a través de la experiencia. Sin embargo, el valor para la organización aumenta si los individuos contribuyen a compartir, integrar y utilizar su conocimiento con un propósito superior. La teoría del conocimiento organizacional identifica cuatro fases distintivas de aprendizaje de los individuos en las organizaciones: la identificación de información relevante para el aprendizaje, el intercambio y la difusión del conocimiento, la incorporación del 
conocimiento en los sistemas existentes y la transformación del nuevo conocimiento en acción y su incorporación en las rutinas organizacionales (Welo y Ringen, 2018).

La habilidad de adquirir un conocimiento, que no está relacionado con las áreas de experticia habituales de la organización, e incorporarlo efectivamente a las prácticas de la organización depende de la capacidad de absorción de la misma (Cohen y Levinthal, 1990; González-Campo y Hurtado, 2014). El concepto capacidad de absorción se fundamenta en que se debe reconocer, asimilar y aplicar el conocimiento relevante para obtener resultados económicos para la organización.

La transferencia del conocimiento se desarrolla en dos etapas (Bierly et al., 2009): la transferencia, propiamente, y la aplicación (Figura 5). En la primera etapa ocurre la adquisición y la asimilación del conocimiento. En una segunda etapa, el conocimiento externo es aplicado en la organización al desarrollo de nuevas capacidades (exploración) o a la mejora de las capacidades existentes (explotación). Ambas etapas forman parte del mecanismo de integración social para compartir y explotar el conocimiento como resultado de las relaciones formales o informales entre las estructuras organizativas y se convierten en un mecanismo para responder a demandas que exigen cambios en los soportes ya establecidos.

Cada etapa en la transferencia del conocimiento se relaciona con una forma específica de capacidad de absorción, la capacidad potencial, que incluye la adquisición y comprensión del conocimiento externo, y la capacidad alcanzada, centrada en la incorporación del conocimiento a las prácticas de la organización (Guerra et al., 2017). 
Figura 5. Etapas de la transferencia del conocimiento externo y su relación con la capacidad de absorción de la organización

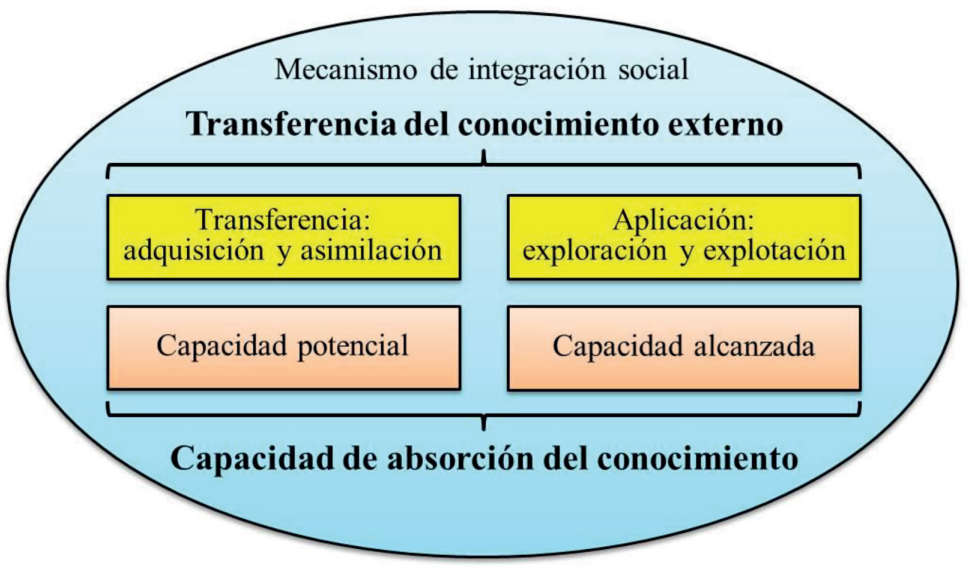

Otro aspecto a resaltar lo constituye el hecho de que en los procesos de gestión del conocimiento algunos miembros de la organización actúan como intermediarios (gatekeepers) entre la organización y el entorno externo o entre las estructuras internas de la organización, generalmente asociados a los procesos de transferencia del conocimiento externo (Gopalakrishnan y Santoro, 2004; Jones, 2006). Estos intermediarios del conocimiento y los agentes internos del cambio contribuyen a la transferencia del conocimiento entre los grupos y organizaciones y sus roles varían en dependencia del contexto de la organización (Haas, 2014).

El aprendizaje es de gran importancia, pues constituye el proceso que con mayor integración permite en las organizaciones transformar información en conocimiento, difundirlo y explotarlo con el fin de incrementar su capacidad innovadora y competitiva. En algunos casos, la capacidad de absorción también se interpreta como capacidad dinámica de aprendizaje, concepto en el que se hace mayor énfasis en la habilidad de la organización para responder a un entorno en constante cambio (Jones, 2006). Esta capacidad incluye las prácticas asociadas al desarrollo de nuevos productos y servicios, la toma de decisiones estratégicas, la adquisición y asignación de los recursos. 
Una buena comunicación entre las estructuras de la organización, así como entre la organización y su entorno, y las capacidades para el procesamiento de la información y la absorción del conocimiento son elementos esenciales para la creación de capacidades no solo de aprendizaje sino de innovación.

Al sintetizar todos los conceptos expuestos, la autora define la gestión del conocimiento como un proceso:

- $\quad$ sistemático, integrador, sistémico, dinámico, interactivo, con identidad propia, abierto;

- que demanda de una gestión explícita de un conjunto de subprocesos que incluyen la identificación, adquisición,

- organización, creación, socialización, utilización y mantenimiento del conocimiento;

que considera al capital humano como el principal activo de la organización, con capacidad de articularse de manera coherente con otros procesos dentro y fuera de la organización;

- que se realiza para desarrollar capacidades y competencias, con el objetivo final de crear valor, mejorar el desempeño, obtener ventajas competitivas, cumplir misión y objetivos, mejorar la toma de decisiones y solucionar problemas de la organización.

\subsection{Modelos para gestionar el conocimiento}

Varios autores contemporáneos han realizado estudios comparativos de los modelos desarrollados para la gestión del conocimiento (Alba, 2015; Alba y Herrera, 2014; La Fé Jiménez, 2017; Mesinas y Griego, 2014; Pérez Morfi, 2018; Salazar y Zarandona, 2007). Otros estudios se han enfocado a la medición del capital intelectual (Borrás y Ruso, 2015; Monagas, 2012). El análisis de estas fuentes secundarias y de los propios autores, que han generado los modelos de gestión del conocimiento de 
mayor reconocimiento internacional, han permitido a la autora sistematizar los enfoques existentes en esta temática, los que pueden ser agrupados en tres escuelas de pensamiento fundamentales: la japonesa, la europea y la norteamericana (Franch y Guerra, 2016; Orozco et al., 2007; Seguí, 2007).

La existencia de estos diferentes enfoques no los ha convertido en islotes del conocimiento, sino que, como resultado del constante intercambio y de su complementariedad, se observa entre ellos un proceso de convergencia (Franch y Guerra, 2016). Además, la literatura revisada no permite agrupar bajo el calificativo de escuela los trabajos realizados por los autores latinoamericanos en la temática de gestión de conocimiento. Por lo general, estos autores aplican los conceptos de las mencionadas escuelas, adhiriéndose a una de ellas o acopiando lo mejor de cada una, con un enfoque mixto.

De la escuela japonesa, el más conocido es el modelo dinámico de creación del conocimiento de Nonaka y Takeuchi (1995), que comprende cuatro etapas: Socialización - Externalización Combinación - Internalización (Figura 6).

Figura 6. Modelo gestión del conocimiento de Nonaka y Takeuchi

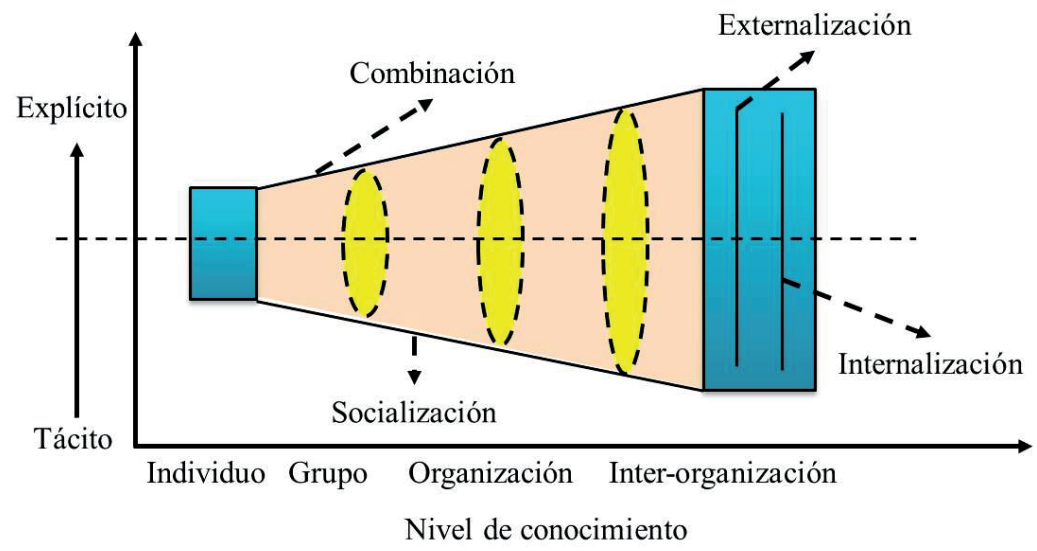

Fuente: Nonaka, I., y Takeuchi, H. (1995, p. 73). The Knowledge Creating Company: How Japanese Companies Create the Dynamics of Innovation. Oxford University Press. 
En la concepción inicial del modelo de Nonaka y Takeuchi, la creación de conocimiento en las organizaciones está basada en tres ideas fundamentales:

a) La creación de conocimiento a nivel individual como resultados del diálogo continuo entre el conocimiento explícito y el tácito.

ß) Existen cuatro procesos básicos de conversión del conocimiento: socialización, externalización, combinación e internalización.

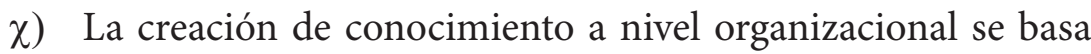
en los cuatro procesos de conversión mencionados y la fuerza motriz de la espiral.

En un desarrollo posterior, Nonaka et al. (2006) plantean que existe un contexto $(\mathrm{Ba})$ donde el conocimiento es compartido, creado y utilizado, definiéndose cuatro tipos de $B a$ según el tipo de interacción (individual o colectiva) y el medio de comunicación empleado (cara a cara o virtual). Ellos son el $\mathrm{Ba}$ originario que corresponde al proceso de socialización del conocimiento en interacciones personales cara a cara; el $\mathrm{Ba}$ de interacción, relacionado con el proceso de externalización del conocimiento en una interacción colectiva; el Ciber $\mathrm{Ba}$ que corresponde a la etapa de combinación del conocimiento y puede involucrar a muchos individuos mediante las tecnologías; y el $\mathrm{Ba}$ ejercitante, donde se desarrolla en el proceso de internalización del conocimiento (Ponjuán y Hernández, 2017).

La escuela europea se ha centrado fundamentalmente en la medición del valor de los activos intangibles en la empresa (capital intelectual), el cual se encuentra tanto en los individuos como en las capacidades y competencias organizacionales relacionadas con el liderazgo, la cultura, la innovación y los procesos, así como en las relaciones existentes entre la organización y los clientes. Esta escuela también es llamada de contabilidad de activos intangibles, 
con representantes como Sveiby, Edvinson y Malone (Borrás y Ruso, 2015; Monagas, 2012). Sveiby (1997), por ejemplo, caracteriza y evalúa los activos intangibles, especialmente el conocimiento, mediante indicadores de la estructura externa, las estructuras internas y de competencia de las personas de la organización (Figura 7).

Figura 7. Contexto de los activos intangibles

\begin{tabular}{|c|c|c|}
\hline \multicolumn{3}{|c|}{ Monitor de activos intangibles } \\
\hline \begin{tabular}{l}
\multicolumn{1}{c}{$\begin{array}{c}\text { Indicadores de } \\
\text { estructura externa }\end{array}$} \\
- Rentabilidad por \\
cliente. Crecimiento \\
orgánico. Clientes \\
cautivos potenciales. \\
- Índice de clientes \\
satisfechos: ventas por \\
cliente. Índice \\
ganancia/pérdida. \\
- Proporción de clientes \\
importantes. Estructura \\
de edades de los \\
clientes. Proporción de \\
clientes leales. \\
Frecuencia de pedidos \\
repetidos.
\end{tabular} & $\begin{array}{l}\text { Indicadores de } \\
\text { estructura interna } \\
\text { - Inversión en IT. } \\
\text { Estructura-Clientes } \\
\text { cautivos. } \\
\text { - Proporción de valores } \\
\text { / actitudes del } \\
\text { personal. } \\
\text { - Edad de la } \\
\text { organización. } \\
\text { - Rotación del personal. } \\
\text { - Proporción de nuevo } \\
\text { personal. } \\
\text { - Antigüedad }\end{array}$ & $\begin{array}{l}\text { Indicadores de Competencia } \\
\text { - Número de años en la } \\
\text { profesión. Nivel educativo. } \\
\text { Costos de formación y } \\
\text { educación. Marketing. } \\
\text { Rotación de la competencia. } \\
\text { Clientes cautivos por la } \\
\text { competencia. } \\
\text { Proporción de profesionales. } \\
\text { Efecto de apalancamiento. } \\
\text { Valor añadido por } \\
\text { profesional. Beneficios por } \\
\text { empleado. Beneficios por } \\
\text { profesional. } \\
\text { Rotación de profesionales. } \\
\text { Pago relativo. Antigüedad. }\end{array}$ \\
\hline
\end{tabular}

Fuente: Adaptado de Sveiby, K. E. (1997). The Intangible Assets Monitor. Journal of Human Resource Costing \& Accounting, 2(1), 73-97.

El enfoque norteamericano está basado en el uso de las tecnologías de la información y las comunicaciones, como herramienta fundamental para la gestión del conocimiento, facilitando el acceso y uso del mismo mediante bases de datos. Dentro de estos modelos cabe destacar el modelo de gestión del conocimiento organizacional desarrollado por Andersen (1999), que involucra los niveles individual y organizacional y plantea la necesidad de fomentar un clima que favorezca este intercambio, tiene en su centro la innovación e incorpora el aprendizaje (Figura $8)$. 
Por su parte, el modelo KMAT (Knowledge Management Assessment Tool) es una herramienta de evaluación y diagnóstico del conocimiento organizacional (Andersen \& APC, 1996) y establece cuatro elementos facilitadores: el liderazgo, la cultura, la tecnología y la medición (Figura 9).

Figura 8. Modelo de gestión del conocimiento organizacional de Andersen (1999)

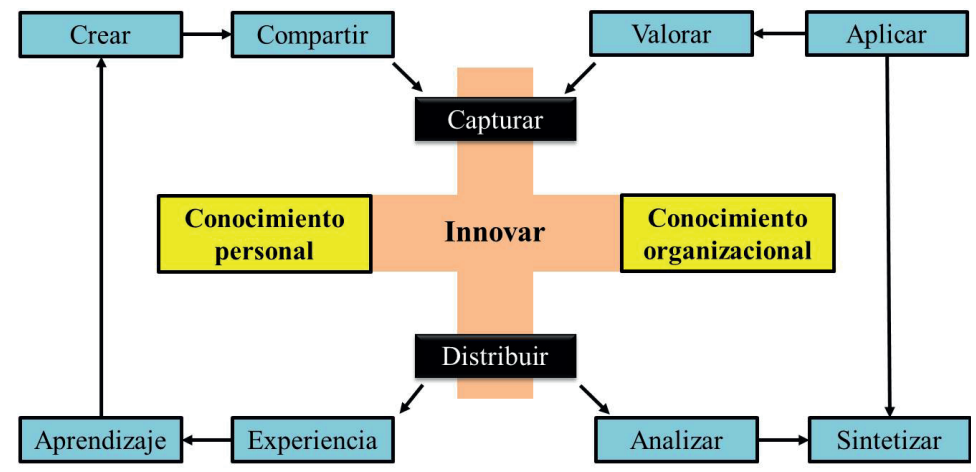

Fuente: Andersen (1999), adaptado de Trejo, D. (2009, p. 75). Identificación, análisis y aprovechamiento de la administración del conocimiento para la organización y empresa mexicana del siglo XXI. Amazon.

Figura 9. Herramienta de Evaluación de la Gestión del Conocimiento

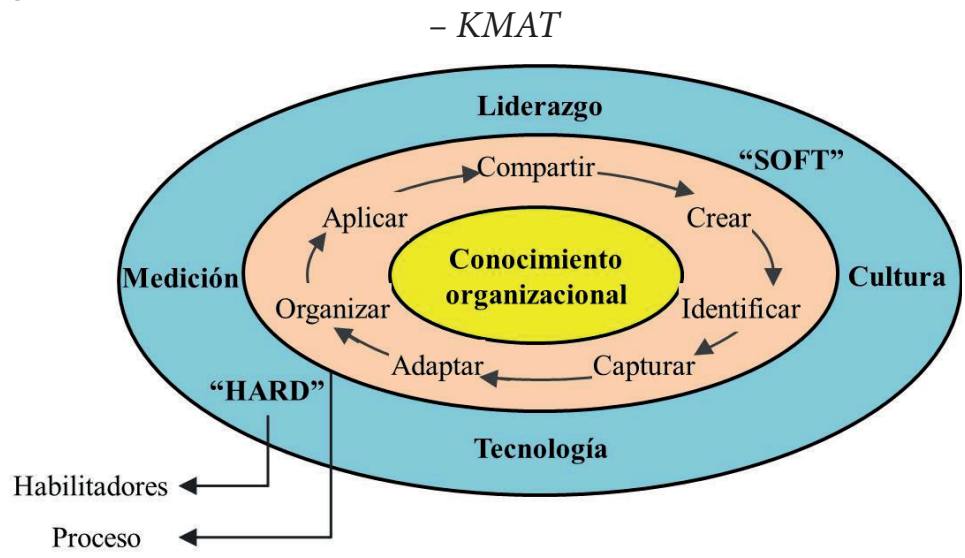

Fuente: Andersen y APC (1997), adaptado de Holsapple, C. W., y Joshi, K. D. (1999, p. 9). Description and Analysis of Existing Knowledge Management Frameworks. En: Proceedings of the 32nd Hawaii International Conference on System Sciences. IEEE. 
Finalmente, el modelo del KPMG Consulting ${ }^{2}$ se basa en un enfoque sistémico-organizacional enfocado en el aprendizaje, que expone los factores que condicionan la capacidad de aprendizaje de una organización, así como los resultados esperados del aprendizaje (Aguirre \& Tejedor, 1998). Sus elementos (la estructura organizativa, la cultura, el liderazgo, los mecanismos de aprendizaje, las actitudes de las personas, trabajo en equipo, etc.) se presentan como un sistema (Figura 10).

Figura 10. Modelo de KPMG Consulting

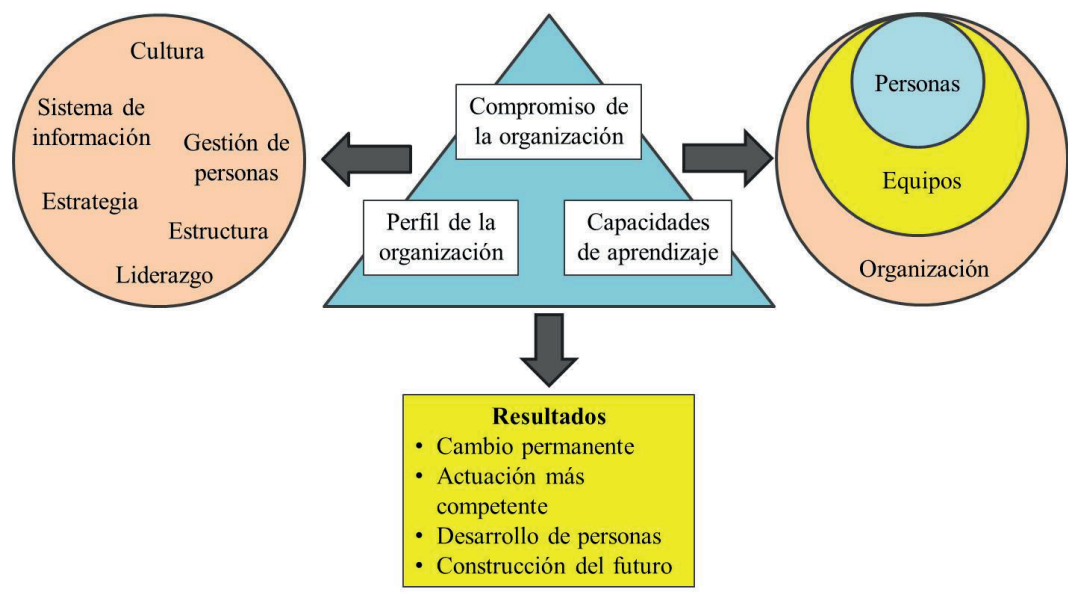

Fuente: Aguirre, A., y Tejedor, B. (1998), citado en Márquez Montoya, S. C., Ramírez Estévez, M. E., y Losada Losada, M. C (2007, p. 7). La gestión del conocimiento, una herramienta imprescindible en la investigación. Ciencia en su PC, 5, 3-15.

Si bien los modelos de gestión del conocimiento analizados fueron desarrollados en el pasado siglo, sientan las bases del escenario actual en que el conocimiento puede transcender dentro de la organización.

Rodríguez (2006) considera que los modelos de gestión del conocimiento existentes se centran en uno de los aspectos siguientes:

2 KPM - Knowledge Practices Management. 
- Almacenamiento, acceso y transferencia de conocimiento. Son modelos que no distinguen entre el conocimiento, la información y los datos y que lo conciben como flujo independiente de las personas que lo crean y lo utilizan.

- Sociocultural, centrado en el desarrollo de la cultura organizacional necesaria para el desarrollo de los procesos de gestión del conocimiento.

- Tecnológico, modelos en los que se destaca el desarrollo y la utilización de herramientas tecnológicas para la gestión del conocimiento.

No obstante, aun cuando los modelos puedan tener un enfoque central, ellos reúnen en sí mismos varios de los aspectos identificados, por lo que para esta investigación estos aspectos no son excluyentes, sino que deben ser ponderados proporcionalmente, ya que la gestión del conocimiento requiere de las tres dimensiones para su éxito, idea que resulta central en esta investigación. De igual forma se constata que los elementos vinculados con la gestión de la información, las competencias, el capital intelectual y la gestión tecnológica sirven de base para que las personas, el conocimiento y la innovación puedan desarrollarse, cuestiones que vienen desarrollándose con mayor fuerza en los últimos años (La Fé Jiménez, 2017; Pérez Morfi, 2018).

El modelo de gestión del infoconocimiento propuesto por Alba (2015) rompe con la estructura tradicional de la separación entre información y conocimiento, ya que genera un solo ciclo, la espiral del infoconocimiento, que ofrece la posibilidad de su integración a los procesos de una cadena de suministro. A tenor con las tendencias tecnológicas actuales, este modelo se soporta en la aplicación de las tecnologías de la información y las comunicaciones (TIC), que se expresa en la concepción de un portal corporativo. Sin embargo, este modelo al estar encaminado a desarrollar una concepción propia de infoconocimiento, sustentada en la integración de los flujos de información y 
conocimiento, introduce un sesgo que impide revelar la relación de la gestión del conocimiento con otros aspectos de la gestión organizacional, como son el aprendizaje y la innovación como expresión más completa y práctica de la generación y aplicación del conocimiento.

En un trabajo realizado por Alba y Herrera (2014), se identificaron 27 variables presentes en los modelos de gestión del conocimiento, que fueron agrupadas en cinco categorías generales: procesos empresariales, gestión del conocimiento, gestión de la información, tecnología y gestión de capital humano. En este estudio se identificó que, si bien dentro de la categoría procesos empresariales se incluye la innovación, ella solo estaba presente en dos de los modelos analizados.

Franch y Guerra (2016) reconocen que la mejora del desempeño organizacional, basada en el aprendizaje y la innovación, requiere de procesos estructurados de gestión de la información y el conocimiento. Sin embargo, el modelo planteado en este trabajo tiene un alcance muy específico a la gestión integrada del conocimiento y la información documentada en un sistema de gestión de la calidad, según la norma internacional ISO 9001:2015 (Organización Internacional de Normalización, 2015b), por lo que en este trabajo no desarrollan en profundidad todas las categorías abordadas.

De acuerdo con el análisis realizado, se puede indicar que la propuesta de un modelo teórico que revele los detalles de la relación entre las categorías gestión del infoconocimiento e innovación resulta necesario e impostergable, si se aspira a que las organizaciones no solo se ajusten y respondan a las necesidades existentes, sino que asuman un rol proactivo coherente con su responsabilidad social. 


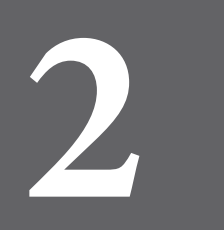

CAPÍTULO DOS 


\section{LA INNOVACIÓN Y SU GESTIÓN}

En la actualidad, el término innovación es muy utilizado en el mundo empresarial, puesto que una empresa competitiva basa su éxito en la introducción de novedosos productos y servicios que satisfagan, cada vez más, las crecientes necesidades de los clientes y otros grupos de interés.

En términos generales, los autores consultados analizan la innovación desde diversos ámbitos, tales como: la tecnología, las patentes, la mejora del desempeño de una organización, el desarrollo local, la inteligencia empresarial, la formación de directivos y otros (Delgado, 2001; Díaz, 2005; Armenteros et al., 2008; Valdés, 2010; Filgueiras, 2010; Boffill, 2010; Zaldívar, 2011; Stable, 2012).

\subsection{El concepto y los tipos de innovación}

La innovación es un tema tratado desde los trabajos seminales de Schumpeter (1934), con autores muy reconocidos del siglo XIX, tales como Nelson (1974), Gee (1981), Pavón y Gudman (1981), Tushman y Nadler (1986), Piatier (1987), Porter (1993) y Escorsa y Valls (1997). Sin embargo, reconociendo la actualidad del tema, en este acápite se analizan diferentes definiciones sobre la innovación dadas por autores contemporáneos.

El término innovación tiene dos grandes acepciones: como proceso y como resultado del mismo (Robayo, 2016; Velasco et al., 2007). En este último enfoque está la concepción de Van de Ven (2017), quien plantea que innovaciones, por definición, son ideas excepcionales que son implementadas o el concepto de Rogers (2003) para quien una innovación es una idea, práctica $\mathrm{u}$ objeto que es percibido como nuevo por un individuo $\mathrm{u}$ otra unidad adoptante. Sin embargo, la presente investigación se centra en la innovación como proceso, para lo cual se analizaron 15 definiciones del período 2001-2017, recogidas en las Tablas 4a (2001-2010) y 4b (20011-2017). 
Tabla 4a. Definiciones de innovación del periodo 2001-2010

\begin{tabular}{|c|c|c|}
\hline Autores & Definición & Enfoque \\
\hline $\begin{array}{l}\text { Jaramillo et al. } \\
\qquad(2001)\end{array}$ & $\begin{array}{l}\text { La innovación tecnológica en productos y procesos se refiere a la } \\
\text { implementación tecnológica de nuevos productos y procesos o a mejoras } \\
\text { significativas en éstos, ya sea como resultado de la difusión de conocimientos } \\
\text { tecnológicos o de inversiones en I+D que generan novedades a nivel de la firma. } \\
\text { Además de las definiciones del Manual de Oslo de } 1997 \text { se incluyen la } \\
\text { innovación organizacional, la innovación en comercialización, aspectos tales } \\
\text { como “esfuerzo tecnológico", "gestión de la actividad innovadora” o } \\
\text { "acumulación de capacidades tecnológicas, así como el impacto de la } \\
\text { innovación en el desarrollo económico y social de la región de Latinoamérica } \\
\text { (Manual de Bogotá). }\end{array}$ & $\begin{array}{l}\text { Empresarial } \\
\text { y Social } \\
\text { Tipológico }\end{array}$ \\
\hline Valdés (2004) & $\begin{array}{l}\text { Innovación es el arte de crear algo nuevo, novedoso y original, colocarlo en un } \\
\text { mercado y que el cliente esté dispuesto a pagar por ello... es un proceso } \\
\text { sistémico alineado al cliente y para que este sea completo tiene que lograr un } \\
\text { impacto en el mercado y esto dependerá en gran medida de los niveles de la } \\
\text { innovación, los cuales pueden ser graduales o evolutivos, de rompimiento o de } \\
\text { arquitectura de nuevos modelos de negocio. }\end{array}$ & $\begin{array}{l}\text { Empresarial } \\
\text { Tipológico }\end{array}$ \\
\hline OCDE & $\begin{array}{l}\text { Implementación de un producto (bien o servicio) o proceso nuevo o con un alto } \\
\text { grado de mejora, o un método de comercialización u organización nuevo } \\
\text { aplicado a las prácticas de negocio, al lugar de trabajo o a las relaciones externas } \\
\text { (Manual de Oslo). }\end{array}$ & $\begin{array}{l}\text { Empresarial } \\
\text { Tipológico }\end{array}$ \\
\hline AENOR (2006) & $\begin{array}{l}\text { Aquella actividad cuyo resultado es la obtención de nuevos productos y } \\
\text { procesos, o mejoras sustancialmente significativas de los ya existentes. }\end{array}$ & $\begin{array}{l}\text { Empresarial } \\
\text { Tipológico }\end{array}$ \\
\hline Goleman (2009) & $\begin{array}{l}\text { La innovación empresarial es la creatividad en el lugar de trabajo, es una } \\
\text { capacidad para la creación de nuevos productos y de mejores servicios a sus } \\
\text { clientes; es una capacidad para introducir innovaciones en la administración } \\
\text { mejorando los métodos de distribución o aplicando ideas nuevas para financiar } \\
\text { el negocio. }\end{array}$ & $\begin{array}{c}\text { Empresarial } \\
\text { Tipológico }\end{array}$ \\
\hline $\begin{array}{c}\text { Crossan y } \\
\text { Apaydin (2010) }\end{array}$ & $\begin{array}{l}\text { Producción o la adopción, asimilación y explotación de una novedad de mayor } \\
\text { valor en el campo económico y social: renovación y ampliación de productos, } \\
\text { servicios y mercados; desarrollo de nuevos métodos de producción y } \\
\text { establecimiento de nuevos sistemas de gestión. }\end{array}$ & $\begin{array}{c}\text { Social } \\
\text { Tipológico }\end{array}$ \\
\hline
\end{tabular}

Tabla 4b. Definiciones de innovación del periodo 2011-2017

\begin{tabular}{|c|l|c|}
\hline Autores & \multicolumn{1}{|c|}{ Definición } & Enfoque \\
\hline & Por innovación debe entenderse también el desarrollo de una cultura & \\
Trías de Bes y & $\begin{array}{l}\text { innovadora en la empresa, la cual hará posible que produzca y ponga en el } \\
\text { mercado una corriente continua de innovaciones menores o marginales. Es }\end{array}$ & $\begin{array}{c}\text { Empresarial } \\
\text { Cultura } \\
\text { Kotler (2011) }\end{array}$ \\
& $\begin{array}{l}\text { entonces cuando, aunque parezca paradójico, la innovación radical acabará } \\
\text { innovadora }\end{array}$ & \\
\hline Oliveira y & La innovación es caracterizada como una acción capaz de generar valor a la & Empresarial \\
\hline Martin (2011) & organización por medio una forma nueva de hacer. & \\
\hline
\end{tabular}




\begin{tabular}{|c|c|c|}
\hline $\begin{array}{l}\text { Ramírez et al. } \\
\qquad \text { (2012) }\end{array}$ & $\begin{array}{l}\text { Proceso mediante el cual la sociedad extrae del conocimiento beneficios } \\
\text { sociales y económicos. }\end{array}$ & $\begin{array}{c}\text { Social } \\
\text { Basado en el } \\
\text { conocimiento }\end{array}$ \\
\hline Murcia (2012) & $\begin{array}{l}\text { Proceso permanente de creación de valor basado en el conocimiento, de y } \\
\text { para la sociedad en su conjunto, con el objetivo de generar desarrollo } \\
\text { sostenible. }\end{array}$ & $\begin{array}{c}\text { Social } \\
\text { Basado en el } \\
\text { conocimiento }\end{array}$ \\
\hline $\begin{array}{l}\text { Zawislakl et al. } \\
\text { (2012) }\end{array}$ & $\begin{array}{l}\text { Procesos de aprendizaje tecnológico de las empresas, traducidos en las } \\
\text { capacidades de desarrollo de tecnología y operaciones, así como en las } \\
\text { rutinas de gestión y transaccionales representadas, justamente, por la } \\
\text { capacidad de gestión y transacción. }\end{array}$ & $\begin{array}{l}\text { Empresarial } \\
\text { Basado en el } \\
\text { aprendizaje } \\
\text { tecnológico }\end{array}$ \\
\hline $\begin{array}{l}\text { Garzón e Ibarra } \\
\text { (2013) }\end{array}$ & $\begin{array}{l}\text { La innovación es la utilización de nuevo conocimiento y puede representarse } \\
\text { por una telaraña de vínculos entre múltiples agentes, para introducir o } \\
\text { producir algo novedoso, alguna idea, método, instrumento, modo de pensar } \\
\text { en los negocios o concepto de negocio, servicios, formas de entrar en el } \\
\text { mercado, de producir, de formar u organizar, solucionar problemas, realizar } \\
\text { adaptaciones y modificaciones de bienes y servicios destinados a solucionar } \\
\text { necesidades existentes y a las nuevas que surjan, apropiadas, útiles y viables, } \\
\text { que se comercializan. }\end{array}$ & $\begin{array}{l}\text { Social } \\
\text { Tipológico } \\
\text { Basado en el } \\
\text { conocimiento }\end{array}$ \\
\hline Contreras (2014) & $\begin{array}{l}\text { Desarrollo de nuevos productos, servicios, tecnologías o ideas capaces de } \\
\text { producir cambios significativos en los mercados o en la sociedad... la } \\
\text { innovación es distinta a la mera invención, que es necesaria pero no } \\
\text { suficiente, puesto que innovar implica no sólo inventar, sino llevar a cabo una } \\
\text { aplicación práctica de esa invención. La innovación es también distinta a la } \\
\text { simple mejora, que sería la aplicación de pequeños cambios para optimizar } \\
\text { los productos o procesos, pero sin llegar a cambiarlos de manera } \\
\text { significativa. }\end{array}$ & $\begin{array}{c}\text { Social } \\
\text { Tipológico }\end{array}$ \\
\hline Robayo (2016) & $\begin{array}{l}\text { La innovación debe darse como proceso debido a que abarca todas las } \\
\text { operaciones de la empresa, es decir, que este proceso posibilita combinar las } \\
\text { capacidades técnicas, financieras, comerciales y administrativas y permite a } \\
\text { su vez el lanzamiento al mercado de nuevos y mejorados productos o } \\
\text { procesos que hacen más competitivas a las firmas. }\end{array}$ & $\begin{array}{l}\text { Empresarial } \\
\text { Tipológico }\end{array}$ \\
\hline Cordovéz (2017) & $\begin{array}{l}\text { Proceso mediante el cual, a partir de la determinación de las demandas, se } \\
\text { generan invenciones que se realizan como innovaciones, una vez que sean } \\
\text { apropiadas por el sector productivo y que posteriormente son generalizadas } \\
\text { en la sociedad. }\end{array}$ & Social \\
\hline
\end{tabular}

Las definiciones analizadas tienen dos enfoques fundamentales, el que delimita la innovación como un proceso puramente empresarial siendo el $53 \%$ de los casos estudiados (UNE, 2006; Goleman, 2009; Oliveira y Martins, 2011; Robayo, 2016; Trias de Bes y Kotler, 2011; Valdés, 2004; Zawislak et al., 2012) y aquellas definiciones que incluyen un alcance más amplio que considera 
los impactos de la innovación en la sociedad (47 \%) (Contreras, 2014; Cordovés, 2017; Crossan y Apaydin, 2010; Jaramillo et al., 2001; Murcia, 2012; Ramírez et al., 2012; Garzón e Ibarra, 2013).

Existen criterios que promueven la integración de ambas posturas, la económica y la social, al plantear que la innovación se caracteriza por la transformación del conocimiento en un resultado de utilidad socio-económica (Garzón e Ibarra, 2013; Murcia, 2012; Ramírez et al., 2012), que incluye un aprendizaje tecnológico (Zawislak et al., 2012), como parte de la necesidad de desarrollar una cultura innovadora en la empresa (Trias de Bes y Kotler, 2011).

El $60 \%$ de las definiciones tienen un criterio tipológico al clasificar los diferentes tipos de innovaciones. Por ejemplo, el Manual de Oslo de la Organización para la Cooperación y el Desarrollo Económico $(\mathrm{OCDE})^{3}$ en su tercera edición plantea que

una innovación es la introducción de un nuevo o significativamente mejorado producto (bien o servicio), de un proceso, de un nuevo método de comercialización o de un nuevo método organizativo en las prácticas internas de la empresa, la organización del lugar de trabajo o las relaciones exteriores. (OECD, 2005, p. 9)

De esta forma, el Manual de Oslo establece diferentes tipos de innovaciones, incluyendo las innovaciones en los servicios y las organizacionales (Sánchez y Castrillo, 2006).

Los autores citados emplean diferentes criterios para clasificar las innovaciones, si bien en la práctica ellas no se dan de forma pura, sino que se mezclan entre sí y se complementan para lograr los objetivos de las organizaciones.

3 Por sus siglas en inglés OECD (Organization for Economic Cooperation and Development). 
Las innovaciones pueden diferenciarse por la incorporación o no de tecnología o por el objeto de la innovación (Armbruster et al., 2008). También la literatura consultada incorpora el concepto de innovación social (Echeverría, 2008; Núñez, 2015). A partir del análisis de las diferentes clasificaciones, en la Figura 11 se esquematizan los tipos de innovación, a criterio de la autora, según su objeto y el uso de la tecnología.

Figura 11. Tipos de innovación, según su objeto y el uso de la tecnología

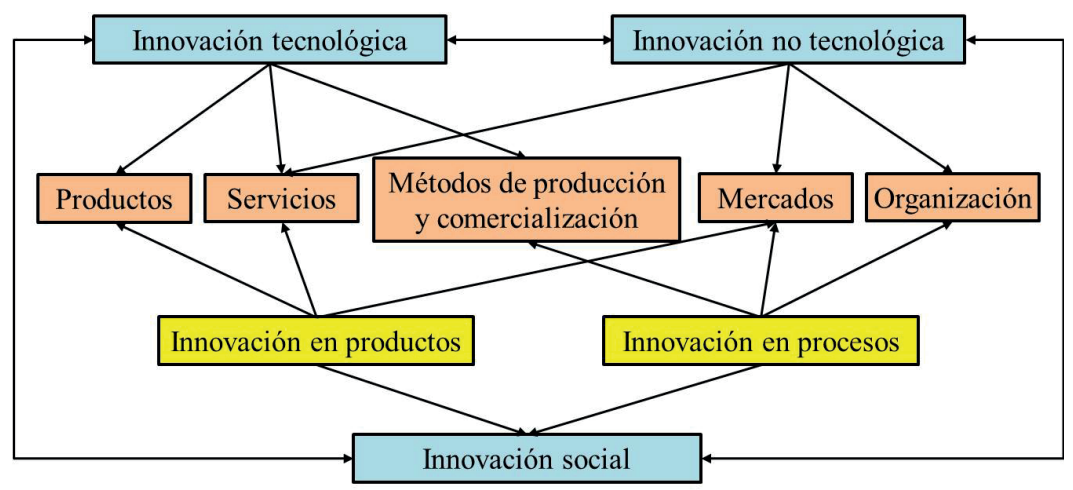

La innovación tecnológica en productos y procesos se refiere a la implementación tecnológica de nuevos productos y procesos o a mejoras significativas en éstos, ya sea como resultado de la difusión de conocimientos tecnológicos o de inversiones en investigación y desarrollo, que generan novedades a nivel de la empresa (Jaramillo et al., 2001). Ejemplos de innovaciones en comercialización son: el lanzamiento de nuevos productos, nuevos métodos de entrega de productos o cambios en el empaque y embalaje.

La innovación social es aquella que intenta contribuir al desarrollo, a partir de la propuesta de nuevas soluciones a los problemas de la sociedad con la participación de sus actores (Núñez, 2015).

La innovación social [...]ha de referirse a valores sociales, por ejemplo, el bienestar, la calidad de vida, la inclusión social, la solidaridad, la participación ciudadana, la calidad 
medioambiental, la atención sanitaria, la eficiencia de los servicios públicos o el nivel educativo de una sociedad. (Echeverría, 2008, p. 610).

A partir de los conceptos analizados, la autora considera que la innovación es la transformación del infoconocimiento en un resultado de utilidad económica y social, a partir de la introducción de un nuevo o significativamente mejorado producto o servicio, proceso o método organizacional en las prácticas internas de las entidades, en sus relaciones con el entorno socio-económico o que generen soluciones a los problemas de la sociedad con la participación de sus actores.

Se reconoce que las ventajas competitivas que tienen las empresas en el mercado son el reflejo del tipo y grado de innovación que realizan (Damanpour y Gopalakrishnan, 2001). Sin embargo, la mera reputación de ser una empresa con productos innovadores incrementa la fidelidad de los consumidores y mejora la imagen corporativa (Henard y Dacin, 2010).

Por su parte, las innovaciones organizacionales favorecen la eficiencia operacional y la mejora el desempeño (Armbruster et al., 2008; Laforet, 2011), traen ventajas competitivas en el mercado (He y Nie, 2008), facilitan el uso eficiente de las nuevas tecnologías (Camisón y Villar-López, 2014) y contribuyen a la reducción de los costos (Schmidt y Rammer, 2007).

Armbruster et al. (2008) clasifican las innovaciones organizacionales en estructurales $y$ de procedimientos. Las estructurales cambian y mejoran las funciones, las responsabilidades, las líneas de mando, los flujos de información, así como los niveles jerárquicos y estructuras funcionales y del negocio. Así, permiten modificar las estructuras que atienden los procesos gerenciales, los clave - orientados a la satisfacción del cliente externo- y los de apoyo. Las innovaciones en los procedimientos intervienen en las rutinas, los procesos y las 
operaciones de la organización. A pesar de su diferenciación, las innovaciones estructurales y de procedimiento, en la práctica, van de la mano.

Avendaño y Flores (2016), por su parte, reconocen que la incorporación por primera vez en una organización de la gestión del conocimiento, de manera sistémica y estructurada, es una innovación organizacional que se realiza con el objetivo de incrementar el capital intelectual de la empresa.

De manera general, se considera que la implementación por primera en una organización de un modelo o de un sistema de gestión, ya sea de gestión de la calidad, ambiental, del conocimiento $\mathrm{u}$ otro, son innovaciones organizacionales que crean un marco propicio para el logro de las innovaciones en productos, servicios y modelos de negocio, de ahí la importancia para la presente investigación de reconocer la existencia de diferentes tipologías de innovación. Además, el establecimiento de prácticas y procedimientos para fomentar la innovación son un importante paso para contribuir a la cultura innovadora de una organización a partir de su incorporación en el saber hacer individual y organizacional.

Otra forma de clasificar las innovaciones es de acuerdo a su alcance transformador (Sáenz, 1999; Castro Díaz-Balart, 2001; Cuba, 2007), por lo que pueden ser:

- Innovaciones menores que no representan un cambio significativo en los productos y procesos, pero que con un gasto mínimo pueden lograr un efecto económico o social importante.

- Innovaciones incrementales que producen mejorías en los productos y procesos de la organización, pero sin alterar su característica fundamental. Las innovaciones menores y las incrementales contribuyen a la mejora continua del desempeño de las organizaciones (Herrera et al., 2012). 
- Innovaciones radicales o disruptivas que constituyen una ruptura total de la manera de hacer las cosas (son también conocidas como innovaciones disruptivas). Generalmente se basan en nuevos conocimientos científicos o de ingeniería; abren nuevos mercados, industrias o campos de actividad. Mediante ellas surgen productos, servicios, procesos de producción, de distribución, organizacionales totalmente nuevos y cualitativamente distintos a otros anteriores. También, abren nuevos campos en la aplicación de productos o servicios, permite la obtención de cambios significativos en parámetros productivos, tales como eficiencia, costos, productividad y calidad.

El concepto de innovación disruptiva fue introducido en la década de 1990 por Bower y Christensen (1995). Estas innovaciones generan un salto en el desarrollo, impactan en varios sectores de actividad y logran que determinados productos o servicios desaparezcan al contraponer estrategias disruptivas frente a estrategias establecidas, con la finalidad de combatir las marcas dominantes y posicionarse en el mercado.

En otra sistematización de la innovación de acuerdo con las actividades que abarca, Sawhney et al. (2006) proponen una tipología en una estructura denominada "radar de la innovación", que incluye doce dimensiones en las que se puede innovar: oferta, plataforma, marca, clientes, soluciones, experiencia del cliente, captura de valor, procesos, organización, cadenas de suministro, presencia y redes (Figura 12). Cada dimensión del radar de innovación representa un vector a lo largo del cual las empresas pueden concentrar sus estrategias de innovación. 
Figura 12. Radar de la innovación

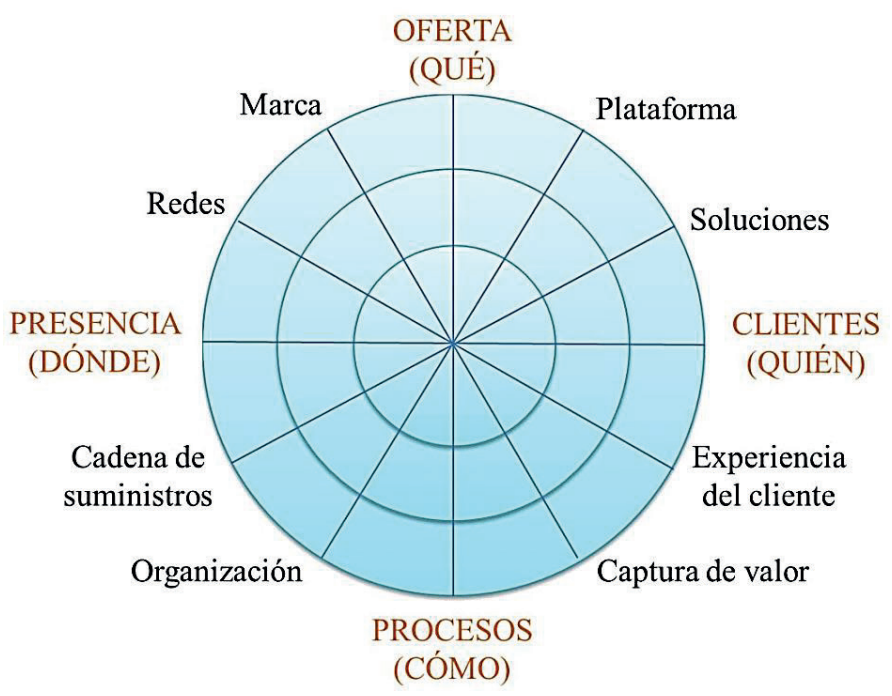

Fuente: Sawhney, M., Wolcott, R. C., y Arroniz, I. (2006, p. 30). The 12 different ways for companies to innovate. MIT Sloan Management Review, 47(3), 75-81.

Bachmann y Destefani (2008) aumentaron la estructura del radar de la innovación en una nueva dimensión denominada "ambiente innovador", al considerar que un clima organizacional propicio a la innovación es un prerrequisito para una empresa innovadora. Por otra parte, los ejes de la innovación fueron modificados por Chen y Sawhney (2010) en un trabajo posterior, puntualizando los siguientes: producto, plataforma, solución, captura de valor, gestión, procesos, necesidades de los clientes, comunicación, interface, cadena de suministros, canales de distribución y ecosistema para la innovación.

Las innovaciones que solo afectan las estructuras y procesos internos de la organización pueden denominarse "intraorganizacionales". Sin embargo, las innovaciones también pueden ser "inter-organizacionales" o "abiertas" si involucran a otros actores hacia atrás o hacia delante en la cadena de suministro, tales como: proveedores, clientes, aliados y otras partes interesadas 
(Chesbrough, 2012; Dubickis y Gaile-Sarkane, 2017; Gassmann et al., 2010; Oliveira et al., 2017; Spender et al., 2017; Vo et al., 2011).

La cuarta edición del Manual de Oslo (OECD, 2018) incorpora como agentes de la innovación, no solo al sector empresarial, sino también a las instituciones sin ánimo de lucro y a la economía informal, incluyendo los hogares y sus miembros individuales. Además, profundiza en los conceptos relacionados con las actividades e innovación, la innovación abierta y la transferencia de conocimientos (Benavente, 2018).

Los conceptos y prácticas relacionados con la gestión de la información y el conocimiento, el aprendizaje y la innovación están en una misma línea con los procesos de mejora en las organizaciones, que pueden realizarse a partir de los enfoques de mejora continua o como proyectos de mejora que generan cambios sustanciales.

En la mejora continua se promueve el desarrollo de innovaciones menores o incrementales, toda vez que se despliega un conjunto de actividades para mejorar los resultados cualitativos o cuantitativos en la organización de manera recurrente, a diferencia de realizar mejoras aisladas (Guerra y Meizoso, 2019; Herrera et al., 2012). Las mejoras realizadas pueden ser una corrección puntual de una desviación o una acción correctiva, que va a subsanar la causa de un incumplimiento de un requisito establecido.

Otros proyectos de mejora más abarcadores pueden inducir cambios significativos en los procesos existentes, la implementación de nuevos procesos, productos y servicios o la introducción de nuevas tecnologías como resultado de innovaciones radicales o disruptivas (Garzón y Ibarra, 2013).

De manera general, el análisis de los datos, su conversión en información pertinente para la organización y ésta en conocimiento relevante, que proviene tanto de fuentes internas como externas, propician un ambiente de aprendizaje y creación 
organizacional que contribuye a la mejora de los procesos, productos y servicios existentes y a la innovación en otros nuevos o significativamente mejorados, lo que genera un desempeño exitoso de las organizaciones al satisfacer de manera creciente las necesidades y expectativas de todas las partes interesadas.

\subsection{Los modelos de innovación y su gestión}

Una forma de analizar la innovación es a través del estudio de sus principales modelos, que han sido agrupados por diferentes estudiosos del tema (Pavón e Hidalgo, 1997; Peres et al., 2016; Robayo, 2016; Velasco et al., 2007) en varias generaciones. Ellos son: Empuje de la Tecnología (Technology-Push), Tirón de la Demanda (Market-Pull), Modelo por etapas (Stage Models), Modelo Interactivo (Coupling Model), Proceso de Innovación Integrado, Modelo de Integración en Sistemas y Establecimiento de Redes.

Los modelos Technology-Push (Figura 13) y Market-Pull (Figure 14) son lineales, secuenciales y ordenados. El primero va desde la ciencia a la tecnología, es decir, a partir del conocimiento científico llega a la comercialización de un producto o servicio. En el segundo, los mercados son vistos como fuentes de ideas a las que se dirige la investigación y el desarrollo, que desempeñan un papel meramente reactivo en el proceso de innovación, aunque todavía juega un papel esencial como fuente de conocimiento para desarrollar y mejorar productos y procesos (Pavón e Hidalgo,1997). Estos modelos resultan útiles para entender de forma simplificada y racional el proceso de innovación. Sin embargo, presentan deficiencias ya que en el proceso de innovación ocurre retroalimentación entre las fases, ciclos de intercambio de información hacia adelante y hacia atrás y solapamiento de fases o etapas (Van de Ven, 2017). 
Figura 13. Modelo lineal de innovación Empuje de la Tecnología (Technology-Push)

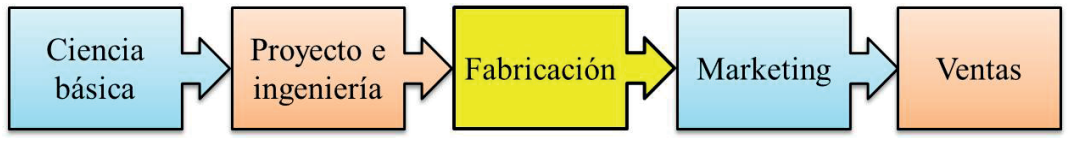

Figura 14. Modelo lineal de innovación Tirón de la Demanda (Market-Pull)

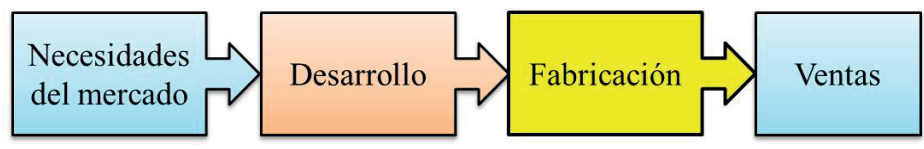

Los modelos de innovación por etapas son también lineales secuenciales e incluyen elementos de los dos modelos lineales anteriores. Las etapas pueden establecerse por departamentos, actividades o decisiones. Un ejemplo es el modelo de tres etapas o fases (Figura 15): generación de una idea a partir de diferentes fuentes, desarrollo de la idea o invención, implementación de la solución o invento y su difusión (ingeniería, manufactura, prueba de marketing y promoción).

Figura 15. Modelo lineal de innovación en tres etapas

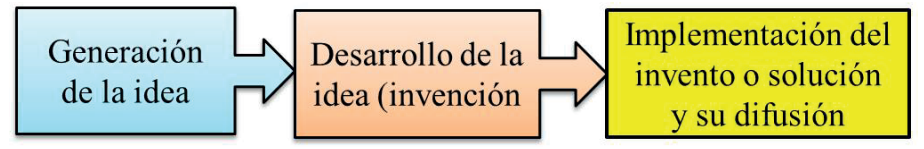

Los modelos interactivos o mixtos (Coupling Model) resaltan la importancia de la retroalimentación entre las distintas fases de la innovación y la posibilidad de que existan diferentes vías para la innovación, aunque en esencia siguen siendo modelos secuenciales con las deficiencias ya señaladas. Entre ellos el más conocido como es el modelo de enlaces en cadena del proceso innovador o modelo de Kline. 
El modelo Kline relaciona la ciencia y la tecnología en todas las etapas y no solamente al inicio del proceso innovador ya que considera que la innovación surge de la ciencia y conocimiento acumulado que se utiliza cuando surge un problema tecnológico $y$, esta vuelve a intervenir cuando no se encuentran las soluciones necesarias y es necesario emprender nuevas investigaciones. El modelo de enlaces en cadena fue empleado por la Asociación Española de Normalización (UNE, 2002) en la primera versión de la norma española UNE 166002 para un sistema de gestión de la investigación, el desarrollo y la innovación (Figura 16).

Figura 16. Modelo de enlaces en cadena para la innovación

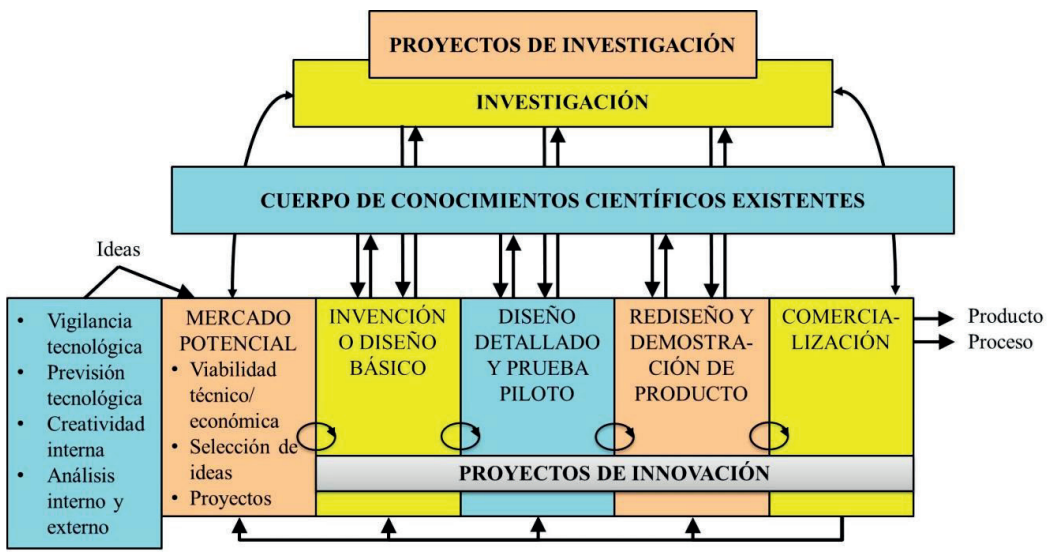

Fuente: UNE (2002, p. 7). UNE 166002:2002 Gestión de la I+D+i: Requisitos del sistema de gestión de la I+D+i. Asociación Española de Normalización.

En los modelos de proceso de innovación integrado pueden ocurrir solapamientos en las fronteras entre las etapas o extenderse los mismos a lo largo de diversas etapas (Figura 17). Se orientan a la integración de las fases del proceso de innovación, lo que requiere mayor coordinación y control. La innovación es gestionada a través de procesos que se dan de manera solapada o incluso simultánea y concomitante; se va realizando a través de las interacciones de los miembros del equipo innovador, el cual puede estar compuesto por las áreas interesadas en la innovación 
(Ciencia, Ingeniería y Marketing) Estos modelos intentan capturar la integración funcional que ocurre dentro y entre las organizaciones, incluyendo a los proveedores, clientes, sector académico y agencias gubernamentales (Velasco et al., 2007).

Figura 17. Modelo del proceso de innovación integrado

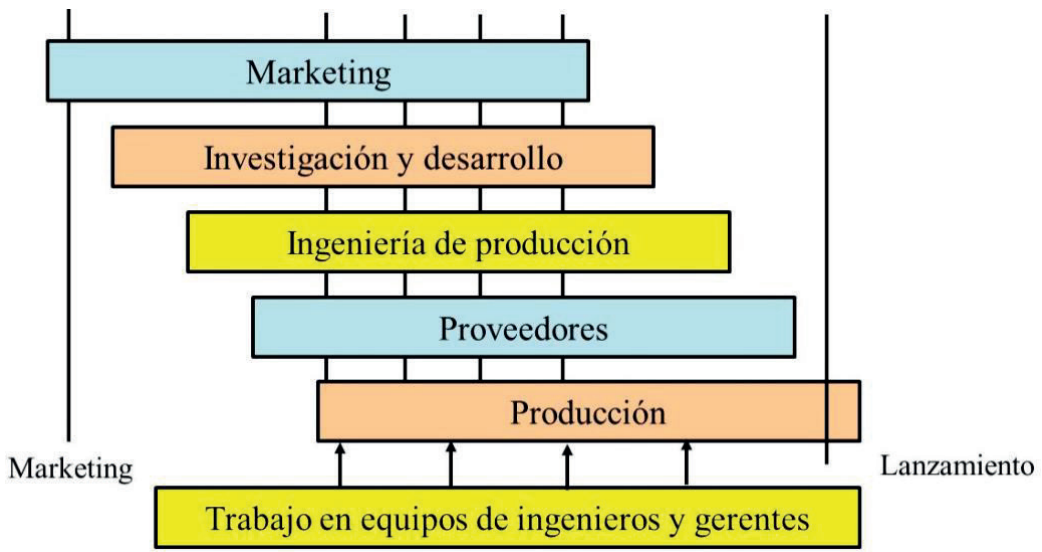

Fuente: Pavón e Hidalgo (1997, p. 57). Gestión e innovación. Un enfoque estratégico. Pirámide.

Ya para finales del siglo XX, el modelo imperante para la innovación era el de la integración de sistemas en redes de cooperación (Trott, 2002), en cuyo contexto se desarrollan los Sistemas Nacionales de Innovación (Arocena y Sutz, 1999; Lundvall, 1992; Perez, 2010; Perdomo, 2009) y la llamada innovación abierta (Chesbrough, 2003). El modelo en red resalta el aprendizaje que tiene lugar dentro y entre las organizaciones y plantea que la innovación es un proceso que se caracteriza por la utilización de las tecnologías que permiten a las empresas incrementar la velocidad y eficiencia en el desarrollo de nuevos productos, tanto internamente (distintas actividades funcionales), como externamente entre la red de proveedores, clientes y colaboradores externos (Figura 18). 
Figura 18. Modelo en red para la innovación

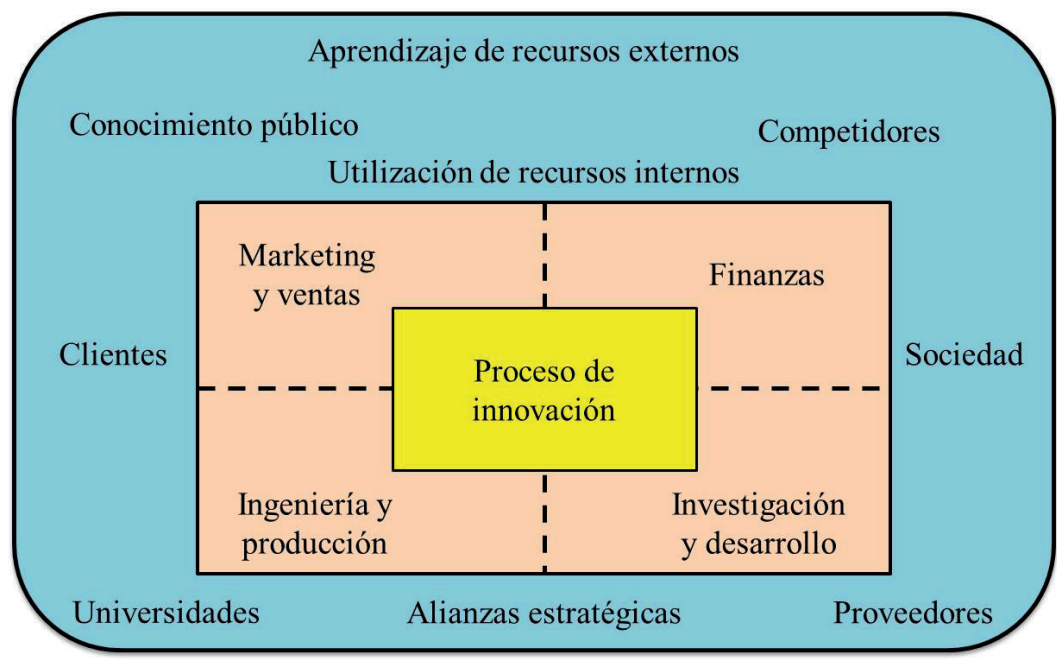

Fuente: Trott (2002), adaptado por López, O., Blanco, M., y. Guerra, S. (2009, p. 260). Evolución de los modelos de la gestión de innovación. Innovaciones de Negocios, 5(2), 251-264.

La innovación abierta es el uso por parte de las organizaciones de las entradas y salidas de conocimiento para acelerar la innovación interna y expandir el mercado para el uso externo de sus resultados (Figura 19). Las empresas hacen uso, tanto del conocimiento externo como del interno, y utilizan diferentes vías de acceso al mercado (Chesbrough, 2012). Estas innovaciones resultan de la decisión estratégica de la organización de participar activamente con otras organizaciones en actividades de transferencia del conocimiento (Chesbrough, 2012; Hagemann, 2012; Lichtenthaler y Lichtenthaler, 2009).

Chesbrough (2003) plantea que la innovación abierta radica en el uso de entradas y salidas intencionales de conocimiento para acelerar la innovación interna y expandir los mercados con el uso externo de la innovación. En una definición más acabada, el mismo autor considera que la innovación abierta es un paradigma en el que las empresas pueden y deben emplear ideas externas tanto como ideas internas y estrategias de mercado externas e internas, cuando buscan avanzar en su tecnología. Los requisitos 
de la arquitectura y los sistemas mediante los cuales se combinan las ideas internas y externas están definidos por el modelo de negocio de la organización (Chesbrough, 2006; 2012).

Figura 19. Modelo de innovación abierta

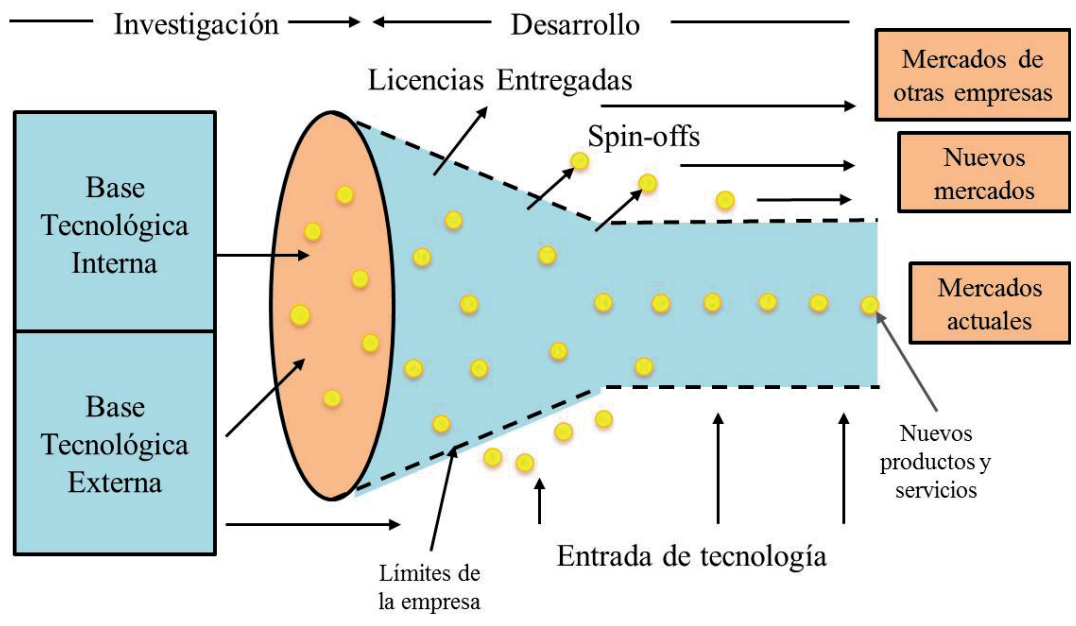

Fuente: Chesbrough, H. (2012, p. 23). Open Innovation. Where we've been and where we're going. Research-Technology Management. Special Issue: Open Innovation Revisited, 20-27.

Según Van de Vrande, de Jong y Vanhaverbeke (2009) y Chesbrough y Crowther (2006), las empresas adoptan la filosofía de innovación abierta para impulsar el crecimiento y disminuir costos. Gassmann et al. (2010) consideran que en la actualidad la innovación abierta ha pasado de ser una actividad exclusiva de las empresas de alta tecnología para convertirse en una práctica de innovación ampliamente extendida e implementada.

En las Tablas $5 \mathrm{a}, 5 \mathrm{~b}$ y $5 \mathrm{c}$ se muestran diez modelos de innovación abierta del período 2008-2015 que fueron analizados por Pavón et al. (2015). Los autores concuerdan en que la innovación abierta se produce como resultado de las interacciones establecidas entre los diferentes actores que intervienen en el proceso innovador (Bravo, Castro, \& León, 2015; Chiaroni, Chiesa, \& Frattini, 2010; González \& García, 2011; Iglesias, Jambrino, \& de la Heras, 
2014; Love, 2014; Markhorst, 2009; MINTIC, 2012; Mozilla Corporation, 2008; Openbasque, 2012; Wallin \& Von Krogh, 2010). Si bien no en todos los modelos se refleja explícitamente la gestión del conocimiento interno y externo de la organización, está claro que este es el principal incentivo para el trabajo en redes de colaboración.

Tabla 5a. Modelos de innovación abierta 2008 y 2010

\begin{tabular}{|c|c|c|c|c|}
\hline & \multicolumn{4}{|c|}{ Autores } \\
\hline & $\begin{array}{c}\text { Mozilla Corporation } \\
\text { (2008) }\end{array}$ & $\begin{array}{c}\text { Markhorst } \\
\text { (2009) }\end{array}$ & $\begin{array}{l}\text { Wallin y Von Krogh } \\
\text { (2010) }\end{array}$ & $\begin{array}{l}\text { Chiaroni et al. } \\
\text { (2010) }\end{array}$ \\
\hline $\begin{array}{c}\text { Proceso } \\
\text { Innovador }\end{array}$ & Participativo & $\begin{array}{l}\text { Integración de procesos de } \\
\text { innovación. } \\
\text { Negocio abierto y la co- } \\
\text { creación en el desarrollo de } \\
\text { la innovación interna } \\
\text { Tres niveles: } \\
\text { - Individuo (tarea), } \\
\text { - Organización } \\
\text { (innovación interna), } \\
\text { Redes de innovación } \\
\text { (innovación externa) }\end{array}$ & $\begin{array}{l}\text { Modelo de cinco fases: } \\
\text { - Definir los pasos del } \\
\text { proceso innovador } \\
\text { - Identificar el } \\
\text { conocimiento } \\
\text { relevante. } \\
\text { - Seleccionar un } \\
\text { mecanismo de } \\
\text { integración del } \\
\text { conocimiento. } \\
\text { - Crear mecanismos de } \\
\text { gobierno eficaces. } \\
\text { Equilibrar los } \\
\text { incentivos y el control. }\end{array}$ & $\begin{array}{l}\text { Dimensiones } \\
\text { organizacionales: } \\
\text { - Redes. } \\
\text { - Estructura } \\
\text { organizacional. } \\
\text { - Procesos de } \\
\text { evaluación. } \\
\text { - Sistema de } \\
\text { gestión del } \\
\text { conocimiento. }\end{array}$ \\
\hline $\begin{array}{c}\text { Núcleo } \\
\text { fundamental }\end{array}$ & $\begin{array}{l}\text { Desarrollo de } \\
\text { software entre } \\
\text { proveedores y } \\
\text { usuarios }\end{array}$ & \begin{tabular}{|l|} 
Diferencias significativas \\
entre los criterios de los \\
investigadores de las \\
universidades, los centros de \\
investigación y los expertos \\
de la industria. \\
Las investigaciones deben \\
desarrollarse en conjunto.
\end{tabular} & $\begin{array}{l}\text { El uso de las tecnologías de } \\
\text { la información y la } \\
\text { comunicación facilita la } \\
\text { entrada de conocimiento } \\
\text { externo y utiliza la } \\
\text { propiedad intelectual para } \\
\text { explotar el conocimiento } \\
\text { internamente desarrollado }\end{array}$ & $\begin{array}{l}\text { Utiliza el } \\
\text { conocimiento } \\
\text { generado dentro y } \\
\text { fuera de la empresa } \\
\text { para aprovechas las } \\
\text { oportunidades de } \\
\text { innovación. }\end{array}$ \\
\hline Variables & $\begin{array}{l}\text { Red colaborativa, } \\
\text { estímulos e incentivos } \\
\text { innovación de } \\
\text { usuario, mecanismos } \\
\text { coordinación }\end{array}$ & $\begin{array}{l}\text { Red colaborativa, estímulos e } \\
\text { incentivos, estructura } \\
\text { organizacional y procesos } \\
\text { implicados. } \\
\text { Experticia, motivación, } \\
\text { creatividad, gestión, recursos } \\
\text { para la innovación }\end{array}$ & \begin{tabular}{|l|} 
Estímulos e incentivos, \\
sistemas de gestión del \\
conocimiento, mecanismos \\
de integración, y regulación, \\
control-evaluación, \\
estructura organizacional y \\
procesos implicados
\end{tabular} & $\begin{array}{l}\text { Red colaborativa, } \\
\text { estímulos e incentivos, } \\
\text { sistemas de gestión del } \\
\text { conocimiento, control } \\
\text { - evaluación, estruc- } \\
\text { tura organizacional, } \\
\text { innovación colectiva }\end{array}$ \\
\hline
\end{tabular}

El análisis de las variables que se mencionan en los modelos analizados indica que la innovación abierta se realiza a partir de estimular e incentivar a sus participantes; con la participación en redes colaborativas (inter e intra organizacionales); implica 
cambios en la estructura organizacional. Además, los procesos y el conocimiento deben gestionarse en plataformas tecnológicas; se requiere una dirección estratégica con metas claras; una cultura organizacional de tipo colaborativa y el adecuado control y evaluación de los procesos organizacionales.

Tabla 5b. Modelos de innovación abierta 2011 y 2012

\begin{tabular}{|c|c|c|c|}
\hline & \multicolumn{3}{|c|}{ Autores } \\
\hline & González et al. (2011) & OpenBasque (2012) & MINTIC (2012) \\
\hline $\begin{array}{l}\text { Proceso } \\
\text { Innovador }\end{array}$ & $\begin{array}{l}\text { Exploratorio, teórico } \\
\text { Factores clave de éxito de la IA, } \\
\text { relaciones inter organizativas }\end{array}$ & $\begin{array}{l}\text { Desarrolla la innovación abierta } \\
\text { en cuatro escenarios: colectiva, } \\
\text { del usuario, inter e intra- } \\
\text { organizacional. } \\
\text { Multiplica las posibilidades de } \\
\text { cocreación de Personas- } \\
\text { Organización-Territorio }\end{array}$ & $\begin{array}{l}\text { Administración pública, nodo de } \\
\text { innovación }\end{array}$ \\
\hline $\begin{array}{l}\text { Núcleo } \\
\text { fundamental }\end{array}$ & $\begin{array}{l}\text { Factores clave: Liderazgo técnico } \\
\text { basado en la experiencia, uso de } \\
\text { las tecnologías, existencia de } \\
\text { agentes o facilitadores con un } \\
\text { carácter neutral. } \\
\text { Las tecnologías favorecen el } \\
\text { intercambio y trasferencia de } \\
\text { conocimientos entre los agentes }\end{array}$ & $\begin{array}{l}\text { Redes inter o intra } \\
\text { organizacionales }\end{array}$ & $\begin{array}{l}\text { El postulado fundamental de este } \\
\text { modelo es que el conocimiento } \\
\text { disponible en la sociedad abierta } \\
\text { y en red es superior al de sus } \\
\text { representantes y expertos }\end{array}$ \\
\hline Variables & $\begin{array}{l}\text { Red colaborativa, estímulos e } \\
\text { incentivos, plataformas } \\
\text { tecnológicas, cultura cooperativa, } \\
\text { procesos implicados } \\
\text { Factores internos: coordinación, } \\
\text { incentivos y cultura } \\
\text { organizacional }\end{array}$ & $\begin{array}{l}\text { Red colaborativa, estímulos e } \\
\text { incentivos, innovación de } \\
\text { usuario, plataforma tecno-lógica, } \\
\text { cultura cooperativa, procesos } \\
\text { implicados, innovación colectiva, } \\
\text { dirección estratégica }\end{array}$ & $\begin{array}{l}\text { Sistema de GC, cultura y } \\
\text { estructura organizacional, } \\
\text { plataformas tecnológicas, } \\
\text { procesos implicados, } \\
\text { dirección estratégica }\end{array}$ \\
\hline
\end{tabular}

Entre los modelos relacionados en la Tabla 5b, se encuentra el modelo de gestión del conocimiento e innovación abierta para el Subsistema de Innovación para el Uso y Apropiación de las Tecnologías de la Información y las Comunicaciones (TIC) dentro del Sistema de Investigación, Desarrollo e Innovación, desarrollado por el Ministerio de Tecnologías de la Información y las Comunicaciones de la República de Colombia (MINTIC, 2012). Si bien este modelo incluye indicadores relacionados con la gestión del conocimiento y la innovación abierta, no se observa la interrelación entre estas dos categorías, ya que se presentan como 
dos subsistemas diferenciados: el Modelo integral de gestión del conocimiento y la Innovación Abierta a partir del modelo desarrollado por Álvarez (2010) con base en Chesbrough (2003).

Tabla 5c. Modelos de innovación abierta 2014 y 2015

\begin{tabular}{|c|c|c|c|}
\hline & \multicolumn{3}{|c|}{ Autores } \\
\hline & Love (2014) & Iglesias Sánchez et al. (2014) & Bravo Ibarra et al. (2015) \\
\hline $\begin{array}{c}\text { Proceso } \\
\text { Innovador }\end{array}$ & $\begin{array}{l}\text { Crea un nuevo fondo de } \\
\text { compromisos, aplica nuevas } \\
\text { políticas y normas. } \\
\text { Garantías y estimulaciones para } \\
\text { inducir y desarrollar la } \\
\text { innovación }\end{array}$ & $\begin{array}{l}\text { Define estrategias de búsqueda } \\
\text { de conocimiento externo e } \\
\text { identifica el capital relacional } \\
\text { más adecuado }\end{array}$ & $\begin{array}{l}\text { Estrategias de acuerdo al tipo del } \\
\text { sector donde se desarrolle la } \\
\text { innovación, con contratos formales. } \\
\text { Busca de oportunidades, evaluación } \\
\text { del potencial del mercado y su nivel } \\
\text { de innovación. Captura de valor a } \\
\text { través de la gestión del } \\
\text { conocimiento interno y externo }\end{array}$ \\
\hline $\begin{array}{c}\text { Núcleo } \\
\text { fundamental }\end{array}$ & $\begin{array}{l}\text { 1. Desarrollo de una nueva } \\
\text { estructura de gobiernos y } \\
\text { 2. Propone una nueva tarifa de } \\
\text { impuestos }\end{array}$ & $\begin{array}{l}\text { Aprendizaje colaborativo } \\
\text { Soportado en plataformas de } \\
\text { colaboración virtual, }\end{array}$ & $\begin{array}{l}\text { Tres etapas: } \\
\text { 1. Gestión de cambios internos. } \\
\text { 2. Gestión de las relaciones de } \\
\text { innovación y recursos externos. } \\
\text { 3. Analiza la efectividad de la } \\
\text { protección de la propiedad } \\
\text { intelectual resultado de la } \\
\text { innovación }\end{array}$ \\
\hline Variables & $\begin{array}{l}\text { Red colaborativa, estímulos e } \\
\text { incentivos, estructura } \\
\text { organizacional, dirección } \\
\text { estratégica }\end{array}$ & $\begin{array}{l}\text { Red colaborativa, estímulos e } \\
\text { incentivos, sistemas de gestión } \\
\text { del conocimiento, control- } \\
\text { evaluación, plataformas } \\
\text { tecnológicas }\end{array}$ & $\begin{array}{l}\text { Estímulos e incentivos, } \\
\text { mecanismos de coordinación, } \\
\text { sistemas de gestión del } \\
\text { conocimiento, estructura } \\
\text { organizacional, plataformas } \\
\text { tecnológicas, cultura cooperativa, } \\
\text { dirección estratégica }\end{array}$ \\
\hline
\end{tabular}

El Modelo integral de gestión del conocimiento para el subsistema de Innovación en TIC en el Gobierno de Colombia incluye cinco variables, las cuales deben ser consideradas de forma integral e interrelacionada por el Subsistema de innovación y sus diferentes Nodos. Ellas son:

- El potencial humano.

- La cultura organizacional.

- $\quad$ El direccionamiento y pensamiento estratégico. 
- Las actividades propias de la gerencia del conocimiento.

- Las tecnologías de la información y las comunicaciones.

Respecto a la innovación abierta el modelo del MINTIC considera que esta es la estrategia de las organizaciones de buscar, adentro y afuera, ideas innovadoras y personal competente, y que también consiste "en abrir los procesos de innovación de una empresa a recursos tecnológicos externos, comenzando por el proceso de búsqueda de oportunidades tecnológicas" (MINTIC, 2012, p. 34). Esta apertura puede realizarse a partir de:

- Visitas a centros de investigación, universidades o empresas spin-out ${ }^{4}$.

- Realización de alianzas tecnológicas.

- Adquisición de licencias o productos para comercializarlos con marcas propias.

- Adquisición de innovaciones externas que brinden la oportunidad de desarrollar nuevas generaciones de tecnología propia.

- Creación de negocios spin-out que no tienen espacio en el núcleo de negocio pero que hacen uso de tecnologías y propiedad intelectual desarrolladas internamente.

El modelo del MINTIC (2012) reconoce la importancia de la gestión del conocimiento para los nodos de innovación, pero no queda claro quién es la comunidad, los usuarios, los asociados y los aspectos de la gestión del conocimiento presentes en un nodo de innovación.

Como resultado del análisis realizado se afirma que la innovación abierta consiste en el empleo del conocimiento tanto externo como interno, mediante el trabajo en redes de

4 Spin-out es el proceso por el cual una empresa secciona parte de sus líneas de negocio o departamentos para la creación de una nueva empresa, puede suponer una nueva fuente de financiación para la empresa matriz. 
conocimiento e innovación, con el fin de acelerar el proceso interno de innovación de la organización y, al mismo tiempo, conectar con los mercados para el uso externo de sus resultados.

Entre los procesos incluidos en la innovación, se encuentran su difusión y adopción por otras organizaciones (Arpaci et al., 2012). Tres de los modelos teóricos que explican la adopción de las tecnologías al nivel organizacional son: el marco TecnologíaOrganización-Entorno (TOE) (Tornatzky y Fleischer, 1990), la teoría de la Difusión de la Innovación (IDT) (Rogers, 2003) y la Teoría Institucional (Scott, 2004). Estas tres teorías y los factores en ellas involucrados son empleados conjuntamente por diferentes autores (Oliveira y Martins, 2011; Zhu et al., 2006).

A partir de reconocer la importancia de la innovación para el desarrollo, se han elaborado normas nacionales e internacionales para los sistemas de gestión de la innovación en las organizaciones, la primera de ellas fue la norma española UNE 166002 del 2002 para un sistema de gestión de la investigación, el desarrollo y la innovación $(\mathrm{I}+\mathrm{D}+\mathrm{i})$. Este documento ha sido actualizado (UNE, 2014), siguiendo la estructura común de las normas para los sistemas de gestión de la Organización Internacional de Normalización (ISO).

La gestión de la innovación es la parte del sistema de gestión de la organización encargada de desarrollar, implantar, llevar a efecto, revisar y mantener al día la política de $\mathrm{I}+\mathrm{D}+\mathrm{i}$ de la organización, establecer los objetivos de $\mathrm{I}+\mathrm{D}+\mathrm{i}$ y los procesos necesarios para darles cumplimiento, lo que incluye la estructura organizativa, la planificación de actividades, las responsabilidades, las prácticas, los procedimientos y los recursos tanto humanos como materiales $\mathrm{y}$ financieros requeridos.

En el año 2008 Colombia y México fueron pioneros en América Latina en la adopción de normas para la gestión de la innovación (NTC 5801:2008 y NMX-GT-003-INMC: 2008, respectivamente), seguidos por Brasil en el 2011 (ABNT NBR 165001:2011).

Sobre la base de la aplicación de las normas de sistemas de gestión de la $\mathrm{I}+\mathrm{D}+\mathrm{i}$ existentes en varios países europeos, el Comité Técnico CEN/TC 389 Gestión de la Innovación del Comité Europeo de Normalización (CEN) aprobó, entre el 2013 y el 2015, siete especificaciones técnicas de la serie CEN/TS 16555. Estos 
documentos normativos abarcan las siguientes dimensiones del proceso de innovación (European Committee for Standardization, 2018):

- Desarrollo de la estrategia y visión de innovación.

- Construcción de la estructura y la cultura organizacional para promover la innovación.

- Introducción de un proceso de innovación óptimo.

- Utilización de métodos, técnicas y herramientas para promover la innovación.

- Orientación y medición del resultado de la innovación.

Actualmente, el comité técnico ISO/TC 279 está trabajando en la serie de normas ISO 56000 para la gestión de la innovación, en un inicio codificada como ISO 50500 (De Casanove et al., 2017; Ozan, 2017). Las primeras normas de la serie fueron publicadas en 2019.

Al analizar la literatura relacionada con los modelos de empresas innovadoras, Ávila y Alarcón (2014) identifican los elementos críticos para el éxito de la gestión de la innovación. Ellos son: liderazgo estratégico para la innovación; equipos multifuncionales; sistema de reconocimientos a la innovación; proceso tecnológico para el desarrollo de nuevos productos y procesos; análisis de mercados para nuevos productos o servicios; inversión en $\mathrm{I}+\mathrm{D}$.

Del análisis de los diferentes modelos de innovación realizado, se observa que involucran el conocimiento interno de las organizaciones y el de fuentes externas, sin embargo, no dan suficiente explicación respecto a la integración de la gestión del conocimiento y la innovación para el logro de los resultados. En esta investigación se emplea el modelo de innovación abierta como paradigma para desarrollar la integración entre la espiral del infoconocimiento y la gestión de la innovación como proceso sistemático, integrador y recurrente para el logro de productos, servicios y formas de gestión innovadores. 


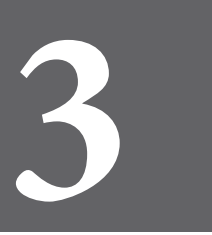

CAPÍTULO

TRES 


\section{GESTIÓN INTEGRADA DEL INFOCONOCIMIENTO Y LA INNOVACIÓN}

El presente capítulo tiene como objetivo presentar el diseño del modelo que explica la integración entre la gestión del infoconocimiento y la innovación, así como el mecanismo para su posible aplicación en la Universidad Tecnológica de Pereira, con la finalidad de estimular el desarrollo de innovaciones hacia los sectores económicos de la región. Asimismo, se presenta el procedimiento gráfico y descriptivo para la implementación del modelo, así como los resultados de la validación de ambos desde el punto de vista de especialistas y usuarios y de la factibilidad económica de su desarrollo.

\subsection{Fundamentación del modelo}

Para la fundamentación de la propuesta es necesario establecer los marcos de actuación que se consideraron para el diseño de un modelo, tomando como referencia los criterios que diversos autores establecen sobre el término modelo:

- $\quad$ "Los modelos pueden ser considerados como abstracciones que intentan identificar, simplificar y explicar los procesos y las relaciones existentes entre los diferentes componentes de un fenómeno estudiado" (Ferriol, 2011, p. 32). Por lo tanto, se considera que los modelos suministran pautas para colocar en funcionamiento el objeto de estudio.

- El modelo es un constructo que crea el investigador a partir de su conocimiento teórico del objeto de la investigación, como guía que le permite abordar el análisis de los diferentes fenómenos y explicita todos los elementos, relaciones y 
estructuras internas del objeto, que resultan precisas para abordar su estudio y la solución del problema de investigación. (Taboada, 2010, p. 43)

- Un modelo se puede definir como "una construcción teórica para interpretar, reproducir y diseñar simplificadamente la realidad" (López Gutiérrez, 2010, p. 72).

Según Almuiñas y Galarza (2013), Ferriol (2011) y Galarza (2007), las relaciones y la teoría son esenciales para soportar el modelo. A la par, el modelo debe considerar dentro de su estructura los objetivos, las premisas, los principios y la secuencia de las acciones a realizar. A lo anterior se suma la necesidad de destacar en la definición de modelo los elementos y actores clave del contexto en que este se desarrolla y su sistema de relaciones.

A tenor de las consideraciones expuestas, la autora da como definición la siguiente: un modelo es una representación de una realidad o situación, fundamentada en referentes teóricos y tecnológicos y definida para un contexto particular que, a partir del estudio de una unidad de análisis determinada, define un conjunto de componentes (directrices, micro y macro entornos, estructura interna, soporte tecnológico y sistema de relaciones entre los actores), para explicar o generar una dinámica o fenómeno de la realidad objetiva.

De manera coherente con la definición planteada, en la Figura 20 se muestra el modelo de gestión integrada del infoconocimiento y la innovación. A través de sus seis componentes, el modelo delimita los aspectos del entorno, define los elementos que integran su estructura interna (flujo de infoconocimiento e innovación), establece la secuencia de las etapas y las relaciones necesarias para la realización de innovaciones con base en el infoconocimiento. Con ello, el modelo busca expresar una dinámica de innovación abierta, sistémica e iterativa que va desde y hacia el entorno. 
Figura 20. Modelo de gestión integrada del infoconocimiento y la innovación

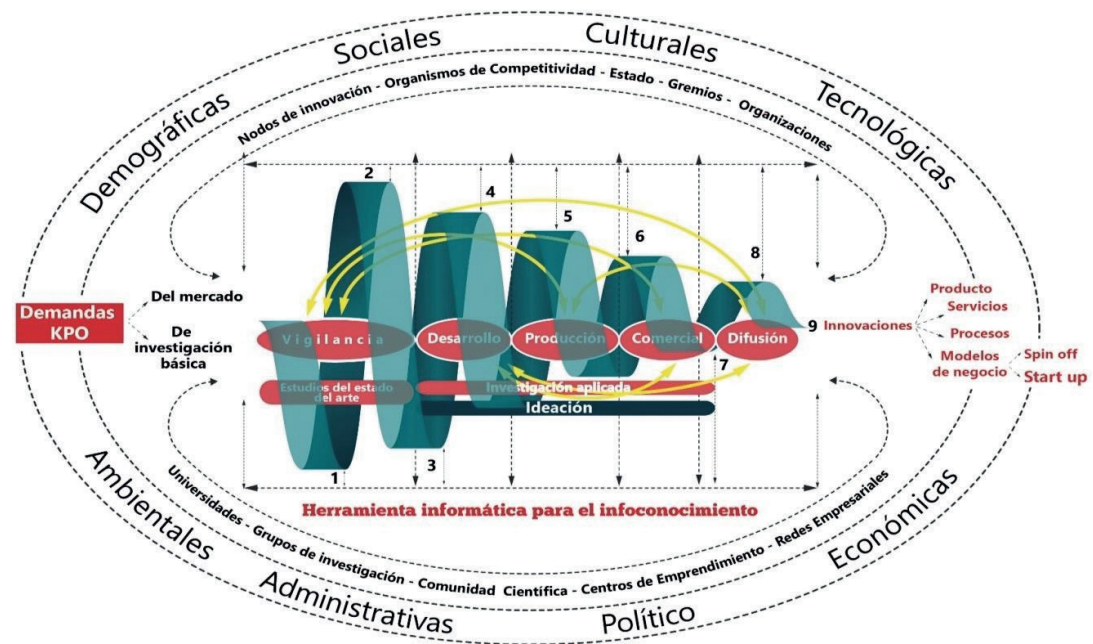

Leyenda: 1. Identificación de información relevante, 2. Información disponible, 3. Valoración de expertos, 4. Toma de decisiones, 5. Aplicación, 6. Socialización, 7. Transformación, 8. Repositorio, 9. Retroalimentación.

Para profundizar en los fundamentos del modelo, a continuación, se explican los seis componentes que lo integran: directrices, macroentorno, microentorno, estructura interna, soporte tecnológico y sistema de relaciones.

\section{Directrices}

Son los criterios y preceptos soporte del modelo de gestión integrada del infoconocimiento y la innovación tales como objetivo, principios y premisas. El objetivo del modelo de gestión integrada del infoconocimiento y la innovación propuesto es: establecer el marco propicio en la organización para el desarrollo de innovaciones que contribuyan a la transformación productiva y social de Risaralda con base en la investigación, el desarrollo tecnológico, la innovación, y el emprendimiento de base tecnológica, que cumpla con las expectativas y condiciones definidas por los demandantes y potencie el trabajo en red. 
El modelo propuesto se rige por los siguientes principios:

1. Holístico: El modelo propone una gestión integrada del infoconocimiento y la innovación, que aproveche las sinergias entre estos dos componentes y las diversas interacciones entre ellos y que presupone, a su vez, un trabajo sistémico con el entorno a partir del trabajo en red y la innovación abierta.

2. Enfoque relacional: Basado en el modelo relacional por su analogía con la lógica de conjuntos y predicados, cuyos elementos se pertenecen recíprocamente. Sus dinámicas establecen un acto precedente (causa) y uno posterior (consecuencia). De esta manera, permite identificar las relaciones de entrada, salida, internas y externas.

3. Multidisciplinario: Este principio reconoce la operación y el trabajo articulado de diferentes personas, cuyos saberes y conocimientos desde varias disciplinas aportan a resolver un objetivo común. Es importante definir que el modelo propuesto incluye el enfoque de procesos, planeación estratégica, comunicación, sistemas de información, tecnología, competencias, factor humano, motivación, estímulos, entre otras áreas del conocimiento, la ciencia y la tecnología.

4. Concurrente: El momento del desarrollo de la gestión del infoconocimiento e innovación involucra las necesidades del mercado, los requisitos de calidad, los costos, los medios y métodos de fabricación, la venta y servicio necesario para garantizar la satisfacción de los demandantes en todo el ciclo de vida del producto. Todos estos momentos requieren de un trabajo articulado simultáneo e integrado de todas las áreas de la organización.

5. Enfoque de procesos: Es un principio de gestión básico y fundamental para la obtención de resultados, que permite a las organizaciones establecer la secuencia de actividades 
necesarias para lograr un resultado e identificar indicadores a fin de evaluar el rendimiento de las diversas etapas, que se llevan a cabo en el modelo propuesto, estrictamente interconectadas. El enfoque de procesos es el primer paso para la mejora continua, por cuanto valora el estado actual de las dinámicas ocurridas en el proceso y es una estrategia que garantiza el éxito en los actuales mercados.

6. Colaborativo: Se refiere a la relación entre integrantes y organizaciones de manera intencional en un contexto para alcanzar objetivos específicos. En este enfoque, el trabajo individual no es el aporte aislado al trabajo común, sino que es un aporte individual consensuado de manera asertiva, para la construcción de la solución a la situación susceptible de ser mejorada u objetivo común.

7. Creativo: Entendido como la generación de novedosas percepciones, nociones, significados o acciones. Entender la creatividad remite a la comprensión propia de la tecnología como empresa humana y como proceso creativo. Ella está fundamentada en el conocimiento y en una serie de procesos cognitivos denominados ideaciones. En este orden de ideas, la organización debe caracterizarse siempre por su espíritu de creatividad e innovación en los distintos sectores y la generación de los cambios que conduzcan a mejoramientos y adelantos. Este espíritu de innovación es esencial en el mejoramiento continuo de los productos y servicios para satisfacer las necesidades de los diferentes mercados donde esté presente la organización. Debe también ser considerado como un compromiso para estimular el cambio y el mejoramiento de los productos y servicios, incluso mucho antes de que el contexto externo lo exija.

8. Incentivador: Los colaboradores, investigadores y expertos deben tener estímulos tangibles e intangibles y el debido reconocimiento de su producción intelectual. Estas dinámicas permiten generar compromiso y sentido de pertenencia con 
su quehacer. Este principio podría estar relacionado con la propiedad industrial como incentivo para aumentar la innovación cuando se protegen las innovaciones contra la copia por sus competidores.

9. Basado en las competencias: Las competencias se entienden como atributos actitudinales, procedimentales y cognitivos que se expresan en desempeños y permiten la resolución de situaciones demandadas por el entorno próximo o global. En este caso, la organización debe asegurase de la pertinencia de cierto tipo de competencias en concordancia con el talento humano para el desarrollo de las dinámicas del modelo. En caso contrario debe emprender las acciones para que sus colaboradores adquieran las competencias necesarias a través de procesos de capacitación.

Además, para la implementación del modelo son necesarias las siguientes premisas:

- Existencia de un marco de referencia que sirva para orientar las acciones en $\mathrm{I}+\mathrm{D}+\mathrm{i}$.

- Presencia de recursos tales como: competencias de los recursos humanos (ser, hacer, conocer), capacidades, métodos de trabajo, servicios, laboratorios, infraestructura física, dotación tecnológica, amueblamiento, etc.

- Liderazgo, compromiso y voluntad de la dirección de la organización, que promueva la creatividad, el aprendizaje, la gestión participativa del infoconocimiento y la innovación y potencie en trabajo en red.

\section{Macroentorno}

Se define como el espacio figurativo más alejado de la organización, que ejerce una influencia sobre ella, en donde surgen relaciones y dinámicas sociales producidas por los involucrados que forman parte del macroentorno y las categorías 
de fuerzas (ambientales, regulaciones administrativas y legales, políticas, económicas, sociales, tecnológicas, culturales, sociales y demográficas). Del macroentorno surgen tensiones o disposiciones que inciden en el funcionamiento de un centro de innovación y desarrollo tecnológico, en las áreas de conocimiento que se han de gestionar y en las demandas pendientes de una respuesta innovadora. Aunque estas categorías están fuera del ámbito de control de la organización, deben ser reconocidas y evaluadas para la toma de decisiones.

En la representación gráfica del modelo (Figura 20), el macro entorno está ubicado entre la línea oval discontinua más externa y la inmediata línea discontinua. En este espacio, se han ubicado las categorías de fuerza para representar los lineamientos que lo rigen. Las líneas discontinuas simbolizan el paradigma de la innovación abierta.

\section{Microentorno}

Es un escenario figurativo más próximo al CIDT, delimitado por el óvalo discontinuo más interno. En este escenario se encuentran los diferentes actores o aliados: nodos de innovación, organismos de competitividad, estado, gremios, organizaciones, universidades, grupos de investigación, comunidades científicas, centros de emprendimiento, redes empresariales y otros ubicados en el entorno cercano a la organización. Los aliados tienen un alcance global desde: lo regional, nacional e internacionalmente. $\mathrm{Al}$ igual que la frontera del macroentorno, esta es discontinua puesto que se ratifica el enfoque de innovación abierta.

La concepción del macro y microentorno denota una constante interacción con todos los involucrados tanto intra como interorganizacionales. Esto, debido a que la innovación no se realiza de forma aislada ni lineal, más bien es un proceso iterativo e involucra conocimiento tanto interno como externo, además es coherente con las características identificadas en el análisis del concepto de innovación abierta. 


\section{Estructura interna}

La estructura interna del modelo está formada por la espiral del infoconocimiento y por la innovación, lo que se corresponde con las variables definidas en la investigación. La espiral en la Figura 20 representa los elementos del infoconocimiento, su crecimiento y aplicación. Cada individuo aprende a través de lo que ya sabe desde el contexto social a medida que interactúa con otros seres dotados de conocimientos. Durante este proceso la información y el conocimiento crecen en extensión y en profundidad tal como lo representa la espiral. A medida que crece en extensión, el infoconocimiento toca otros campos lo que posibilita su aplicación y transformación.

Para definir los elementos de la gestión del infoconocimiento, se tomó como base el modelo de Alba (2015). Específicamente, se toman los nueve elementos siguientes: 1. Identificación de información relevante, 2. Información disponible, 3. Valoración de expertos, 4 . Toma de decisiones, 5 . Aplicación, 6 . Socialización, 7. Transformación, 8. Repositorio, 9. Retroalimentación. Estos elementos se recrean en el modelo que se propone a través de su interacción con el proceso de innovación abierta.

Los elementos del infoconocimiento interactúan en la espiral con las cinco etapas de la innovación que conforma el eje central del modelo (Figura 20): I- Vigilancia, II- Desarrollo, III- Producción, IV- Comercial y V- Difusión. Cada una de estas etapas está conformada por procesos y cada proceso tiene sus respectivas entradas (insumos) y salidas (resultados). Estas entradas y salidas generan una conexión directa con un conjunto de actores denominados proveedores en las entradas y clientes en las salidas.

El establecimiento de las etapas de la innovación no limita el carácter interactivo y abierto del modelo, ya que ellas pueden solaparse y generar entradas y salidas desde y hacia en el entorno en dependencia de las necesidades del proceso innovador. Así 
mismo, el modelo induce a transitar -mediante la gestión de los proyectos- por las etapas de la innovación con una concepción diseñada para permitir que se desarrolle una etapa, varias etapas o todas de manera independiente, continua o complementaria, dependiendo de las necesidades de los diferentes aliados que se identificaron en el entorno y que acuerde el proyecto.

Un aliado del entorno puede realizar su proceso de vigilancia y solo necesitar el apoyo del centro de innovación y desarrollo tecnológico desde la etapa de desarrollo para continuar con el acompañamiento en etapas subsiguientes, o llegar con las etapas de vigilancia y desarrollo concluidas para buscar el apoyo del centro en las etapas de producción y comercialización, como verdadero proceso iterativo de innovación abierta.

El proceso de innovación puede generar innovaciones de diferente tipo. En la etapa de desarrollo se pueden generar invenciones de productos y servicios, en la etapa de producción se pueden obtener innovaciones en el proceso y en la etapa de comercial, innovaciones de modelo de negocio. Indiscutiblemente, la innovación solo se da cuando se pone el resultado innovador al servicio de la sociedad.

Para que se desarrolle el ciclo innovador, el centro de innovación y desarrollo tecnológico debe establecer sus lineamientos estratégicos y políticas, alineados con la Política Nacional de Ciencia e Innovación para el Desarrollo Sostenible (Colciencias, 2018). Además, ha de definir una estructura organizativa que permita flexibilidad al sistema, acompañada del conjunto de procesos, funciones, procedimientos y perfiles de trabajo que aseguren el adecuado transitar por cada una de las etapas de innovación. Se adiciona desde la óptica de la gestión del infoconocimiento la determinación del mapa de conocimiento, los expertos y especialistas propios y externos necesarios para la gestión de los proyectos y la ejecución misma de las etapas de innovación. 
A continuación, se describen las actividades presentes en cada una de las etapas del proceso de innovación.

\section{Primera Etapa: Vigilancia}

Comprende el análisis exhaustivo del entorno (macro y micro), la identificación de capacidades y necesidades de los actores internos - externos y la apropiación de resultados de investigaciones básicas con el objetivo de identificar el potencial de futuros desarrollos, cuyo resultado permite la identificación de oportunidades y demandas. En este sentido, las demandas del entorno y la investigación básica se convierten en los principales insumos o entradas del centro de innovación y desarrollo tecnológico para definir proyectos con potencial innovador en concordancia con los lineamientos estratégicos definidos por el sistema de innovación. Por lo tanto, en esta etapa se debe realizar una exploración para identificar el infoconocimiento relevante, las ideas creativas y dar respuesta a la pregunta ¿Qué se va a hacer?

La etapa de vigilancia involucra la observación, análisis, investigación e interpretación objetiva del estado actual de los conocimientos científicos, tecnológicos y culturales, las normas y tendencias del conocimiento científico, las tecnologías patentadas o patentes, involucrando y analizando las categorías de fuerzas que proporciona el macro entorno y que existen sobre el tema a nivel local, nacional y mundial que permitan identificar necesidades, oportunidades que puedan convertirse en innovación y nuevos conocimientos tendientes a la difusión de la información generada en el centro de innovación y desarrollo tecnológico.

De la misma manera, en esta etapa, se definen los dos primeros elementos que conforman la espiral del infoconocimiento: el primero se refiere la Identificación de Información Relevante (1) mediante la exploración del estado del arte del conocimiento científico, con el propósito de reconocer oportunidades a nivel local desde la oferta y a nivel global para la demanda. Dichas fuentes tienen dos protocolos de vigilancia: una con cobro o 
bases de datos exclusivos para suscriptores y abiertos y otra de bases de datos gratuitos. Se deben tener en cuenta, además, la normatividad vigente, fuentes de financiación, software, laboratorios, documentos, fichas de solicitud, análisis de mercados potenciales, fichas técnicas, convocatorias, patentes existentes e indudablemente un análisis de riesgo.

En este orden de ideas, la selección, análisis, la difusión y comunicación sistemática de las fuentes generan información de valor estratégico y le permite al centro de innovación y desarrollo tecnológico tomar decisiones con menor riesgo, así como poder anticiparse a los cambios del mercado. Es por esto, que se define como segundo elemento del infoconocimiento la Información Disponible (2), para todos los interesados.

La vigilancia reconoce los diferentes actores involucrados en este proceso y se relaciona de forma permanente con ellos, admitiendo que la innovación trasciende los límites locales. Así, se propone que debe ser asumida a nivel global para advertir las tendencias en un marco amplio y no reducido solo a nivel local. Debido a su especificidad y complejidad, se deben elaborar protocolos, instructivos o documentación por parte del centro de innovación y desarrollo tecnológico para determinar los modos de llevar a cabo la vigilancia, además de tener claridad sobre el perfil profesional de quien realiza la vigilancia, los denominados vigías. La vigilancia se realiza de manera alineada con los objetivos estratégicos, la política de innovación y la estrategia de innovación definida por el centro de innovación y desarrollo tecnológico, según su marco de referencia y sus resultados deben ser actualizados de forma permanente durante el proceso de innovación.

\section{Segunda Etapa: Desarrollo}

El análisis del estado del arte y la generación de información valiosa para la generación de ideas, que comienza en la etapa de vigilancia, se continúa en la etapa de desarrollo. Puede considerarse 
que la generación de ideas es un momento inicial y fundamental en la etapa de desarrollo y se perfecciona alrededor de la pregunta ¿Cómo se va a hacer? Esta pregunta se deriva en los retos de innovación, que se realizan en el desarrollo del producto o en el despliegue de un modelo de negocio. En el desarrollo se transforman los conocimientos disponibles mediante la investigación aplicada, que permite validar el concepto. En esta etapa se concreta el tercer elemento de la espiral del infoconocimiento (3. Valoración de Expertos).

Cuando se innova en productos, se diseñan prototipos que permiten una producción a pequeña escala o prueba piloto a fin de ser validados inicialmente y ser desarrollados a fin de ser nuevamente validados en un mercado, hacer los ajustes respectivos, refinarlos y finalizar el diseño/desarrollo del producto o servicio con las características requeridas para su funcionamiento. El ejercicio de registro (derechos de autor) y obtención de patentes (propiedad industrial) es un aspecto relevante en esta etapa para proteger la invención, para lo cual se requiere que se concreten decisiones fundamentales que dan paso al cuarto elemento de la espiral del infoconocimiento: 4 . Toma de Decisiones.

La investigación aplicada es aquella que se realiza para adquirir nuevos conocimientos dirigidos, fundamentalmente, al desarrollo de un objetivo práctico específico. Parte de los resultados de la investigación básica, involucra además todos los conocimientos tecnológicos existentes y los profundiza con el objetivo de desarrollar ideas que puedan convertirse en tecnologías o métodos organizativos. También se conoce como fase de InvestigaciónDesarrollo $(\mathrm{I}+\mathrm{D})$. La $\mathrm{I}+\mathrm{D}$ puede realizarse en su totalidad de forma interna o incorporar elementos externos de otros entes como universidades, grupos de investigación, otros centros de investigación y empresas, donde se involucra un enfoque de innovación abierta. 


\section{Tercera etapa: Producción y prestación del servicio}

A través de la producción y la prestación del servicio se concreta el quinto elemento de la espiral del infoconocimiento, 5. Aplicación, que involucra los conocimientos, mecanismos, sistemas, tecnologías, capacidades, recursos e infraestructura adecuados para la fabricación a escala industrial de los productos, o para brindar los servicios, nuevos o sustancialmente mejorados, resultados de la etapa de desarrollo.

La producción o la prestación del servicio pueden darse de las siguientes maneras:

1. Por transferencia tecnológica, cuando el centro de innovación y desarrollo tecnológico no cuenta con las condiciones para la fabricación del producto o la prestación del servicio a una mayor escala. De esta manera, se entregan los derechos para que una empresa lo realice con las condiciones preestablecidas en la etapa de desarrollo.

2. Por outsourcing o coproducción, cuando el centro de innovación y desarrollo tecnológico contrata parte o la totalidad del proceso productivo o de prestación del servicio a una empresa aliada, que cumpla con las condiciones necesarias, con un acompañamiento permanente por parte del centro. Este tipo de innovación permite obtener beneficios para ambas partes.

En esta etapa se crean los modelos de negocio (spin-offo start up). Se inicia con la elaboración del lienzo de negocio. Así, se establece el modelo de negocio como tal de acuerdo a los siguientes tipos de emprendimiento:

- $\quad$ Spin-off: Empresa con base a la creatividad, la investigación y el desarrollo tecnológico, que se desprende de una institución madre (universidad, centro de investigación o empresa). En este tipo de emprendimiento, el centro de innovación y desarrollo tecnológico tendría un tipo de relación con las 
empresas, bien sea a través de un licenciamiento o acciones. Su objetivo es aprovechar el conocimiento generado para lograr aumentar la competitividad del país a través de productos y servicios de alto valor agregado.

- Start up: Empresa de nueva creación que presenta unas grandes posibilidades de crecimiento y, en ocasiones, un modelo de negocio escalable. Pueden referirse a compañías de cualquier ámbito, pero normalmente se utilizan para aquellas que tienen un componente tecnológico fuerte $y$ que están relacionadas con las tecnologías de la información y el conocimiento. No necesariamente requiere realizar previamente una investigación científica.

\section{Cuarta Etapa: Comercial}

La comercialización es una etapa concomitante con la producción, pero sus características deben ser identificadas desde la etapa de vigilancia, por cuanto el éxito de esta etapa depende de las soluciones que brinde el producto o servicio a ser comercializado y que se genere a partir de las necesidades detectadas. La comercialización permite introducir eficazmente el producto o servicio en el mercado objetivo para el cual fue diseñado. En esta etapa se consolida el sexto elemento de la espiral del infoconocimiento, 6. Socialización, la cual permite analizar el vínculo entre consumidores y vendedores con el fin de establecer las rutas de su comercialización. Al realizarse la comercialización, también se produce el séptimo elemento de la espiral, 7. Transformación, donde el infoconocimiento a través de la innovación se transforma en un producto o servicio con valor de uso para la sociedad.

\section{Quinta Etapa: Difusión}

En la etapa de Difusión, la innovación se interrelaciona con las dimensiones sociales y psicológicas del comprador, usuario, consumidor o cliente. La difusión es un proceso por el cual una 
innovación se comunica por ciertos canales a través del tiempo entre individuos de un sistema social, como una idea, práctica u objeto percibido como nuevo por un individuo u otra unidad de adopción (Rogers, 2003).

La difusión se realiza en los siguientes contextos:

- Académico. Se realiza a través de un repositorio, memoria tecnológica o centro de documentación en espacios físicos y/o virtuales. En el repositorio se encuentran artículos publicados en revistas o documentos académicos producto de investigaciones, ponencias, memorias de congresos, fichas, procedimientos, patentes, entre otros. Todos estos medios de difusión se pueden emplear finalizando la etapa de desarrollo, producción y/o comercialización, según sea el tipo de innovación. Así se incorpora el octavo elemento de la espiral del infoconocimiento, 8. Repositorios, que se alimenta desde y hacia cada una de las etapas del proceso innovador bien sea en portal en internet, portal en intranet, bibliotecas virtuales, páginas web, observatorio de tendencias y observatorio de innovación con diferentes matices y funciones como: centro de documentación, centro de análisis de datos, espacio de información, intercambio y colaboración.

- Social. Se formaliza cuando se sitúan los productos o servicios a disposición de la comunidad a través de diferentes medios de comunicación para su distribución.

El noveno y último elemento de la espiral del infoconocimiento, 9. Retroalimentación, se realiza de forma permanente e iterativa en y desde cualquier etapa del proceso innovador.

\section{Soporte Tecnológico}

Se refiere al conjunto de elementos (herramientas informáticas) que permiten apoyar a los actores en la integración de la gestión del infoconocimiento y la innovación. Estos elementos de apoyo 
permiten incorporar la acción de lo procedimental, instrumental y computacional a lo conceptual o desarrollo del conocimiento e incluye las capacidades del talento humano necesarias para dar uso al soporte tecnológico. Así mismo, se entiende que debe contener un conjunto de módulos virtuales con el fin de permitir la articulación de la información y convertirla en conocimiento como elemento primordial en la generación de valor en los resultados de la innovación.

\section{Sistema de relaciones}

El sistema de relaciones del modelo se fundamenta en el enfoque relacional descrito anteriormente, el cual a criterio de la autora es fundamental para alcanzar un máximo rendimiento en las organizaciones.

\subsection{Procedimiento para la aplicación del modelo de gestión integrada del infoconocimiento y la innovación}

En la Figura 21 se presenta el procedimiento propuesto para desarrollar las etapas del proceso de innovación, de manera integrada con la gestión del infoconocimiento. Cada una de las etapas considera entradas (de los proveedores) y salidas (a los clientes), que se convierten en entradas de otra etapa.

Los primeros elementos de entrada provienen del entorno externo e interno, los cuáles proporcionan los principales aspectos a considerar para dar inicio al proceso innovador cuando se definen los lineamientos estratégicos del centro de innovación con el apoyo de los siguientes documentos rectores: Guía sectorial de programas y proyectos de Ciencia, Tecnología e Innovación de Colciencias, Plan de Desarrollo Nacional, Ley 1838 de 2017 Creación de Spin-off y Estatuto de Propiedad Intelectual de la UTP. Los dos últimos documentos contienen un soporte y motivador importante para la generación y consolidación de la innovación a manera de incentivos. 
Si bien, para su mejor comprensión, el procedimiento se presenta como una secuencia de etapas con sus respectivas actividades, en la realidad la innovación es un proceso interactivo y sistémico, donde cada paso se relaciona con el anterior y se puede volver atrás o saltar pasos según el avance del proceso innovador. Por ello, el procedimiento propuesto aplica enfoques del modelo interactivo, del modelo del proceso de innovación integrado y de la innovación abierta. Además, a cada una de las etapas se le puede aplicar el ciclo de mejora continua PlanificarHacer-Verificar-Actuar (PHVA).

Figura 21.Procedimiento para la aplicación del modelo propuesto

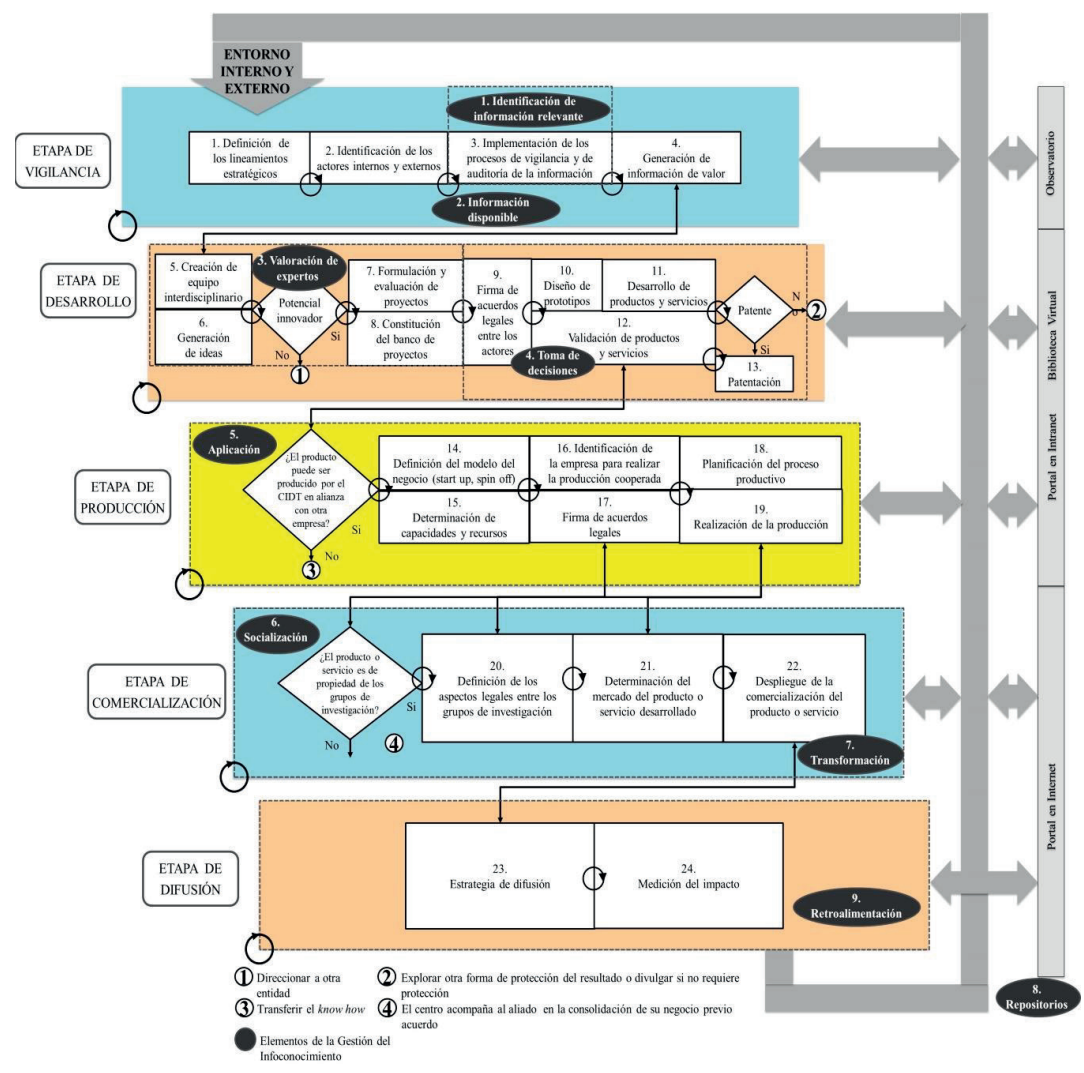

El procedimiento cuenta con 24 actividades a realizar en las etapas correspondientes, las cuales se describen a continuación. 


\section{Etapa 1. Vigilancia}

1. Definición de los lineamientos Estratégicos. El centro de innovación define los lineamientos estratégicos, apoyado por el sistema nacional y regional de innovación y de acuerdo a las tradiciones, los contextos sociales, políticos, las normatividades y las necesidades del mercado. De la misma manera, la directriz definida por el centro debe estar dirigida al enfoque KPO (knowledge process outsourcing).

2. Identificación de actores internos y externos. Responde a: quiénes son, donde están, cuáles son las necesidades de los clientes, quienes son los competidores y cuáles son las relaciones existentes. Además, se identifican los grupos de investigación con proyectos potencialmente innovadores, así como las competencias con que se cuenta en la organización.

3. Implementación de Procesos de Vigilancia y de Auditoria de la Información. La implementación del proceso de vigilancia evoca la ejecución del "qué", "para qué" y "cómo" se desea vigilar. Se refiere a la metodología adecuada para identificar, analizar, validar y usar la información más relevante y confiable recolectada de las fuentes de información y de las etapas previas, a fin de determinar sistemática y organizadamente las necesidades del mercado.

Se identifican las demandas del mercado como una de las entradas al proceso de innovación. También se identifican las investigaciones básicas existentes, las cuales constituyen otra de las entradas del modelo. El centro de innovación define sus proyectos de investigación basados en la combinación de las demandas del entorno, investigación básica relevante, las ofertas y las competencias de los grupos de investigación.

La auditoría de la información se utiliza como una herramienta de apoyo en el diseño, revisión y ejecución de las estrategias y la gestión de información. 
4. Generación de información de valor. La implementación de la etapa de vigilancia genera información de valor para reducir riesgos. Toma la información, el conocimiento y los recursos disponibles para generar valor en bienes o servicios dando respuesta al qué y modelos de negocio al cómo. Como resultado de esta etapa se genera información de valor para identificar las oportunidades y los riesgos de la innovación.

\section{Etapa 2. Desarrollo}

5. Creación del equipo de trabajo interdisciplinario. La información disponible se transmite a personas o grupos de personas con competencias y experiencia en $\mathrm{I}+\mathrm{D}+\mathrm{i}$, con intereses comunes en desarrollar los proyectos dirigidos y coordinados por el CIDT, en colaboración con el entorno. Los interesados pueden ser: grupos de investigación, expertos o empresas en calidad de usuario, propietario, socio, contratista. Cuando las personas interesadas reciben y analizan la información disponible, se realiza una reunión con el fin de determinar intereses y compromisos que permitan conformar un equipo de trabajo interdisciplinario con representación de diferentes actores a nivel interno y externo.

6. Generación de ideas. La generación de ideas es un punto crucial del procedimiento. En ella la creatividad y el pensamiento divergente de los investigadores se integran a la solución de las necesidades y situaciones detectadas en la etapa de vigilancia arte. La generación de ideas parte con una lluvia de arquetipos o posibles soluciones a la situación susceptible de ser mejorada que se debaten con el equipo interdisciplinario y en consenso se definen cuáles son las más aceptadas para continuar con el proceso. Si las ideas tienen un alto potencial de innovación continua el proceso, de lo contrario se direcciona el proyecto a otra entidad.

7. Formulación y evaluación de proyectos. Se caracteriza por la toma de decisiones y es de gran importancia ya que el equipo interdisciplinario consolida las diferentes ideas y propuestas de soluciones a las demandas definidas en las etapas previas para 
concebir los proyectos de innovación. Interviene la creatividad y el liderazgo. El Comité Innovador con el apoyo de expertos, se encarga de seleccionar los proyectos innovadores.

8. Constitución del Banco de Proyectos. Una vez definidos los proyectos innovadores, se introducen en el sistema de información, y se constituye una base de datos con el portafolio de proyectos innovadores. Los interesados pueden acceder a él y tener una gama de posibles proyectos a ser desarrollados.

9. Firma de los acuerdos legales entre los actores. La elaboración de los acuerdos legales entra a formar parte de la producción intelectual como instrumento mediador, equitativo y normativo entre las partes interesadas. Los acuerdos relacionados con la propiedad intelectual se orientan a través de las directrices de Colciencias y otras entidades gubernamentales. La oficina de contratación elaborará lo pertinente para dar claridad a los derechos de producción intelectual y las contrataciones de los integrantes en los proyectos.

10. Diseño de prototipos. El prototipo definido como un modelo de un arquetipo, inicia con la "generación de ideas" para la realización de un boceto que permite mostrar sus partes y sus funciones básicas sobre planos o maquetas. Permite realizar una validación inicial del concepto. También puede ser es diseño preliminar de un servicio.

11. Desarrollo de productos o servicios. Se refiere a la construcción del dispositivo, fabricación del producto o experimentación de los modos de llevar a cabo el servicio, que permita su implementación en ambientes reales y/o simulados como prueba piloto para refinar los elementos del diseño inicial. El alcance del diseño lo estipula el proyecto, la modalidad de contratación y el presupuesto destinado para el tipo de diseño de prototipo.

12. Validación de los productos o servicios. Se realizan diferentes tipos de validación según el prototipo desarrollado. El prototipo 
tipo concepto (define las ventajas y riesgos para decidir sobre su posible continuidad) u operacional (prototipo funcional con miras a ser producido). Retroalimenta la etapa de desarrollo permitiendo la realización del refinamiento o establecimiento de los últimos ajustes al producto a través de la estructuración, aplicación y análisis de entrevistas $\mathrm{u}$ otras pruebas sobre el producto o servicio que conduzcan a un reporte de su validación. La validación implica el evaluar que se cumplan las características y especificaciones establecidas en el diseño. Si el producto o servicio va a ser patentado, se continúa con el proceso, de lo contrario se debe explorar otra forma de protección del resultado, o divulgar sino requiere protección.

13. Patentación. El registro y patentación ante las instancias respectivas son muy importantes en los procesos de innovación, estos proporcionan incentivos y estímulos para fortalecer la innovación ya que garantizan la protección del conocimiento, desarrollos, marcas, entre otros. Si el producto o servicio puede ser producido por el centro en alianza con otra empresa, se continua el proceso, de lo contrario debe transferir el Kwon How.

\section{Etapa 3. Producción o prestación del servicio}

14. Definir el modelo de negocio. Se elabora el lienzo del negocio, a partir del cual se establece el modelo de negocio Spin-off o Start $U p$, de acuerdo al tipo de emprendimiento.

15. Determinar capacidades y recursos. Es necesario coordinar todas las capacidades y recursos (factor humano idóneo, equipos, espacios, materias primas, diseños, procesos) para garantizar un producto de calidad, bajo costo y disponible a tiempo en el mercado.

16. Identificación de las empresas para realizar la producción cooperada. Se puede comenzar desde la actividad no. 9, en tanto la etapa de validación y desarrollo se proporcione con la misma empresa que realizara la etapa de producción. En caso de contar 
con entes cuya capacidad logística y operativa puedan ejecutar las dos primeras etapas del modelo, se deben establecer las posibles empresas, quienes permitirán la producción del bien o servicio. Para el caso de la UTP, esta podría considerar la base de datos de convenios con el sector productivo para la ejecución de estas actividades.

17. Firma de acuerdos legales. Aquí se esclarecen los términos legales de la etapa de producción.

18. Planificación del proceso productivo. Se definen los procesos y los recursos humanos, tecnológicos, físicos, económicos de forma anticipada para realizar la manufactura del producto o la prestación del servicio, teniendo en cuenta la capacidad instalada y las demandas.

19. Realización de la producción. Se refiere a la ejecución de las actividades que permiten la fabricación del producto o la prestación del servicio.

\section{Etapa 4. Comercialización}

Si el producto o servicio es propiedad de los grupos de investigación se continúa con el proceso, de lo contrario el centro podría acompañar al aliado en la consolidación de su negocio previo acuerdo.

20. Definición de los aspectos legales de participación y de responsabilidad entre los grupos de investigación. Nuevamente la normatividad y legalidad de esta etapa es fundamental para tener claridad sobre los modos de ser de esta etapa en caso de no haberse dado con claridad en las etapas anteriores o en caso de entrar una nueva instancia en esta parte del proceso. El tipo de emprendimiento debe quedar estipulado en los acuerdos legales.

21. Determinación del mercado del producto o servicio desarrollado. Se realizan los estudios de marketing. Es el eje central 
de la etapa de comercialización y permite ubicar el producto o servicio en el mercado.

22. Despliegue de comercialización del producto o servicio. Se refiere a la ejecución de las actividades de introducción del producto o servicio a partir de los estudios de marketing.

\section{Etapa 5. Difusión}

23. Estrategia de difusión. Se identifican los medios a ser utilizados para la difusión del producto o servicio en el mercado. Seidentifican los medios apropiados para la difusión, según el segmento del mercado al cual va dirigido el producto o servicio y se elaboran los formatos adecuados al tipo de medio. Esta elaboración de los medios de difusión debe contar con el personal idóneo para lograr el objetivo comunicativo. Una vez elaborados los formatos de acuerdo al tipo de medio, se sitúan en los diferentes espacios físicos o virtuales en concordancia con las disposiciones legales.

24. Medición del impacto. Con el ánimo de realizar un mejoramiento continuo, se realiza la retroalimentación de las diferentes etapas o una evaluación de los procesos puestos a disposición de los diferentes actores de la innovación. 



\section{BIBLIOGRAFÍA}

Acosta, Y. (2012). Propuesta para potenciar el apoyo a la gestión del conocimiento en el Ministerio del Interior a partir de la Intranet administrada por el Centro de Gestión de Conocimientos (CGC). Trabajo de Diploma. Facultad de Comunicación. Universidad de la Habana.

Aguirre, A. y Tejedor, B. (1998). Proyecto Logos: Investigación relativa a la capacidad de aprender de las empresas españolas. Boletín de Estudios Económicos, 53(164), 231-249. https://dialnet. unirioja.es/servlet/articulo? codigo $=4784$

Alba, M. (2013). Diseño de un portal corporativo para la gestión del conocimiento en la cadena del ron granel Havana Club. Tesis en opción al grado de Máster en Gestión de Información. Universidad de La Habana.

Alba, M. (2015). Modelo de gestión del infoconocimiento para cadenas de suministro de ron a granel. Tesis en opción al grado científico de Doctor en Ciencias Económicas. Universidad de La Habana.

Alba, M., y Herrera, K. (2014). La Gestión del Conocimiento: conceptos, modelos, procesos y experiencias en Cuba. En Investigaciones doctorales en las ciencias administrativas $y$ contables (p. 199). CÓDICE. https://www.redalyc.org/ pdf/4096/409650120005.pdf

Alba, M., y Herrera, K. (2016). Modelo de gestión del infoconocimiento para cadenas de suministro de ron a granel. COFIN Habana, 10(1), 28-38. http://scielo.sld.cu/pdf/cofin/ v10n1/cofin03116.pdf

Alfaro, G. G., y Alfaro, V. G. (2012). Modelo de gestión del conocimiento para la pequeña y mediana empresa. Sotavento 
M.B.A., 20, 8-21. https://revistas.uexternado.edu.co/index.php/ sotavento/article/view/3347

Álvarez, A. (2010). La innovación abierta: ideas de Chesbrough y Von Hippel. http://sociedadinformacion. fundacion.telefonica.com/seccion $=1188 \mathrm{yidioma}=\mathrm{s}_{-}$ ESyid=2009100116310224yactivo=4.do.

Anand, A., y Singh, M. D. (2011). Understanding Knowledge Management: A Literature Review. International Journal of Engineering Science and Technology, 3(2), 926-939. https://pdfs.semanticscholar. org/8722/071067c796cd557231bb19cb602d5fc31fc5.pdf.

Andersen Business Consulting \& APC. (1996). The Knowledge Management Assessment Tool: External Benchmarking Version. American Productivity and Quality Center.

Andersen, A. (1999). El Management en el Siglo XXI. Granica. ISBN 9789506412722.

Archibold, W. G., y Escobar, A. E. (2014). Gestión del conocimiento en las entidades fiscalizadoras del nivel territorial. Ibergecyt'2014. Seminario Iberoamericano para el intercambio y la actualización de Gerencia del Conocimiento y la Tecnología para el desarrollo sustentable, 12-14 noviembre (PIF-012). GECYT.

Armbruster, H., Bikfalvi, A., Kinkel, S., y Lay, G. (2008). Organizational innovation: The challenge of measuring nontechnical innovation in large-scale surveys. Technovation, 28, 644-657. https://doi.org/10.1016/j.technovation.2008.03.003

Armenteros Acosta, M. C., García Abreu, N, Negrín Perez, R. C. (2008). Innovación educativa en la formación de directivos. Experiencias desde un enfoque basado en competencias. Revista Ingeniería Industrial, 29(1), 34-41. http://rii.cujae.edu.cu/index. $\mathrm{php} /$ revistaind/article/view/24 
Arocena, R., y Sutz, J. (1999). Mirando los Sistemas Nacionales de Innovación desde el Sur. Organización de Estados Iberoamericanos para la Educación, la Ciencia y la Cultura (OEI). https://www.oei.es/historico/salactsi/sutzarcena.htm

Arpaci, I., Yardimci, Y. C., Ozkan, S., y Turetken, O. (2012). Organizational adoption of information technologies: a literature review. International Journal of eBusiness and eGovernment Studies, 4(2), 37-50. http://www.sobiad.org/eJOURNALS/ journal_IJEBEG/2012_no_1-2.htm

Artiles, S. (2001). Las redes del conocimiento como producto de la gerencia de información en ambientes académicos. VI Seminario Iberoamericano para el Intercambio y Actualización de la Ciencia y la Innovación, IBERGECYT. GECYT.

Avendaño, V., y Flores, M. (2016). Modelos teóricos de gestión del conocimiento: descriptores, conceptualizaciones y enfoques. Entreciencias: Diálogos en la Sociedad del Conocimiento, 4(10), 201-227. http://dx.doi.org/10.21933/J.EDSC.2016.10.181

Ávila, L. E., y Alarcón, G. J. (2014). Factores críticos de éxito de las empresas innovadoras: una investigación documental. Innovaciones de Negocios, 11(21), 143-167. http://eprints.uanl. $\mathrm{mx} / \mathrm{id} / \mathrm{eprint} / 12600$

Bachmann, D. L., y Destefani, J. H. (2008). Metodologia para Estimar o Grau de Inovação na MPE - Cultura do Empreendedorismo e Inovação. Anais do IXVIII Seminário Nacional de Parques Tecnológicos e Incubadoras de Empresas. Aracaju. http://www.bachmann.com.br/website/art.htm

Barreiro, A. (2001). La Asociación Nacional de lnnovadores y Racionalizadores, instrumento de la gestión del conocimiento en las empresas. VI Seminario Iberoamericano para el Intercambio y Actualización de la Ciencia y la Innovación. GECYT. 
Bejerano, D. (2011). Análisis del Capital Intelectual del Centro de Estudios Martianos. Trabajo de Diploma. Facultad de Comunicación. Universidad de la Habana.

Belly, P. L. (2004). El shock del management: la revolución del conocimiento. McGraw-Hill Interamericana. ISBN 970-10-46366.

Benavente, J. (2018). Manual de Oslo Edición 2018. Principales Características y Novedades. http://ctie.economia.cl/wpcontent/uploads/2018/08/20180816-Presentaci\%C3\%B3n-JMBenavente-Revision-Manual-Oslo-cuarta-versi\%C3\%B3n.pdf

Bierly, P. E., Damanpour, F., y Santoro, M. (2009). The application of external knowledge: organizational conditions for exploration and exploitation. Journal of Management Studies, 46(3), 481-509. https://doi.org/10.1111/j.1467-6486.2009.00829.x

Boffill Vega, S. (2010). Modelo general para contribuir al desarrollo local, basado en el conocimiento y la innovación. Caso Yaguajay. Tesis de Doctorado. Centro Universitario Municipal de Yaguajay.

Borrás, F., y Ruso, F. (2015). Capital Intelectual: Visión crítica y propuesta para organizaciones cubanas. Editorial UH. ISBN 978959-7211-54-9.

Bower, J. L., y Christensen, C. M. (1995). Disruptive Technologies: Catching the Wave. Harvard Business Review, 73(1), 43-53. https://hbr.org/1995/01/disruptive-technologies-catchingthe-wave

BPO\&O. (2012). Informe de Sostenibilidad 2012. Sector de Tercerización de Procesos de Negocio (BPOßO). https://www. colombiaproductiva.com/ptp-capacita/publicaciones/sectoriales/ publicaciones-bpo-kpo-e-ito/informe-de-sostenibilidadbpo-2012 
Bravo, E. R., Castro, J. A., y León, A. P. (2015). Mapping of the Challenges for the Open Innovation Model's Implementation in Service Sector. Journal of Advanced Management Science, 3(4), 354-361. http://www.joams.com/index. $\mathrm{php} ? \mathrm{~m}=$ content $\& \mathrm{c}=\mathrm{index} \& \mathrm{a}=$ show $\&$ catid $=43 \& \mathrm{id}=227$

Burbano, J. M. (2013). Sistema de gestión del conocimiento para la definición de estrategias que eviten la deserción escolar en los colegios de Mocoa - Putumayo en el nivel de educación básica secundaria. Tesis de Maestría en Ingeniería de Sistemas y Computación. Pontificia Universidad Javeriana. http://hdl.handle. net/10554/15072

Bustelo, C., y Amarilla, R. (2001). Gestión del Conocimiento y Gestión de la Información. Boletín del Instituto Andaluz de Patrimonio Histórico Infor@rea S.L., 8(34), 226-230. https://doi. org/10.33349/2001.34.1153

Camisón, C., y Villar-López, A. (2014). Organizational innovation as an enabler of technological innovation capabilities and firm performance. Journal of Business Research, 67, 2891-2902. https://ideas.repec.org/a/eee/jbrese/v67y2014i1p2891-2902.html

Castro Díaz-Balart, F. (2001). Ciencia, innovación y futuro. Instituto Cubano del Libro.

Chen, J., y Sawhney, M. (2010). A Systemic View of Innovation: The Innovation Radar. American Marketing Association Conference 2010, Boston MA.

Chesbrough, H. (2003). The Era of Open Innovation. MIT Sloan Management Review, 44(3), 35-41. https://sloanreview.mit. edu/article/the-era-of-open-innovation/

Chesbrough, H. (2006). Open innovation: A new paradigm for understanding industrial innovation. En: H. W. Chesbrough, W. Vanhaverbeke, y J. West, Open Innovation: Researching a New 
Paradigm (1-14). Oxford University Press. https://global.oup. com/academic/product/open-innovation-9780199226467

Chesbrough, H. (2012). Open Innovation. Where we've been and where we're going. Research-Technology Management. Special Issue: Open Innovation Revisited, 20-27. https://www.econbiz.de/ Record/open-innovation-where-we-ve-been-and-where-we-regoing-chesbrough-henry-william/10009571094

Chiaroni, D., Chiesa, V., y Frattini, F. (2010). Unravelling the process from Closed to Open Innovation: evidence from mature, asset-intensive industries. RyD Management, 40(3), 222-245. https://doi.org/10.1111/j.1467-9310.2010.00589.x

CIDEC. (2004). Gestión del conocimiento y capital intelectual. Donostia-San Sebastián: Michelena Artes Gráficas S.L. http:// www.cidec.net/cidec/pub/archivos/31.pdf

Cohen, W. M., y Levinthal, D. A. (1990). Absorptive Capacity: A New Perspective on Learning and Innovation. Administrative Science Quarterly, 1(35), 128-152.https://doi.org/10.2307/2393553

Colciencias. (2016). Documento $N^{\circ} 1602$ - Actores del Sistema Nacional de Ciencia, Tecnología e Innovación. Resolución No. 1473/2016. http://repositorio.colciencias.gov.co/ handle/11146/34016

Colciencias. (2017). Centros de Investigación y Desarrollo Tecnológico reconocidos. http://colciencias.gov.co/sites/default/ files/upload/centrosdeinvestigacionreconocidos.pdf.

Colciencias. (2018). Libro Verde 2030 Política Nacional de Ciencia e Innovación para el Desarrollo Sostenible. Panamericana Formas e Impresos SA. http://repositorio.colciencias.gov.co/

Contreras, P. F. (2014). Hacia una ética y una estética de la innovación. Tesis Doctoral en Derecho y Ciencias Políticas. 
Universidad de Barcelona. http://www.bioeticayderecho.ub.edu/ es/defensa-de-la-tesis-doctoral-hacia-una-etica-y-una-esteticade-la-innovacion

Cordovés, D. (2017). Sistema de Innovación Agraria de la Provincia Mayabeque. Tesis en opción al grado científico de Doctor en Ciencias Económicas. Universidad de La Habana.

Crossan, M. M., y Apaydin, M. (2010). A multi-dimensional framework of organizational innovation: a systematic review of the literature. Journal of Management Studies, 47(6), 1154-1191. https://doi.org/10.1111/j.1467-6486.2009.00880.x

Cuba. (2007). Decreto No. 281 Reglamento para la implantación y consolidación del sistema de dirección y gestión empresarial estatal. Consejo de Estado. https://www.gacetaoficial.gob.cu/es/ decreto-281-de-2007-de-consejo-de-ministros-0

Damanpour, F., y Gopalakrishnan, S. (2001). The dynamics of the adoption of product and process innovations in organizations. Journal of Management Studies, 38(1), 45-65. https://doi. org/10.1111/1467-6486.00227

Dánjer, J. (2006). Modelo para la Gestión del Conocimiento en los destacamentos fronterizos del país. Tesis presentada en opción al grado científico de Doctor en Ciencias Técnicas. Universidad de Matanzas "Camilo Cienfuegos".

Davenport, T., y Prusak, L. (2001). Conocimiento en acción: cómo las organizaciones manejan lo que saben. Pearson Education.

De Casanove, A., Morel, L., y Negny, S. (2017). ISO 50500 series innovation management: overview and potential usages in organizations. https://hal.univ-lorraine.fr/hal-01624970

Delgado, M. (2001). Enfoques integrados de la gestión en la innovación tecnológica. Revista Ingeniería Industrial, 22(4), 2937. http://rii.cujae.edu.cu/index.php/revistaind/article/view/214 
Díaz, E. (2005). Propuesta metodológica para potenciar el desarrollo de grupos formales de trabajo del sistema de ciencias e innovación tecnológica. Tesis de Maestría. Universidad de La Habana.

Druker, P. (1993). The new productivity challenge. Harvard Business Review. https://hbr.org/1991/11/the-new-productivitychallenge?_ga $=2.114536590 .849939830 .1591114479$ 647478603.1591114479

Dubickis, M., y Gaile-Sarkane, E. (2017). Transfer of knowhow based on learning outcomes for development of open innovation. Journal of Open Innovation: Technology, Market, and Complexity, 3, 4. https://doi.org/10.1186/s40852-017-0053-4

Easy Finance Project. (2012). Autoevaluación de la gestión de la innovación. Comunidad Europea del Mediterráneo. www. easyfinanceproject.eu/files/doc/Documentos/TestEs.pdf

Echeverría, J. (2008). El Manual de Oslo y la innovación social. ARBOR Ciencia, Pensamiento y Cultura, CLXXXIV(732), 609-618. http://arbor.revistas.csic.es/index.php/arbor/article/ view/210

Edvinsson, L., y Malone, M. S. (1997). Intellectual Capital: Realizing your Company's True Value by Finding its Hidden Brainpower. Harper Business. https://www.amazon. com/Intellectual-Capital-Realizing-Companys-Brainpower/ $\mathrm{dp} / 0887308414$

Escorsa, P., y Valls, J. (1997). Tecnología e innovación en la empresa: dirección y gestión. Barcelona: Universidad Politécnica de Cataluña. http://www.gcd.udc.es/subido/catedra/ materiales/economia_competencia_ii/innovacion/tecnologia_e_ innovacion_en_la_empresa_pere_escorsa.pdf 
European Committee for Standardization. (2018). CEN/TC 389 Innovation Management. https://standards.cen.eu.

Ferriol, F. (2011). Modelo de planificación estratégica para el Ministerio de Educación Superior de la República de Cuba. Tesis presentada en opción al Grado Científico de Doctor en Ciencias de la Educación. Universidad de La Habana.

Filgueiras, M. L. (2010). Herramientas de inteligencia empresarial para el desarrollo de la innovación. Caso Saude. Revista Ingeniería Industrial, 31(1), 1-7. http://rii.cujae.edu.cu/ index.php/revistaind/article/view/286

Franch, K., y Guerra, R. M. (2016). Las Normas ISO 9000: una mirada desde la gestión del conocimiento, la información, innovación y el aprendizaje organizacional. COFIN Habana, 10(2), 29-54. http://scielo.sld.cu/pdf/cofin/v10n2/cofin02216.pdf.

Franch, K., y Herrera, K. (2011). La gestión del conocimiento como herramienta de apoyo al proceso de toma de decisiones: caso de estudio Dirección General TRD Caribe. CETED, Universidad de La Habana.

Galarza López, J. (2007). Propuesta de modelo para evaluar el proceso de formación básica del médico en la Escuela Latinoamericana de Medicina. Tesis de Doctorado. Escuela Nacional de Salud Pública de Cuba.

Galarza López, J., y Almuiñas Rivero, J.L. (2013). La prospectiva: Una herramienta para la evaluación de la calidad de los procesos universitarios. Revista Congreso Universidad, 2(3). http://www.congresouniversidad.cu/revista/index.php/ congresouniversidad/article/viewFile/191/985.

Galvis, J. A. (2009). Mapas de conocimiento como una herramienta de apoyo para la gestión del conocimiento. Interactic, 9, 2-15. https://cintel.co/wp-content/uploads/2013/05/16. GESTION-DE-CONOCIMIENTO.pdf 
Garvin, D. A., Edmondson, A. C., y Gino, F. (2008). Is Yours a Learning Organization? Harvard Business Review, 86(3), 109-116. https://www.hbs.edu/faculty/Pages/item.aspx?num=31883

Garzón, M. A., e Ibarra, A. (2013). Innovación empresarial, difusión, definiciones y tipología. Una revisión de literatura. Revista Dimensión Empresarial, 11(1), 45-60. https://doi. org/10.15665/rde.v11i1.160

Gassmann, O., Enkel, E., y Chesbrough, H. (2010). The future of open innovation. RyD Management, 40(3), 213-222. https://doi. org/10.1111/j.1467-9310.2010.00605.x

Gee, S. (1981). Technology transfer, Innovation y International Competitiveness. New York: Wiley y Sons. https://www.iberlibro. com/9780471084686/Technology-Transfer-InnovationInternational-Competitiveness-0471084689/plp

Goleman, D. K. (2009). El Espíritu Creativo. Zeta Bolsillo. https://www.amazon.com/El-Espiritu-Creativo-Zeta-Spanish/ $\mathrm{dp} / 8498721741$

Gómez, D., Pérez, M., y Curbelo, I. (2005). Gestión del conocimiento y su importancia en las organizaciones. Revista Ingeniería Industrial, 26(2), 37-46. http://rii.cujae.edu.cu/index. $\mathrm{php} /$ revistaind/article/view/136

González, R., y García, F. E. (2011). Innovación abierta: Un modelo preliminar desde la gestión del conocimiento. Intangible Capital, 7(1), 82-115. https://doi.org/10.3926/ic.2011.v7n1.p82115

González, Y. (2010). La toma de decisiones en las organizaciones: aproximación desde la gestión del conocimiento. Trabajo de Diploma. Facultad de Comunicación. Universidad de La Habana. 
González-Campo, C. H., y Hurtado-Ayala, A. (2014). Influencia de la capacidad de absorción sobre la innovación: un análisis empírico en las mipymes colombianas. Estudios Gerenciales, 30(132), 277-286. http://dx.doi.org/10.1016/j. estger.2014.02.015

Gopalakrishnan, S., y Santoro, M. D. (2004). Distinguishing Between Knowledge Transfer and Technology Transfer Activities: The Role of Key Organizational Factors. IEEE Transactions on Engineering Management, 51(1), 57-69. https://doi.org/10.1109/ TEM.2003.822461

Grant, R. M. (1996). Toward a Knowledge-Based Theory of the Firm. Strategic Management Journal, 17(Winter), 109-122. https://doi.org/10.1002/smj.4250171110

Guerra, R. M., y Meizoso, M. C. (2019). Calidad. Conceptos, principios, modelos y herramientas. 2da. Edición. Editorial UH. ISBN 978-959-7251-40-8.

Guerra, R. M., Meizoso, M. C., Ramírez, J. R., y Iglesias, A. (2017). Los programas de maestría como canal de transferencia del conocimiento universidad-industria en Cuba. COFIN Habana, 11(1), 1-22. http://scielo.sld.cu/scielo.php?script=sci_ arttext\&pid=S2073-60612017000100001

Haas, A. (2014). Crowding at the frontier: knowledge brokers, gatekeepers, boundary spanners and marginal-intersecting individuals. XXIIIème Conférence Annuelle de l'Association Internationale de Management Stratégique - AIMS 2014 du 25 au 27 Mai 2014. https://doi.org/10.1108/JKM-01-2015-0036

Hagemann, M. (2012). Innovation Management. Lifelong Learning Program. Creative Trainer Module 4. InnoSupport. http://www.innosupport.net 
He, W., y Nie, M. (2008). The impact of innovation and competitive intensity on positional advantage and firm performance. Journal of American Academy of Business, 14(1), 205-209.

Henard, D. H., y Dacin, P. A. (2010). Reputation for product innovation: Its impact on consumers. The Journal of Product Innovation Management, 27(3), 321-335. https://doi.org/10.1111/ j.1540-5885.2010.00719.x

Henczel, S. (2000). The Information Audit as a first step towards effective Knowledge Management: An opportunity for the special librarian. INSPEL, 34(3/4), 210-226. http://citeseerx.ist.psu.edu/ viewdoc/download?doi=10.1.1.453.7589\&rep=rep1\&type $=$ pdf

Hermida, M. (2009). La identificación del conocimiento organizacional como inicio para la concepción de un proyecto de gestión del conocimiento en CAROIL DT. Trabajo de Diploma. Facultad de Comunicación. Universidad de la Habana.

Herrera, J., D’Armas, M., y Arzola, M. (2012). Análisis de los diferentes métodos de mejora continua. Jornadas de investigación. UNEXPO. https://www.academia.edu/18571860/ANALISIS_DE_ LOS_DIFERENTES_METODOS_DE_MEJORA_CONTINUA

Holsapple, C.W y Joshi, K. D. (1999, p. 9). Description and Analysis of Existing Knowledge Management Frameworks. In: Proceedings of the 32nd Hawaii International Conference on System Sciences. IEEE. https://doi.org/10.1109/HICSS.1999.772796

Hoskisson, R. E., Hitt, M. A., Wan, W. P., y Yiu, D. (1999). Theory and research in strategic management: Swings of a pendulum. Journal of Management, 25(3), 417-456. https://doi. org/10.1177/014920639902500307

Iglesias, P., Jambrino, C., y de la Heras, C. (2014). Propuesta de un modelo de innovación abierta en entornos educativos. 
http://gtea.uma.es/congresos/wpcontent/uploads/2014/02/2.15. Comu_.Completa.pdf

Jaramillo, H., Lugones, G., y Salazar, M. (2001). Manual de Bogotá. Normalización de Indicadores de Innovación Tecnológica en América Latina y el Caribe. Red Iberoamericana de Indicadores de Ciencia y Tecnología (RICYT). http://www.ricyt.org/wpcontent/uploads/2019/09/bogota_manual.pdf

Jones, O. (2006). Developing Absorptive Capacity in Mature Organizations: The Change Agent's Role. Management Learning, 37(3), 355-376. https://doi.org/10.1177/1350507606067172

Kaplan, R. S., y Norton, D. P. (1996). The Balanced Scorecard: Translating Strategy into Action. Harvard Business School Press. https://www.amazon.com/Balanced-Scorecard-TranslatingStrategy-Action/dp/0875846513

La Fé Jiménez, R. Y. (2017). Gestión del conocimiento en empresas de comercio minorista de bienes culturales en Cuba. Ciencias Económicas, Universidad Central de Las Villas.

Laforet, S. (2011). A framework of organizational innovation and outcomes in SMEs. International Journal of Entrepreneurial Behavior and Research, 17(4), 380-408. https:// doi.org/10.1108/13552551111139638

Lage, A. (2013). La Economía del Conocimiento y el Socialismo. Editorial Academia. ISBN 978-959-270-286-8.

Larrea, M. (2012). Gestión del conocimiento y la institución universitaria, una visión aupoiética. ARJÉ: Revista de Postgrado, 6(10), 41-67. http://www.arje.bc.uc.edu.ve/arj10/art03.pdf

León, M. (2008). Propuesta de un modelo de medición de la gestión del conocimiento para organizaciones de información. Tesis para optar por el grado de Doctor en Ciencias de la Información. Universidad de La Habana. 
León, M., Ponjuán, G., y Rodríguez, M. (2006). Procesos estratégicos de la gestión del conocimiento. Acimed, 14(2). http:// bvs.sld.cu/revistas/aci/vol14_2_06/aci08206.htm.

Leonard, D. A. (1995). Wellsprings of Knowledge: Building and Sustaining the Sources of Innovation. Harvard Business School Press. http://id.lib.harvard.edu/alma/990060514740203941/ catalog

Lichtenthaler, U., y Lichtenthaler, E. (2009). A capabilitybased framework for open innovation: complementing absorptive capacity. Journal of Management Studies, 46(8), 1315-1338. https:// doi.org/10.1111/j.1467-6486.2009.00854.x

Lopera, M. E., y Quiroz, N. L. (2013). Caracterización de un modelo de gestión del conocimiento aplicable a las funciones universitarias de investigación y extensión: caso universidad CES. Tesis de Maestría en Dirección. Universidad del Rosario, Medellín. https://repository.urosario.edu.co/handle/10336/4651

López Gutiérrez, J. C. (2010). Modelo de gestión del proceso de preparación y superación de cuadros en el contexto de las organizaciones en Cuba. Tesis presentada en opción al Grado Científico de Doctor en Ciencias de la Educación.

López, L. (2010). Diseño de Red de Gestión de Conocimiento para el Proyecto de Manejo Sostenible de la Tierra de la Agencia de Medio Ambiente. Trabajo de Diploma. Facultad de Comunicación. Universidad de La Habana.

López, O., Blanco, M., y. Guerra, S. (2009, p. 260). Evolución de los modelos de la gestión de innovación. Innovaciones de Negocios, 5(2), 251-264. http://revistainnovaciones.uanl.mx/ index.php/revin/article/view/210/195

Love, J. (2014). New open innovation business model for the development of antibiotics. World Health Organization. http:// 
www.who.int/phi/implementation/5_infobrief_new_open_ innovation_business_model_for_development_antibiotics.pdf

Lundvall, B. -Å. (1992). National Systems of Innovation: Towards a theory of innovation and interactive learning. London: Pinter Publishers.

Markhorst, F. E. (2009). Open Innovation in the Polimery Industry. Thesis Master of Science in Innovation Management, Technology Entrepreneurship and Marketing. Eindhoven University of Technology. https://pure.tue.nl/ws/ files/46938228/643054-1.pdf

Márquez Montoya, S. C., Ramírez Estévez, M. E., y Losada Losada, M. C. (2007). La gestión del conocimiento, una herramienta imprescindible en la investigación. Ciencia en su PC, 5, 3-15 https://www.redalyc.org/articulo.oa?id=181315033002

Medellín, E. (2001). Gestión del conocimiento y la entrega del valor en las organizaciones de Investigación y Desarrollo Tecnológico. VI Seminario Iberoamericano para el Intercambio y Actualización de la Ciencia y la Innovación, IBERGECYT. GECYT.

Mesinas, C., y Griego, M. (2014). Economía del conocimiento: importancia y medición de lo intangible. Seminario Iberoamericano para el intercambio y la actualización de Gerencia del Conocimiento y la Tecnología para el desarrollo sustentable, IBERGECYT'2014, 12-14 noviembre (PIF-028). GECYT.

MINTIC. (2012). Modelo de Gestión del Conocimiento e Innovación Abierta para el susbsistema de innovación para el uso y apropiación de las TIC en el Gobierno. Ministerio de Tecnologías de la Información y las Comunicaciones de la República de Colombia. https://www.mintic.gov.co/portal/604/articles-6116_ recurso_5.pdf 
Monagas, M. (2012). El Capital Intelectual en las empresas hoteleras en Cuba. Procedimiento para su medición. Tesis presentada en opción al grado científico de Doctor en Ciencias Técnicas. Instituto Superior Politécnico "José Antonio Echeverría".

Morgan, R. A., Alcober, V., López, D., Carbonell, J., Filgueiras, M. L., y Sánchez, N. (2014). La gestión del conocimiento: una opción estratégica para incrementar la competitividad en el Grupo Empresarial Industria Ligera. Seminario Iberoamericano para el intercambio y la actualización de Gerencia del Conocimiento y la Tecnología para el desarrollo sustentable IBERGECYT'2014, 12-14 noviembre (PIC-037-T1). GECYT.

Mozilla Corporation. (2008). Modelo de innovación abierta en Firefox. http://getfirefox.com.

Muñoz Seca, B., y Riverola, J. (1997). Gestión del conocimiento. Folio. https://www.abebooks.com/ Gesti\%C3\%B3n-Conocimiento-Mu\%C3\%B1oz-Seca-RiverolaFolio/14620915063/bd

Murcia, C. (2012). Modelo de análisis para la evaluación de la innovación. Un enfoque multidimensional e interdisciplinar. Tesis Doctoral Facultad de Ciencias Económicas y Empresariales Universidad Autónoma de Madrid. https://repositorio.uam.es/ bitstream/handle/10486/13793/64710_murcia\%20rivera\%20 cecilia.pdf

Nelson, E. R. (1974). Innovación. En D. Hill, Enciclopedia Internacional de las Ciencias Sociales. Aguiar. https://www. worldcat.org/title/enciclopedia-internacional-de-las-cienciassociales/oclc/2458236

Nonaka, I., y Takeuchi, H. (1995). The Knowledge Creating Company: How Japanese Companies Create the Dynamics of Innovation. Oxford University Press. https://www.strategybusiness.com/media/file/8592.PDF 
Nonaka, I., Von Krogh, G., y Voelpel, S. (2006). Organizational Knowledge Creation Theory: evolutionary paths and future advances. Organizational Studies, 27, 1179-1208. https://doi. org/10.1177/0170840606066312

North, K., y Rivas, R. (2008). Gestión del conocimiento. Una guía práctica hacia la empresa inteligente. Libros en Red. https://www.librosenred.com/libros/gestion delconocimientounaguiapracticahacialaempresainteligente.html

Núñez, I. (2004). La gestión de la información, el conocimiento, la inteligencia y el aprendizaje organizacional desde una perspectiva socio-psicológica. Acimed, 12(3). http:// bvs.sld.cu/revistas/aci/vol12_3_04/ aci04304.htm

Núñez, J. (2015). University, social innovation and inclusive development in Cuba: theory or practice. 13th Globelics International Conference, Sept 23 - 25. Havana.

OECD. (2005). The Measurement of Scientific and Technological Activities: Guidelines for Collecting and Interpreting Innovation Data: Oslo Manual (3rd ed.). Organization for Economic Cooperation and Development. http://www.oecd.org/ science/inno/2367614.pdf

OECD. (2018). Oslo Manual. Guidelines for Collecting, Reporting and Using Data on Innovation (4th. ed.). Organization for Economic Cooperation and Development, OECD Publishing. https://www.oecd.org/science/oslo-manual-20189789264304604-en.htm

Oliveira, L. S., Echeveste, M. S., Cortimiglia, M. N., y Goncalves, C. C. (2017). Analysis of determinants for Open Innovation implementation in Regional Innovation Systems. RAI - Revista de Administração e Inovação, 14(2), 119-129. http://www. redalyc.org/articulo.oa?id $=97351028004$ 
Oliveira, T., y Martins, M. F. (2011). Literature Review of Information Technology Adoption Models at Firm Level. The Electronic Journal Information Systems Evaluation, 14(1), 110121. http://www.ejise.com/issue/download.html?idArticle=705

Openbasque. (2012). Openbasque: un acercamiento a la innovación abierta desde la perspectiva territorial $y$ empresarial. https://www.hacienda.go.cr/Sidovih/uploads// Archivos/Libro/openbasque-un\%20acercamiento\%20a\%20 la $\% 20$ innovaci $\%$ C 3\% B3n \% 20abierta \%20desde\%20la\%20 perspectiva\%20territorial\%20y\%20empresarial-Libro.pdf

Organización Internacional de Normalización. (2015a). ISO 9000:2015 Sistemas de Gestión de la Calidad. Fundamentos y vocabulario. https://www.iso.org/standard/45481.html

Organización Internacional de Normalización. (2015b). ISO 9001:2015 Sistemas de Gestión de la Calidad. Requisitos. https:// www.iso.org/standard/62085.html

Orozco, L. A., Chavarro, D. A., y Rivera, H. A. (2007). Estrategia y conocimiento en la gestión organizacional. Universidad y Empresa, 6(13), 37-58. http://www.urosario.edu.co/ urosario_files/d2/d2af82f8-e07a-4105-97e1-faf2b09a743a.pdf

Ozan, H. (2017). Standardizing innovation management with ISO. http://hakanozan.net/2017/standardizing-innovationmanagement-with-iso/

Pavón, A., Hernández, A. E., Suárez, J., Jiménez, B., y Sánchez, V. (2015). Análisis de los modelos de Innovación Abierta. Ventajas de su aplicación. Revista Avanzada Científica, 18(3), 1-13. https:// dialnet.unirioja.es/descarga/articulo/5265921.pdf

Pavón, J., y Goodman, R. (1981). Proyecto Moltedec. La planificación del desarrollo tecnológico. CDTI-CSIC. ISBN 84-5004407-3. 
Pavón, J., y Hidalgo, A. (1997). Gestión e innovación. Un enfoque estratégico. Pirámide. ISBN 84-368-1067-8.

Perdomo, G. (2009). ¿Por qué, cómo y para qué estudiar los Sistemas Nacionales de Innovación y Estudios de Innovación en Colombia? Pensamiento y Gestión, 27, 132-161. http://rcientificas. uninorte.edu.co/index.php/pensamiento/article/view/849/494

Pereira, H. (2011). Implementación de la gestión del conocimiento en la empresa. Éxito Empresarial, 135, 1-6. https://www.cegesti.org/exitoempresarial/publicaciones/ publicacion_135_310111_es.pdf

Peres, C., Bittencourt, J. V., Cotian, L. F., y Wittmann, A. L. (2016). Modelos de Inovação: uma revisão de literatura. Espacios, 37(15), 8. https://www.revistaespacios.com/a16v37n15/16371508. html

Perez, C. (2010). Technological revolutions and technoeconomic paradigms. Cambridge Journal of Economics, 34(1), 185-202. https://doi.org/10.1093/cje/bep051

Pérez Morfi, D. (2018). Metodología de gestión del conocimiento para el emprendimiento territorial. Tesis Doctoral en Ciencias Empresariales. Universidad de La Habana.

Piatier, A. (1987). Les innovations transsectorielles et la transformation des entreprises. Conférence Européenne, ESADE, Barcelona.

Plaz, R. (2003). Gestión del conocimiento: una visión integradora del aprendizaje organizacional. Revista de Investigación en Gestión de la Innovación y la Tecnología, 18(6). www.madridmasd.org/revista/revista18/ tribuna/tribuna2.asp

Ponjuán, G. (2006). Introducción a la Gestión del Conocimiento. Editorial Félix Varela. 
Ponjuán, G., y Hernández, W. (2017). Contextos para la Gestión del Conocimiento en organizaciones cubanas: un acercamiento al "Ba" en Cuba. Revista Cubana de Información en Ciencias de la Salud, 28(2), 1-17. https://www.redalyc.org/ pdf/3776/377651174003.pdf

Porter, M. (1993). La ventaja competitiva de las naciones. Javier Vergara.

Ramírez, D. C., Martínez, R. L., y Castellanos, D. O. (2012). Divulgación y difusión del conocimiento: las revistas científicas. Universidad Nacional de Colombia. http://www.bdigital.unal. edu.co/8394/1/9789587613346.pdf

Robayo, P. V. (2016). La innovación como proceso y su gestión en la organización: una aplicación para el sector gráfico colombiano. Suma de Negocios, 7, 125-140. https://dx.doi. org/10.1016/j.sumneg.2016.02.007

Rodríguez, D. (2006). Modelos para la creación y gestión del conocimiento: una aproximación teórica. Educar, 37, 25-39. https://dd.uab.cat/pub/educar/0211819Xn37/0211819Xn37p25. pdf

Rodríguez, M. T., y González, J. J. (2013). Gestión del conocimiento y capital intelectual, a través de modelos universitarios. Económicas CUC, 34(1), 85-116. https:// revistascientificas.cuc.edu.co/economicascuc/article/view/578

Rodríguez, M., García, F., Pérez, M. Á., y Castillo, J. V. (2009). La gestión del conocimiento, factor estratégico para el desarrollo. Gestión en el Tercer Milenio. Revista de Investigación de la Facultad de Ciencias Administrativas UNMSM, 12(23), 7-14. https:// revistasinvestigacion.unmsm.edu.pe/index.php/administrativas/ article/view/8904 
Rogers, E. M. (2003). Diffusion of Innovations. Simon and Schuster. ISBN 9780743258234.

Sáenz, T. W. (1999). Ingenierización e innovación tecnológica. En: Tecnología y Sociedad (79-97). Editorial Félix Varela.

Salazar, F. (2014). Estrategias para la implementación de gestión del conocimiento para la empresa UNE-Telefónica de Pereira. Tesis de Maestría en Administración. Universidad Nacional de Colombia. http://www.bdigital.unal.edu.co/21156/1/7710020.2014.pdf

Salazar, J. M., y Zarandona, X. (2007). Valoración crítica de los modelos de gestión del conocimiento. En C. M. (Coord.), Empresa global y mercados locales: XXI Congreso Anual AEDEM, Universidad Rey Juan Carlos, Madrid, 6,7 y 8 de junio de 2007. ISBN 9788473565004.

Sánchez, P., y Castrillo, R. (2006). La tercera edición del manual de Oslo: cambios e implicaciones. Una perspectiva de capital intelectual. Revista mi $+d$, 35, 1-12. http://www.madrimasd. org/revista/revista35/aula/aula1.asp

Sawhney, M., Wolcott, R. C., y Arroniz, I. (2006). The 12 different ways for companies to innovate. MIT Sloan Management Review, 47(3), 75-81. 10.1109/EMR.2007.329139

Schmidl, J., Slavtchev, V., Wittges, H., y Krcmar, H. (2011). Knowledge Management Success or Failure - What Determines the Performance of a KM-Initiative? En R. Maier (Ed.), 6th Conference on Professional Knowledge Management from Knowledge to action. P-182, 161-169. Innsbruck: Lecture Notes in Informatics.

Schmidt, T., y Rammer, C. (2007). Non-technological and Technological Innovation: Strange Bedfellows? ZEW Discussion Paper No. 07-052. Centre for European Economic Research. ftp:// ftp.zew.de/pub/zew-docs/dp/dp07052.pdf. 
Schumpeter, J. (1934). The Theory of Economic Development. Cambridge: Harvard University Press.

Scott, W. R. (2004). Institutional Theory. En: G. Ritzer, Encyclopedia of Social Theory (408-214). Sage.

Seguí, E. (2007).Lagestión del capital intelectualen lasentidades financieras. Caracterización del capital humano en las cooperativas de crédito. Tesis de doctorado, Departamento de Economía y Ciencias Sociales. España: Universidad de Valencia. https://riunet. upv.es/bitstream/handle/10251/1836/tesisUPV2605.pdf

Selva, D., Manuel, J., Carmenate, A., y Cabrera, F. (1998). Gestión del conocimiento, una nueva perspectiva. VII Congreso Nacional de ACEDE. Las Palmas de Gran Canaria: Asociación Científica de Economía y Dirección de la Empresa, ULPGC. http://www.fcee.ulpgc.es/Acede98/acede/mesa02/2_02c.htm

Senge, P. (1990). The Fifth Discipline. Doubleday.

Simeón, R. (2001). La gestión del conocimiento en Cuba. VI Seminario Iberoamericano para el Intercambio y Actualización de la Ciencia y la Innovación, IBERGECYT. GECYT.

Simón, A. (2008). Herramientas para el perfeccionamiento de los sistemas de gestión de conocimiento basados en mapas conceptuales. Tesis presentada en opción al grado científico de Doctor en Ciencias Técnicas. Instituto Superior Politécnico "José Antonio Echeverría".

Sosa, R., Guerra, R. M., y Roque, R. (2017). El papel de la consultoría, la formación de posgrado y la investigación en la mejora de la gestión de la calidad de los procesos organizacionales en los servicios de salud. Revista Caribeña de Ciencias Sociales. http://www.eumed.net/rev/caribe/2017/01/salud.html 
Spender, J. C., Corvello, V., Grimald, M., y Rippa, P. (2017). Startups and open innovation: a review of the literature. European Journal of Innovation Management, 20(1), 4-30. https://doi. org/10.1108/EJIM-12-2015-0131

Stable, Y. (2012). Modelo y metodología de aprendizaje organizacional para el mejor desempeño de una organización de ciencia e innovación tecnológica. Tesis de Doctorado. Instituto Superior Politécnico "José Antonio Echeverría".

Supyuenyong, V., y Islam, N. (2006). Knowledge Management Architecture: Building Blocks and Their Relationships. Technology Management for the Global Future PICMET 2006. Vol.3, 1210-1219. IEEE Xplore. https://ieeexplore.ieee.org/document/4077512/

Sveiby, K. E. (1997). The Intangible Assets Monitor. Journal of Human Resource Costing \& Accounting, 2(1), 73-97. https://www. sveiby.com/files/pdf/the-intangible-assets-monitor.pdf

Taboada, A. (2010). Modelo integrado de gestión de la ciencia, la innovación tecnológica y el conocimiento para la Universidad Agraria de La Habana. Tesis presentada en opción al Grado Científico de Doctor en ciencias de la Educación. Universidad de Pinar del Río.

Texidor, D. (2013). Análisis del capital relacional del Hotel Palco. Trabajo de Diploma. Facultad de Comunicación. Universidad de la Habana.

Tornatzky, L. G., y Fleischer, M. (1990). The Process of Technological Innovation. Lexington, MA: Lexington Books. https://www.worldcat.org/title/processes-of-technologicalinnovation/oclc/20669819

Trejo, D. (2009). Identificación, análisis y aprovechamiento de la administración del conocimiento para la organización y empresa mexicana del siglo XXI. Amazon. https://www.amazon. 
com.mx/Identificacion-Aprovechamiento-AdministracionConocimiento-Organizacion/dp/0578009366

Triana, J. P., Torres, R., y Martín, M. (2005). Cuba: Hacia una Economía Basada en el Conocimiento. Editorial de Ciencias Sociales.

Trias de Bes, F., y Kotler, P. (2011). Innovar para ganar: El modelo A-F. Ediciones Urano, S.A. 9788492452743

Trott, P. (2002). Innovation Management and New Product Development. (2nd ed.). Prentice Hall. ISBN 978-0273655602.

Tushman, M., y Nadler, D. (1986). Organizing for Innovation. California Management Review, 28, 74-92. http://dx.doi. org/10.2307/41165203

UNE. (2002). UNE 166002:2002 Gestión de la $I+D+i$ : Requisitos del sistema de gestión de la $I+D+i$. Asociación Española de Normalización. https://www.aenor.com/normas-y-libros/ buscador-de-normas/une/?Tipo $=\mathrm{N} \& \mathrm{c}=\mathrm{N} 0036136$

UNE. (2006). UNE 166000:2006 Gestión de la I+D+i: Terminología y definiciones de las actividades de $I+D+i$. Asociación Española de Normalización. https://www.une.org/encuentra-tunorma/busca-tu-norma/norma?c=N0036141

UNE. (2014). UNE 166002:2014 Gestión de la $I+D+i$ : Requisitos del sistema de gestión de la $I+D+i$. Asociación Española de Normalización. https://www.aenor.com/normas-y-libros/ buscador-de-normas/une/?c=N0052892

Valdés, H. J. (2010). Innovación tecnológica aplicada al proceso de fermentación del factor de crecimiento epidérmico humano. Tesis de Doctorado. Instituto Superior Politécnico "José Antonio Echeverría". 
Valdés, L. (2004). Innovación: El arte de inventar el futuro. Grupo Editorial Norma. ISBN 9580480710.

Valencia, M. B., Alba, M., y Herrera, K. (2016). La gestión del conocimiento y su relación con la innovación y la mejora continua en modelos de gestión. COFIN Habana, 10(1), 101-112. http://scielo.sld.cu/pdf/cofin/v10n1/cofin08116.pdf

Van de Ven, A. H. (2017). The innovation journey: you can't control it, but you can learn to maneuver it. Innovation: Organization \& Management, 19(1), 39-42. https://doi.org/10.10 $80 / 14479338.2016 .1256780$

Van de Vrande, V., de Jong, J., y Vanhaverbeke, W. (2009). Open innovation in SMEs: Trends, motives and management challenges. Technovation, 29, 423-437. https://doi.org/10.1016/j. technovation.2008.10.001

Velasco, E. M., Zamanillo, I., y Gurutze, C. (2007). Evolución de los modelos sobre el proceso de innovación desde el modelo lineal hasta los sistemas de innovación. Decisiones basadas en el conocimiento y en el papel social de la empresa. XX Congreso anual de AEDEM 2006, Vol. 2 (pág. 28). Palma de Mayorca: Asociación Europea de Dirección y Economía de Empresa. https://dialnet. unirioja.es/descarga/articulo/2499438.pdf

Vo, L.-C., Mounoud, E., y Hminda, N. (2011). Central problems in managing open innovation: a recurrent issue? OLKC 2011: Making waves. Hull University Business School. https:// warwick.ac.uk/fac/soc/wbs/conf/olkc/archive/olkc6/papers/ id_174.pdf

Wallin, M. W., y Von Krogh, G. (2010). Organizing for open innovation: focus on the integration of knowledge. Organizational Dynamics, 39(2), 145-154. https://doi.org/10.1016/j. orgdyn.2010.01.010 
Welo, T., y Ringen, G. (2018). Investigating Organizational Knowledge Transformation Capabilities in Integrated Manufacturing and Product Development Companies. Procedia CIRP, 70, 150-155. https://doi.org/10.1016/j.procir.2018.03.276

Winch, G. M., y Schneider, E. (1993). Managing the knowledge-based organization: The case of architectural practice. Journal of Management Studies, 30(6), 923-937. https://doi. org/10.1111/j.1467-6486.1993.tb00472.x

Zaldívar, A. B. (2011). Propuesta teórico-metodológica para el desarrollo del proceso de innovación tecnológica desde las invenciones patentadas en el ISPJAE en el periodo 1977-2009. Tesis Doctoral. Instituto Superior Politécnico "José Antonio Echeverria".

Zawislak, P. A., Alves, A. C., y Tello-Gamarra, J. (2012). Innovation capability: From technology development to transaction capability. Journal of Technology Management \& Innovation, 7(2), 14-26. https://dx.doi.org/10.406/S071827242012000200002

Zhu, K., Kraemer, K. L., y Xu, S. (2006). The process of innovation assimilation by firms in differentcountries: A technology diffusion perspective on e-business. Management Science, 52(10), 1557-1576. https://doi.org/10.1287/mnsc.1050.0487 
Las redes de conocimiento e innovación constituyen mecanismos indispensables para la mejora del desempeño y la competitividad empresarial, así como para el incremento de la productividad de los diferentes sectores económicos, basada en alianzas estratégicas entre empresas e instituciones académicas.

En este contexto, el Centro de Innovación y Desarrollo Tecnológico de la Universidad Tecnológica de Pereira pretende aunar los esfuerzos de innovación en la región de Risaralda, a través de la conformación de redes y nodos de innovación con las entidades públicas y privadas de la región. Para contribuir a este empeño, el libro que se pone a disposición de los lectores presenta el diseño de un modelo teórico que explica la integración entre la gestión del infoconocimiento y la innovación, así como el mecanismo para su posible aplicación práctica en el mismo Centro, con la finalidad de estimular el desarrollo de innovaciones hacia los sectores económicos de la región.

El libro, estructurado en tres capítulos, inicia analizando cómo han evolucionado el concepto de conocimiento y su gestión en su decurso histórico. Para ello, se fundamenta el concepto de conocimiento, se caracterizan los procesos para gestionarlo y se presentan al lector de manera sintética los modelos propuestos por diferentes autores para gestionar el conocimiento.

El segundo capítulo aproxima al lector al concepto de innovación, como proceso, y su gestión. Para ello, se identifican los diferentes tipos de innovación, y los modelos que han sido propuestos para su gestión, desde los modelos lineales iniciales, modelos por etapas y en cadena, hasta el paradigma actual de innovación abierta en redes de conocimiento.

Finalmente, en el capítulo tres se fundamenta el modelo diseñado por la autora para la gestión integrada del infoconocimiento y la innovación y se ofrece al lector un procedimiento detallado para su aplicación. 